\title{
AVALIAÇÃO DO DESEMPENHO DE UM ATMÔMETRO MODIFICADO NA ESTIMATIVA DA EVAPOTRANSPIRAÇÃO POTENCIAL
}

\section{ANDERSON SOARES PEREIRA}

Engenheiro Agrônomo

Orientador: Prof. Dr. JOSÉ ANTÔNIO FRIZZONE

Dissertação apresentada à Escola Superior de Agricultura "Luiz de Queiroz", Universidade de São Paulo, para obtenção do título de Mestre em Agronomia, Área de Concentração: Irrigação e Drenagem.

P I R A C I C A B A

Estado de São Paulo - Brasil

Novembro - 1996 
Dados Internacionais de Catalogação na Publicação (CIP) DIVISÃo DE BIBLIOTECA E DOCUMENTAÇÃO - Campus "Luiz de Queiroz"/USP

Pereira, Anderson Soares

Avaliação do desempenho de um atmômetro modificado na estimativa da evapotranspiração potencial / Anderson Soares Pereira. - - Piracicaba, 1996.

90 p. : il.

Dissertação (mestrado) - - Escola Superior de Agricultura Luiz de Queiroz, 1997. Bibliografia.

1. Atmômetro 2. Evapotranspiração 3. Irrigação (manejo) I. Titulo

CDD 551.572

631.7 


\section{AVALIAÇÃO DO DESEMPENHO DE UM ATMÔMETRO MODIFICADO NA ESTIMATIVA DA EVAPOTRANSPIRAÇÃO POTENCIAL}

ANDERSON SOARES PEREIRA

Aprovada em: 06.02.1997

Comissão julgadora:

Prof. Dr. José Antônio Frizzone

ESALQ/USP

Prof. Dr. Rubens Duarte Coelho

ESALQ/USP

Prof. Dr. Nilson Augusto Villa Nova

ESALQ/USP

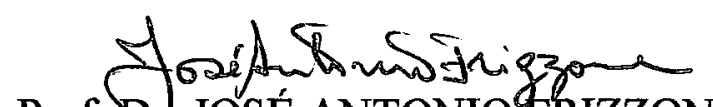

Prof. Qr. JOSÉ ANTONIO FRIZZONE

Orientador 


\section{PRECE DE CÁRITAS}

"DEUS, Nosso Pai, que sois todo poder e bondade, dai força àquele que passa pela provação; dai luz àquele que procura a verdade, pondo no coração do homem a compaixão e a caridade. Deus, dai ao viajor a estrela guia; ao affito a consolação; ao doente o repouso. Pai, dai ao culpado o arrependimento; ao espírito a verdade; à criança o guia, ao órfão o pai. Senhor, que a vossa bondade se estenda sobre tudo que criastes. Piedade Senhor para aqueles que não vos conhece, esperança para aqueles que sofrem. Que a vossa bondade permita hoje aos espíritos consoladores espalharem por toda parte a paz, a esperança e a fé. Deus, um raio, uma faísca do vosso amor pode abrasar a terra. Deixa-nos beber nas fontes dessa bondade fecunda e infinita e todas as lágrimas secarão, todas as dores acalmar-se-ão. Um só coração, um só pensamento subirá até Vós com um grito de reconhecimento e amor. E como Moisés sobre a montanha, nós vos esperamos de braços abertos, oh! Poder... oh! Beleza... oh! Bondade... oh! Perfeição, e queremos de alguma forma alcançar a vossa misericórdia. Deus, dai-nos a força de ajudar o progresso a fím de subirmos até Vós; Dai-nos a caridade pura; dai-nos a fé e a razão; dainos a simplicidade que fará de nossas almas, 0 espelho onde deve refletir a Vossa Santa e pura imagem" 


\section{AGRADECIMENTOS}

A Deus, pela presença constante permitiu a realização desse curso;

Ao Prof. Dr. José Antonio Frizzone, pela orientação, ensinamèntos e amizade no decorrer de toda a minha vida acadêmica;

Ao Prof. Dr, Rubens Duarte Coelho pela orientação na fase inicial desse trabalho, pelas valiosas sugestões apresentadas na banca examinadora e pelo constante incentivo à minha formação;

Ao Prof. Dr. Nilson Augusto Villa Nova pela amizade, ensinamentos e pelo conjunto de suas obras em prol da ciência agronômica;

Ao Engenheiro Agrônomo Dr. Cláudio Tomazela pela amizade, ensinamentos e grande apoio ao meu aprimoramento profissional;

Ao Departamento de Engenharia Rural da ESALQ/USP pelo apoio irrestrito à minha formação;

Ao Departamento de Física e Meteorologia da ESALQ/USP pelas facilidades concedidas para a realização deste trabalho;

A empresa SEEI - Serviços Especializados em Engenharia de Irrigação, SP, na pessoa do Engenheiro Civil MSc. Rodrigo Arthur Prestes Law pela concessão dos atmômetros modificados para a realização desta pesquisa;

Aos técnicos Edivaldo Modesto de Abreu e Francisco Bernardo Dias do Departamento de Física e Meteorologia da ESALQ/USP e Gilmar Batista Grigolon do Departamento de Engenharia Rural da ESALQ/USP pelo grande auxílio na realização do ensaio deste trabalho;

Ao Conselho Nacional de Desenvolvimento Científico e Tecnológico (CNPq) pela bolsa de estudos fornecida;

A todos que de alguma forma contribuiram para que este trabalho fosse realizado. 


\section{SUMÁRIO}

Página

LISTA DE FIGURAS viii

LISTA DE TABELAS $\mathbf{x i}$

LISTA DE SIGLAS, ABREVIATURAS E SÍMBOLOS xv

RESUMO xviii

SUMMARY xix

1 INTRODUÇÃO 1

2 REVISÃO DE LITERATURA 3

2.1 Definições e conceitos básicos sobre evapotranspiração................. 3

2.1.1 Evapotranspiração Potencial ............................................. 4

2.1.2 Evapotranspiracão de Referência.................................... 4

2.1.3 Evapotranspiração Real.................................................... 4

2.1.4 Evapotranspiração de cultura ............................................ 5

2.2 Estimativa da evapotranspiração potencial ................................... 5

2.3 Considerações sobre atmômetros .................................................. 6

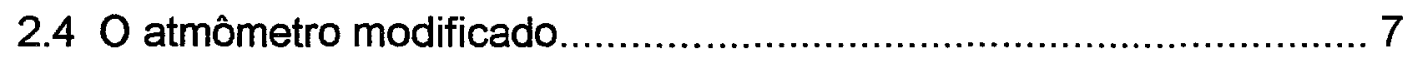

2.4.1 Avaliação do atmômetro modificado .................................. 9

2.4.2 Avaliação do atmômetro modificado na estimativa da evapotranspiração................................................................. 10

2.4.3 Instalação do atmômetro modificado a nível de campo e seu emprego no controle da irrigação.

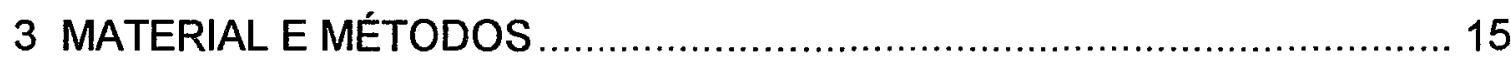

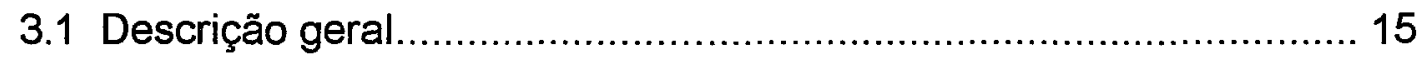

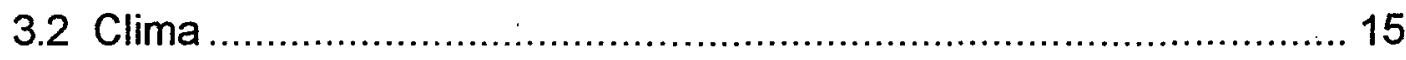

3.3 Parâmetros meteorológicos ...................................................... 15 
Página

3.4 Atmômetros modificados empregados 16

3.4.1 Procedimento para a ampliação da escala de leitura do atmômetro modificado.

3.5 Instalação dos atmômetros modificados e procedimentos de ensaio 22

3.6 Estimativa da evapotranspiração potencial pelo método de PenmanMonteith 24

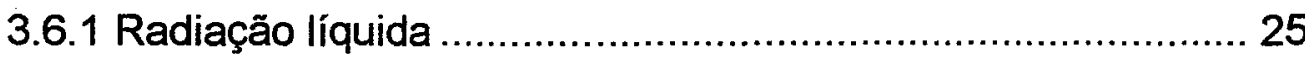

3.6.2 Pressão de saturação do vapor d'água................................ 26

3.6.3 Pressão atual do vapor d"agua......................................... 26

3.6.4 Tangente a curva de pressão de saturação de vapor ........... 26

3.6.5 Constante psicrométrica.................................................... 27

3.6.6 Velocidade do vento a $2 \mathrm{~m}$ de altura.................................. 27

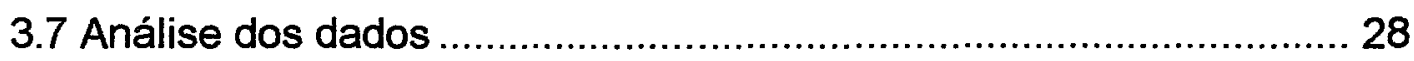

3.7.1 Variabilidade da evaporação medida com os atmômetros modificados 28

3.7.2 Correlações entre os valores de evapotranspiração potencial e evapotranspiração

3.7.2.1 Procedimentos estatísticos para ajuste dos dados e testes das correlações 30

4 RESULTADOS E DISCUSSÃO 34

4.1 Parâmetros meteorológicos, evaporação dos atmômetros modificados, evaporação do tanque classe " $A$ " e evapotranspiração potencial 34

4.2 Verificação da variabilidade das leituras dos atmômetros .............. 35

4.3 Curso dos elementos meteorológicos durante o período de ensaio 38

4.4 Curso da evapotranspiração potencial, da evaporação dos atmômetros modificados e do tanque classe " $\mathrm{A}$ " 41

4.5 Relação entre o Atmômetro modificado com escala de leitura ampliada (ATMEA) e o atmômetro modificado com escala de leitura comercial 43 4.6 Correlações entre a evapotranspiração potencial, a evaporação dos atmômetros modificados e a evaporação do tanque classe " $A$ ". 46 
Página

4.7 Correlação entre a evaporação do tanque classe "A"e a evaporação dos atmômetros modificados........................................................... 56

5 CONCLUSÕES

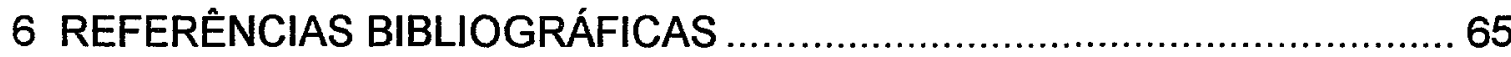

APÊNDICE 


\section{LISTA DE FIGURAS}

1 llustração do primeiro modelo de atmômetro modificado desenvolvido por Altenhofen (1985). O aparelho está instalado sobre um suporte de madeira, juntamente com um pluviômetro para a medida da precipitação pluviométrica, no interior de um campo cultivado com alfafa

2 llustração esquemática do atmômetro modificado

3 Detalhes construtivos do equipamento para ampliação da precisão das medidas de evaporação pelo atmômetro modificado

4 llustração esquemática do atmômetro modificado com o dispositivo para aumentar a precisão de medida da evaporação.

5 Ilustração esquemática das posições de instalação dos atmômetros modificados no posto agrometeorológico do Departamento de Física e Meteorologia da ESALQ/USP.

6 llustração dos constrastes entre os atmômetros modificados com escala de leitura ampliada (ATMEA-1; ATMEA-2 e ATMEA-3) e entre a evaporação do atmômetro modificado com escala de leitura comercial (ATMEC) e o valor médio dos atmômetros com escala ampliada (ATMEA), em função de suas freqüências empíricas acumuladas nos contrastes

7 Cursos dos elementos meteorológicos em períodos quinzenais durante os meses de junho a dezembro de 1992

8 Cursos da Evapotranspiração potencial (ETo); da evaporação do atmômetro modificado com escala de leitura comercia (ATMEC); do atmômetro modificado com escala de leitura ampliada (ATMEA) e da evaporação do tanque classe "A". 
Página

9 Diagramas de dispersão e retas de ajuste entre a evaporação do atmômetro modificado com escala de leitura ampliada (ATMEA) e a evaporação do atmômetro modificado com escala de leitura comercial (ATMEC).

10 Diagramas de dispersão entre os valores da evaporação medida no atmômetro modificado com escala de leitura ampliada (ATMEA) e estimada através do modelo linear utilizando a evaporação do atmômetro modificado com escala de leitura comercial (ATMEC)

11 Diagramas de dispersão e retas de ajuste entre a evapotranspiração potencial (ETo) e a evaporação do atmômetro modificado com escala de leitura comercial (ATMEC).

12 Diagramas de dispersão e retas 1:1 entre os valores da evapotranspiração potencial estimada pelo método de Penman Monteith (ETo-PM) e estimada através do modelo linear utilizando a a evaporação do atmômetro modificado com escala de leitura comercial

(ATMEC)

13 Diagramas de dispersão e retas de ajuste entre a evapotranspiração potencial (ETo) e a evaporação do atmômetro modificado com escala de leitura ampliada (ATMEA)

14 Diagramas de dispersão e retas 1:1 entre os valores da evapotranspiração potencial estimada pelo método de Penman Monteith (ETo-PM) e estimada através do modelo linear utilizando a a evaporação do atmômetro modificado com escala de leitura ampliada (ATMEA).

15 Diagramas de dispersão e retas de ajuste entre a evapotranspiração potencial (ETo) e a evaporação do tanque classe " $A$ " (ECA).

16 Diagramas de dispersão e retas $1: 1$ entre os valores da evapotranspiração potencial estimada pelo método de Penman Monteith (ETo-PM) e estimada através do modelo linear utilizando a a evaporação do tanque classe " $A$ " (ECA). 
Página

17 Diagramas de dispersão e retas de ajuste entre a evaporação do tanque classe "A" (ECA) e a evaporação do atmômetro modificado com escala de leitura comercial (ATMEC).

18 Diagramas de dispersão e retas 1:1 entre os valores da evaporação medida no tanque classe "A" $e$ estimada através do modelo linear utilizando a a evaporação do atmômetro modificado com escala de leitura comercial (ATMEC)

19 Diagramas de dispersão e retas de ajuste entre a evaporação do tanque classe " $A$ " (ECA) e a evaporação do atmômetro modificado com escala de leitura ampliada (ATMEA).

20 Figura 20. Diagramas de dispersão e retas 1:1 entre os valores da evaporação medida no tanque classe " $A$ " e estimada através do modelo linear utilizando a a evaporação do atmômetro modificado com escala de leitura ampliada (ATMEA). 


\section{LISTA DE TABELAS}

Página

1 Valores de Radiação Solar Global ao nível da superfície (RSG), insolação (INS), Precipitação pluviométrica (PP); Umidade Relativa do ar (UR); Evaporação do Tanque Classe (ECA) e Evapotranspiração potencial (ETo) estimada pelo método de Penman-Monteith, para o período de 01/06 a 14/12/1992 em Piracicaba,SP.

2 Valores de evaporação medida com o atmômetro com escala de leitura comercial (ATMEC), e com os atmômetros com escala de leitura ampliada (ATMEA-1; ATMEA-2, ATMEA-3, ATMEA média) durante o período de 01/06 a 14/12/1992 em Piracicaba, SP.

3 Valores de evaporação do Atmômetro modificado com escala de leitura ampliada (ATMEA), do atmômetro modificado com escala de leitura comercial (ATMEC), do tanque classe "A" (mm) e evapotranspiração potencial estimada pelo método de PenmanMonteith, para o período de um dia, utilizados nos ajustes dos modelos de regressão.

4 Valores de evaporação do Atmômetro modificado com escala de leitura ampliada (ATMEA), do atmômetro modificado com escala de leitura comercial (ATMEC), do tanque classe "A" (mm) e evapotranspiração potencial estimada pelo método de PenmanMonteith, para o período de um dia, utilizados na verificação dos modelos de regressão.

5 Valores de evaporação do Atmômetro modificado com escala de leitura ampliada (ATMEA), do atmômetro modificado com escala de leitura comercial (ATMEC), do tanque classe " $\mathrm{A}$ " (mm) e evapotranspiração potencial estimada pelo método de PenmanMonteith, para o período médio de dois dias, utilizados no ajuste dos modelos de regressão 
6 Valores de evaporação do Atmômetro modificado com escala de leitura ampliada (ATMEA), do atmômetro modificado com escala de leitura comercial (ATMEC), do tanque classe "A" (mm) e evapotranspiração potencial estimada pelo método de PenmanMonteith, para o período médio de dois dias, utilizados na verificação dos modelos de regressão.

7 Valores de evaporação do Atmômetro modificado com escala de leitura ampliada (ATMEA), do atmômetro modificado com escala de leitura comercial (ATMEC), do tanque classe "A" (mm) e evapotranspiração potencial estimada pelo método de PenmanMonteith, para o período médio de três dias, utilizados no ajuste dos modelos de regressão

8 Valores de evaporação do Atmômetro modificado com escala de leitura ampliada (ATMEA), do atmômetro modificado com escala de leitura comercial (ATMEC), do tanque classe "A" (mm) e evapotranspiração potencial estimada pelo método de PenmanMonteith, para o período médio de três dias, utilizados na verificação dos modelos de regressão.

9 Valores de evaporação do Atmômetro modificado com escala de leitura ampliada (ATMEA), do atmômetro modificado com escala de leitura comercial (ATMEC), do tanque classe "A" (mm) e evapotranspiração potencial estimada pelo método de PenmanMonteith, para o período médio de quatro dias, utilizados no ajuste dos modelos de regressão

10 Valores de evaporação do Atmômetro modificado com escala de leitura ampliada (ATMEA), do atmômetro modificado com escala de leitura comercial (ATMEC), do tanque classe "A" (mm) e evapotranspiração potencial estimada pelo método de PenmanMonteith, para o período médio de quatro dias, utilizados na verificação dos modelos de regressão.

11 Contrastes entre as medidas dos atmômetros modificados com escala de leitura ampliada (ATMEA-1; ATMEA-2 e ATMEA-3) e com atmômetro modificado com escala de leitura comercial (ATMEA), valor da máxima divergência do teste de Kolmogorov-Smirnov (D) e a significância dos contrastes ao nível de $5 \%$ de probabilidade. 
12 Valores médios quinzenais de umidade relativa do ar (UR), Temperatura do ar $(T)$, precipitação pluviométrica total (PPL), Radiação solar global ao nível da superfície (RSG), velocidade do vento a 2 metros de altura estimada (U2) e insolação (INS)

13 Número de dados ( $n$ ), coeficiente de ajuste (b), coeficiente de correlação $\left(r^{2}\right)$ e indice de concordância de Willmott (d) determinados para às correlações entre a evaporação do atmômetro modificado com escala de leitura ampliada (ATMEA) e a evaporação do atmômetro modificado com escala de leitura comercial (ATMEC) nos diversos períodos de tempo

14 Número de dados ( $n$ ), coeficiente de ajuste (b), coeficiente de correlação $\left(r^{2}\right)$, índice de concordância de Willmott $(d)$, somatório dos quadrados dos resíduos (SQR) e valor de $F$ para o ajuste global referentes às correlações entre a evapotranspiração potencial (ETo) e a evaporação do atmômetro modificado com escala de leitura comercial (ATMEC) nos diversos períodos de tempo.

15 Número de dados ( $n)$, coeficiente de ajuste (b), coeficiente de correlação $\left(r^{2}\right)$, índice de concordância de Willmott (d), somatório dos quadrados dos resíduos (SQR) e valor de $\mathrm{F}$ para o ajuste global referentes às correlações entre a evapotranspiração potencial (ETo) e a evaporação do atmômetro modificado com escala de leitura ampliadal (ATMEA) nos diversos periodos de tempo.

16 Número de dados ( $n$ ), coeficiente de ajuste (b), coeficiente de correlação $\left(r^{2}\right)$, índice de concordância de Willmott (d), somatório dos quadrados dos resíduos (SQR) e valor de $F$ para o ajuste global referentes às correlações entre a evapotranspiração potencial (ETo) e a evaporação do tanque classe "A" (ECA) nos diversos períodos de tempo 
17 Número de dados ( $n$ ), coeficiente de ajuste (b), coeficiente de correlação $\left(\mathrm{r}^{2}\right)$, índice de concordância de Willmott (d), somatório dos quadrados dos resíduos (SQR) e valor de $F$ para o ajuste global referentes às correlações entre a evaporação do tanque classe " $A$ " (ECA) e a evaporação do atmômetro modificado com escala de leitura comercial (ATMEC) nos diversos períodos de tempo.

18 Número de dados ( $n$ ), coeficiente de ajuste (b), coeficiente de correlação $\left(\mathrm{r}^{2}\right)$, índice de concordância de Willmott (d), somatório dos quadrados dos resíduos (SQR) e valor de $F$ para o ajuste global referentes às correlações entre a evaporação do tanque classe " $A$ " (ECA) e a evaporação do atmômetro modificado com escala de leitura ampliada (ATMEA) nos diversos períodos de

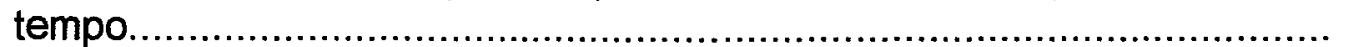




\section{LISTA DE SIGLAS, ABREVIATURAS E SIMMBOLOS}

$\lambda \quad$ - calor latente de vaporização $\left(\mathrm{MJ} \mathrm{kg}^{-1}\right)$

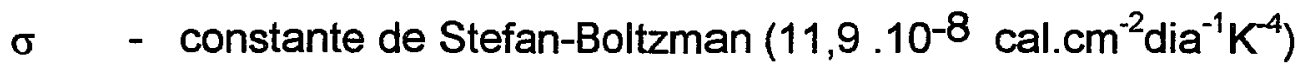

$\gamma \quad$ - constante psicrométrica $\left(\mathrm{kPa}^{\circ} \mathrm{C}^{-1}\right)$

$\delta \quad$ - declinação solar

$\alpha \quad$ - fração média diária da radiação solar refletida (albedo)

$\rho \quad$ - massa específica do ar atmosférico $\left(\mathrm{kg} \mathrm{m}^{-1}\right)$

$\Delta \mathrm{H} \quad$ - variação da lâmina de água no reservatório de água no atmômetro modificado

ASE - área da superfície evaporante

ASTET - área da seção transversal do tubo de PVC

ASTR - área molhada da seção transversal do reservatório

ASTR - área molhada seção transversal do reservatório

ASTTV - área molhada da secão transversal interna do tubo de visualização

$\mathrm{cp} \quad$ - calor específico do ar à pressão constante $\left(1,013 \mathrm{MJ} \mathrm{kg}^{-1}{ }^{\circ} \mathrm{C}^{-1}\right)$

$\mathrm{dpz} \quad$ - deslocamento do plano zero $(\mathrm{m})$

DM - dia do mês

D - valor da maior divergência entre duas distribuições empíricas acumuladas para a aplicação do teste não paramétrico de Kolmogorov-Smirnov

d - Coeficiente do teste de concordância de Willmott

ea - pressão atual de vapor $(\mathrm{kPa})$ 
es - pressão de saturação de vapor à temperatura do $\operatorname{ar}(\mathrm{kPa})$

ECA - evaporação do tanque classe "A" (ECA)

ETo - evapotranspiração potencial ( $\mathrm{mm} \cdot \mathrm{dia}^{-1}$ )

EVAT - evaporação do atmômetro modificado

F $\quad$ - valor do teste "F"

G - fluxo de calor no solo (MJ m$\left.{ }^{-2} \mathrm{dia}^{-1}\right)$

GLi - número de graus de liberdade das regressões índice i

h - ângulo horário em graus decimais

hc - altura média da vegetação $(\mathrm{m})$

INS - Insolação

K - número de regressões índice i empregadas

M - número do mês

N - duração máxima de horas de brilho solar

n - número de horas de brilho solar

Oi - valores observados

P - pressão atmosférica $(\mathrm{kPa})$

$\mathrm{Pi} \quad$ - valores previstos

PPL - precipitação pluviométrica total $(\mathrm{mm})$

ra $\quad$ - resistência aerodinâmica $\left(\mathrm{s} \mathrm{m}^{-1}\right)$

rc - resistência da cobertura vegetal $\left(\mathrm{s} \mathrm{m}^{-1}\right)$

$\mathrm{RL} \quad$ - balanço de ondas longas $\left(\mathrm{cal}_{\mathrm{cm}} \mathrm{cm}^{-2} \mathrm{dia}^{-1}\right)$ 
$\mathrm{Rn} \quad$ - radiação líquida $\left(\mathrm{MJ} \mathrm{m} \mathrm{m}^{-2} \mathrm{dia}^{-1}\right.$ )

RSG - radiação solar global ao nível da superfície (cal.cm ${ }^{-2} \mathrm{dia}^{-1}$ )

s - inclinação da curva de pressão de saturação à temperatura do ar $\left(\mathrm{kPa}{ }^{\circ} \mathrm{C}^{-1}\right)$

SQRi - Somatório dos quadrados dos resíduos da regressão ajustada a um determinado período i

SQRU - somatório dos quadrados dos desvios da regressão global empregando todos os períodos

$\mathrm{T} \quad$ - temperatura média do $\operatorname{ar}\left({ }^{\circ} \mathrm{C}\right)$

U2 - velocidade média do vento a 2 metros de altura $\left(\mathrm{m} . \mathrm{s}^{-1}\right)$.

UR - umidade relativa do ar (\%)

Uz - velocidade do vento na altura Z

VC - volume de água consumido no reservatório (VC)

Zom - comprimento da rugosidade equivalente para a transferência de momento $(\mathrm{m})$ 


\title{
AVALIAÇÃO DO DESEMPENHO DE UM ATMÔMETRO MODIFICADO NA ESTIMATIVA DA EVAPOTRANSPIRAÇÃO POTENCIAL
}

\author{
Autor: ANDERSON SOARES PEREIRA \\ Orientador: Prof. Dr. JOSÉ ANTÔNIO FRIZZONE
}

\section{RESUMO}

Este trabalho teve como objetivos básicos avaliar o desempenho de um atmômetro modificado na estimativa da evapotranspiração potencial e na evaporação do tanque classe " $\mathrm{A}$ ". O ensaio foi conduzido utilizando quatro atmômetros modificados: um aparelho com precisão de $1,0 \mathrm{~mm}$ na medida da evaporação e três aparelhos com escala de leitura ampliada, proporcionando uma precisão de $0,16 \mathrm{~mm}$. As comparações foram feitas através de análises de regressão entre a evapotranspiração potencial estimada pelo método de Penman-Monteith, padrão FAO (ETo), a evaporação do tanque classe "A" e a evaporação dos atmômetros modificados, em escala diária e em periodos médios de 2, 3 e 4 dias. Os resultados indicaram que o atmômetro modificado com precisão de $1,0 \mathrm{~mm}$ na medida da evaporação apresentou correlação satisfatória nas análises citadas para os períodos de tempo médios de 3 e 4 dias. Os atmômetros modificados com escala de leitura ampliada apresentaram ajuste satisfatório para todos os períodos de tempo. As correlações entre ETo versus evaporação dos atmômetros modificados com escala ampliada e ETo versus evaporação do tanque classe " $\mathrm{A}$ " apresentaram similar dispersão nas correlações, porém assumindo coeficientes de ajuste diferentes, sugerindo que o atmômetro modificado e o tanque classe "A" apresentam similar sensibilidade as variações dos parâmetros de clima. 


\title{
EVALUATION OF A MODIFIED ATMOMETER TO ESTIMATE OF THE POTENTIAL EVAPOTRANSPIRATION
}

\author{
Author: ANDERSON SOARES PEREIRA \\ Adviser: Prof. Dr. JOSÉ ANTÔNIO FRIZZONE
}

\section{SUMMARY}

The main purpose of this work was to evaluate the performance of a modified atmometer in estimative of potential evapotranspiration and the class "A" pan evaporation. The trial was carried out with four modified atmometers: one with $1,0 \mathrm{~mm}$ reading and others ones, with amplified reading scale, providing $0,16 \mathrm{~mm}$ of accuracy in evaporation measurements. The potential evapotranspiration estimatives by Penman-Monteith method (ETO) and class "A" pan evaporation were plotted against evaporations of modified atmometers readings in diary scale and average periods of 2, 3 and 4 days. The results indicated that the modified atmometer $(1,0 \mathrm{~mm}$ precision) have satisfatory correlation with ETo and class "A" pan evaporation only for average periods higher than of 3 days. The atmometers with amplificated $(0,16 \mathrm{~mm}$ precision) showed satisfatory correlation in all periods of time. The correlations between ETo - class "A" pan and ETo - atmometers with amplified scales showed similar dispersions in relationships, but with differents coefficients of fitting in linear regressions. Such performance indicates that the modified atmometers and class " $\mathrm{A}$ " pan evaporation have similar responses to variations in climate conditions. 


\section{INTRODUÇÃO}

$\mathrm{Na}$ agricultura contemporânea a irrigação assumiu papel relevante no aumento do rendimento das culturas. No âmbito da engenharia agrícola, o planejamento e manejo dos sistemas de irrigação dependem de estimativas acuradas da evapotranspiração, para que a alternativa do cultivo irrigado manifeste todo o seu potencial de lucratividade.

Irrigações leves e freqüêntes repõem água apenas nas camadas superficiais do solo, reduzindo o desenvolvimento radicular das plantas, impossibilitado-as de explorar o volume de solo disponível, ocasionando redução do rendimento das culturas e desperdiçando recursos. Do mesmo modo, irrigações excessivas também são contraindicadas, pois acarretam perda de água e nutrientes por percolação profunda. Em solos mal drenados, poderá haver redução do desenvolvimento radicular devido à deficiência de aeração (Camargo \& Pereira, 1990). Assim, as estimativas do consumo de água pelas culturas devem ser adequadamente computadas, para que a água seja aplicada em proporções tais, para que o solo armazene uma certa quantidade de água em niveis adequados, de forma que as plantas cultivadas não sejam expostas à déficits ou excedentes hídricos que comprometam o seu rendimento.

Os atmômetros, como o próprio nome sugere, são aparelhos destinados a medir a demanda evaporativa da atmosfera. Dentre os diversos tipos de atmômetros, destacam-se os equipamentos mais simples como os tanques de evaporação; mais complexos como o evaporímetro de Piche, que utiliza papel poroso como superfície evaporante e o atmômetro de Livingston, 
que emprega cápsulas porosas esféricas para essa finalidade. Os atmômetros vem sendo estudados durante muitas décadas para a estimativa do consumo de água pelas plantas. Suas medidas refletem diretamente as condições ambientais, permitindo medir os efeitos integrados da radiação solar, temperatura, umidade relativa do ar e velocidade do vento sobre a evaporação, podendo assim se correlacionar de forma positiva com a evapotranspiração das culturas.

O atmômetro modificado foi idealizado como um instrumento simples e de baixo custo para a estimativa da evapotranspiração. Esse equipamento consiste basicamente em uma superfície evaporante composta de uma cápsula porosa coberta com uma lona especial de cor verde, ligada a um reservatório onde a evaporação é quantificada através da variação do nível de água. Os atmômetros modificados se destacam entre os demais modelos de atmômetros pela cobertura da cápsula porosa com a lona especial de cor verde, que tem como objetivos básicos oferecer uma reflexão da radiação solar e uma resistência ao fluxo de vapor de água semelhante a um dossel vegetativo cultivado sem restrição hídrica, fornecendo assim subsídios para uma estimativa consistente da evapotranspiração potencial.

Esse trabalho tem por objetivos básicos avaliar o desempenho de um atmômetro modificado na estimativa da evapotranspiração potencial para diversos períodos de tempo, visando fornecer subsídios para seu emprego em programas de manejo da irrigação. Objetiva também analisar o seu comportamento evaporativo em relação ao tanque classe " $\mathrm{A}$ ". 


\section{REVISÃO DE LITERATURA}

\subsection{Definições e conceitos básicos sobre evapotranspiração}

Segundo Burman et al. (1983) a evapotranspiração pode ser definida como um processo combinado de transferência de água do solo para a atmosfera, incluindo a evaporação da água diretamente da superficie do solo ou da vegetação como também o processo de transpiração através dos tecidos vegetais. A evapotranspiração pode ser expressa como calor latente de evaporação (cal.cm ${ }^{2} \cdot \mathrm{min}^{-1}$ ) ou a quantidade equivalente de água evapotranspirada por unidade de tempo, geralmente expressa como lâmina por unidade de tempo (mm.dia-1). A evapotranspiração é controlada pela disponibilidade de energia, pela demanda atmosférica (poder evaporante do ar) e pelo suprimento de água do solo às plantas. A disponibilidade de energia depende do local e da época do ano. O local é caracterizado pelas coordenadas geográficas (latitude e altitude) e pelo relevo da região. A latitude determina o potencial diário de radiação solar a ser utilizado no processo evapotranspirativo; a altitude afeta diretamente as temperaturas do solo, do ar, e a pressão atmosférica, que são fatores que também influenciam a evapotranspiração. O relevo determina o ângulo de incidência dos raios solares e conseqüentemente, a disponibilidade de energia. (Pereira, 1992). 


\subsubsection{Evapotranspiração Potencial}

Segundo Pereira (1992) a evapotranspiração potencial é aquela correspondente à uma extensa área vegetada, em crescimento ativo, cobrindo totalmente o terreno, estando esse bem suprido de umidade, ou seja: em nenhum instante a demanda atmosférica é restringida. Essa área deve ser circundada por uma área tampão (bordadura) suficientemente grande para eliminar o efeito advectivo, ficando a evapotranspiração resultante somente do balanço vertical de energia.

Em regiões de clima tropical e subtropical, como ○ Brasil, utiliza-se como referência para a determinação do consumo de água das culturas, a evapotranspiração potencial da grama batatais (Paspalum notatum L.) devido a essa permanecer verde e em pleno desenvolvimento vegetativo durante grande parte do ano, desde que seja irrigada (Reichardt, 1987).

\subsubsection{Evapotranspiracão de Referência}

Segundo Doorenbos \& Pruitt (1979) evapotranspiração de referência é aquela de uma extensa superfície de grama com altura de 8 a $15 \mathrm{~cm}$, em crescimento ativo, cobrindo o solo e sem deficiência de água. Em essência, a evapotranspiração de referência é a potencial (Pereira, 1992; Villa Nova \& Reichardt, 1989).

\subsubsection{Evapotranspiração Real}

Refere-se à perda de água por evapotranspiração de uma superfície em quaisquer condições de vegetação ou de umidade do solo (Villa Nova \& Reichardt, 1987), podendo ser limitada tanto pela disponibilidade de radiação solar como pelo suprimento de umidade pelo solo. 


\subsubsection{Evapotranspiração de cultura}

Desde o plantio até a colheita, uma cultura vai progressivamente crescendo e ocupando a área disponivel. Evidentemente, nessas condições, ocorre a evapotranspiração real, que na prática é denominada como evapotranspiração de cultura (Pereira, 1992; Doorenbos \& Pruitt, 1979).

Para fins de projeto de sistemas ou para o controle da irrigação, a evapotranspiração de cultura é estimada multiplicando-se o valor da evapotranspiração potencial por um coeficiente de cultura $(\mathrm{Kc})$, determinado experimentalmente. $\mathrm{O}$ valor de $\mathrm{Kc}$ varia com a cultura e com seu estádio de desenvolvimento, sendo apresentado em trabalhos de pesquisa ou em tabelas, como em Doorenbos \& Pruitt (1979) e Doorenbos \& Kassan (1994).

\subsection{Estimativa da evapotranspiração potencial}

Conforme Burman at al. (1983) a evapotranspiração pode ser obtida através de medidas diretas no campo, empregando lisímetros ou balanço de água no solo, entre outros, como também através de modelos empregando dados meteorológicos e parâmetros de cultura.

$\mathrm{Na}$ literatura são apresentados diversos métodos para a estimativa da evapotranspiração. Penman (1948) desenvolveu seu modelo combinando o balanço vertical de energia (termo energético) com o poder evaporante do ar, expresso como um uma função linear da velocidade do vento associado ao déficit de saturação de vapor do ar (termo aerodinâmico). Monteith (1965) apresentou uma modificação no método de Penman considerando no termo aerodinâmico dois valores de resistência ao fluxo de vapor de água: a resistência do dossel (rc), decorrente de características fisiológicas da planta e a resistência aerodinâmica ( $r a)$, que descreve a influência da turbulência atmosférica no processo de transporte de vapor de água. Esse modelo ficou 
conhecido como Penman-Monteith, oferecendo diversas vantagens em relação ao modelo original de Penman como a possibilidade de ser utilizado em qualquer tipo de vegetação. A sua aplicação a nível prático é limitada pelas dificuldades de se obterem valores confiáveis de rc e ra.

Em uma reunião envolvendo diversos especialistas da FAO (Smith, 1991) concluiu-se em adotar o método de Penman-Monteith como o mais adequado para a estimativa da evapotranspiração de uma cultura em escala diária. Para a estimativa da evapotranspiração potencial (ETo) sugeriram uma parametrização considerando a altura da vegetação (grama) como $0,12 \mathrm{~m}$, resistência do dossel igual a $69 \mathrm{s.m}-1$ e albedo igual a 23\%, recomendando a validação desses parâmetros para diferentes condições climáticas.

Peres (1994) nas condições climáticas do estado de São Paulo encontrou boa correlação entre valores decadiários e mensais de ETo medida em lisímetros de drenagem e estimada pelo método de Penman-Monteith, utilizando a padronização proposta pela FAO (Smith, 1991). Resultados semelhantes foram obtidos por Chaves (1996) em Piracicaba, SP utilizando valores de ETo medidos em lisímetros de pesagem e estimados em escala diária.

\subsection{Considerações sobre atmômetros}

Segundo Shannon (1968) atmômetros são instrumentos utilizados para a medida da demanda evaporativa da atmosfera. Muitos tipos de atmômetros foram desenvolvidos de forma simples, como os tanques de evaporação de água. Posteriormente, surgiram aparelhos com superficies evaporantes especiais, como tecidos e porcelanas porosas. O evaporímetro de Piche é um exemplo de atmômetro que utiliza papel poroso como superfície evaporante. $O$ atmômetro de Livingston utiliza uma cápsula porosa esférica, ligada à um reservatório de água para a medida da evaporação. A grande susceptibilidade 
a proliferação de algas e a obstrução dos poros das cápsulas porosas com sais são as principais desvantagens, pois causam alterações na condutividade hidráulica dessas e conseqüêntemente na evaporação medida.

\subsection{O atmômetro modificado}

O atmômetro modificado foi desenvolvido por Altenhofen (1985). O aparelho consiste em uma cápsula porosa branca, com superfície evaporante circular plana e horizontal (cápsula de Bellani) de $8 \mathrm{~cm}$ de diâmetro, coberta com uma lona especial de cor verde. Esse conjunto é ligado em um reservatório de água, onde a evaporação é quantificada através da variação do nivel de água, visualizada através de um tubo plástico transparente ligado ao reservatório e medida com uma escala graduada em milímetros. A área da seção transversal interna do reservatório é igual a área da superfície evaporante e, portanto, a lâmina de água evaporada pela cápsula porosa é igual a variação do nível de água do reservatório. A Figura 1 ilustra o primeiro modelo do atmômetro modificado desenvolvido por Altenhofen (1985).

A cobertura da capsula porosa com a lona verde tem como objetivos possibilitar um albedo similar a um dossel vegetativo verde e introduzir uma resistência ao fluxo de vapor de água semelhante àquela oferecida pelos estômatos das folhas de uma cultura de alfafa cultivada sem restrição hídrica (Altenhofen, 1985; Law \& Israeli, 1988). A referida lona é produzida com tecido especial impermeabilizante (conhecido no mercado norte-americano como "vortex") que impede o seu enxarcamento com água de chuva ou irrigação. Em relação aos tanques de evaporação, Altenhofen (1985) relata diversas vantagens do atmômetro modificado, como o baixo custo, melhor portabilidade e operacionalidade a nível de campo e menor acúmulo de energia durante o dia, que pode alterar as medidas do tanque devido a evaporação no período noturno. 


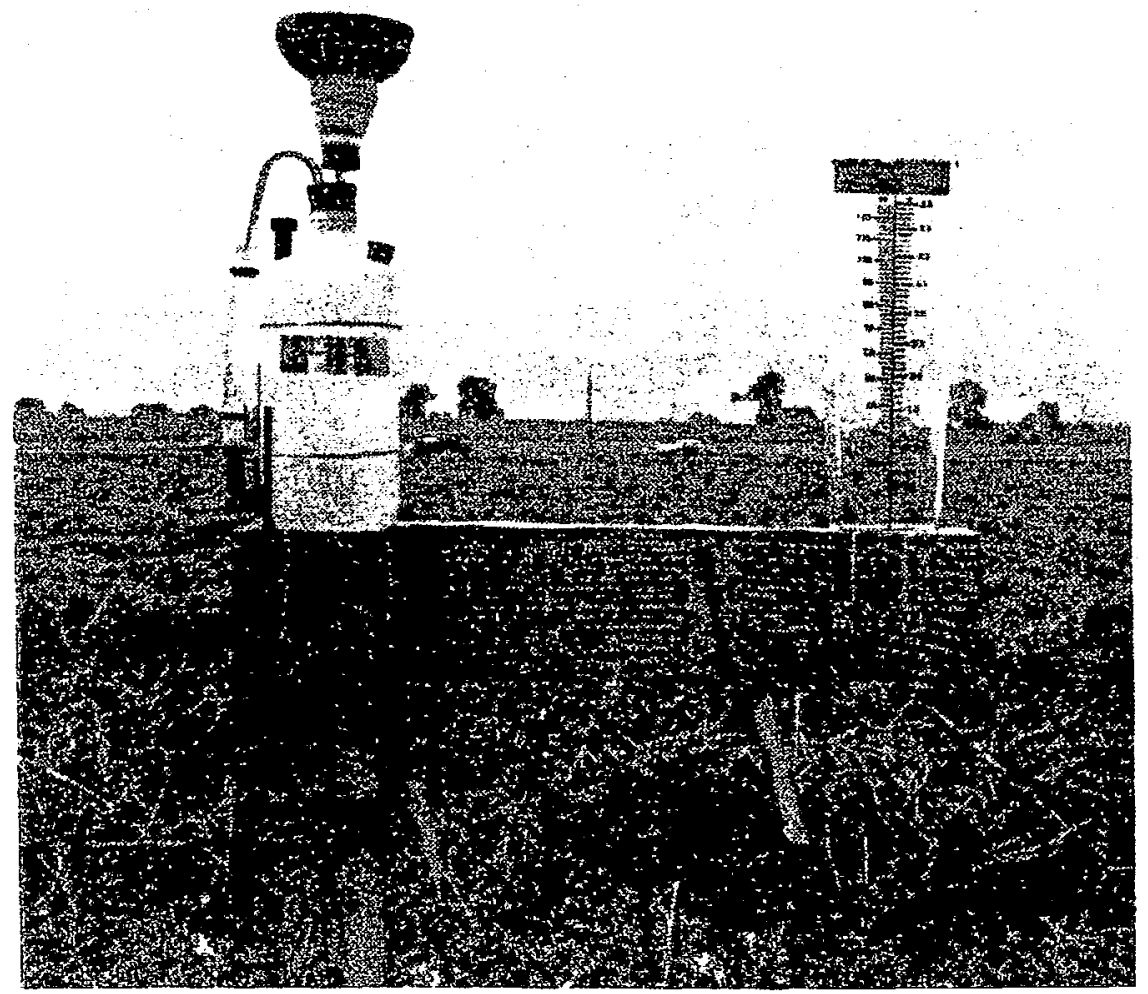

Figura 1 - llustração do primeiro modelo de atmômetro modificado desenvolvido por Altenhofen (1985). O aparelho está instalado sobre um suporte de madeira, juntamente com um pluviômetro para a medida da precipitação pluviométrica, no interior de um campo cultivado com alfafa. 
No mercado brasileiro encontram-se disponíveis dois modelos de atmômetros modificados: um modelo fabricado pela empresa SEEl, estado de São Paulo, com dimensões semelhantes ao modelo de Altenhofen (1985) e outro modelo fabricado pela empresa SOILCONTROL, estado de São Paulo, de dimensões inferiores ao atmômetro SEEI e com superfície evaporante de formato cônico.

\subsubsection{Avaliação do atmômetro modificado}

Altenhofen (1985) mediu a resistência a difusão de vapor oferecida pela lona verde sobre a cápsula porosa do atmômetro modificado e de uma cultura de alfafa (Medicago sativa L.) cultivada sem restrição hídrica. Verificou que a resistência ao fluxo de vapor das folhas de alfafa variou de 0,5 a 3,0 $\mathrm{s} . \mathrm{cm}^{-1}$ e da lona verde sobre a cápsula porosa de 1,0 a $3,0 \mathrm{~s} . \mathrm{cm}^{-1}$, concluindo que esses resultados foram similares e o atmômetro modificado um modelo físico da evapotranspiração da alfafa.

Law \& Israeli (1988) verificaram que a condutividade hidráulica (K) da cápsula porosa não restringiu a evaporação do aparelho sob condições de altas demandas evaporativas. $O$ valor de $K$ determinado foi de $1,2 \times 10^{-7}$ $\mathrm{cm} . \mathrm{s}^{-1}$. Considerando que o diâmetro da cápsula porosa empregada era de $6,55 \mathrm{~cm}$, com expessura de $0,3 \mathrm{~cm}$ temos que a sua condutância é de $1,35 \times$ $10^{-5} \mathrm{~cm}^{2} \cdot \mathrm{s}^{-1}$, valor esse semelhante aos encontrados em cápsulas porosas para tensiômetros, que variam de $1,0 \times 10^{-5} \mathrm{~cm}^{2}$. $\mathrm{s}^{-1}$ a $3,0 \times 10^{-5} \mathrm{~cm}^{2}$. $\mathrm{s}^{-1}$ (Klute, 1986). Law \& Israeli (1988) observaram também que o albedo da lona verde foi semelhante àquele encontrado nas folhas de alfafa e a resistência ao fluxo de vapor e a saturação de vapor entre a lona verde e a cápsula porosa apresentaram valores similares às cavidades estomatais das folhas de alfafa, concluido também que o atmômetro modificado é um modelo físico da evapotranspiração da alfafa. 
O fato de o albedo e as resistência ao fluxo de vapor proporcionadas pela lona verde como também a saturação de vapor entre a lona e a cápsula porosa apresentarem valores similares aos medidos na alfafa é condição necessária, porém não é suficiente para concluir que o atmômetro modificado é um modelo físico de evapotranspiração. Conforme apresentado por diversos autores (Zelich, 1963; Mendner, 1968 e Devlin, 1969) o processo de difusão estomatal de vapor e gases e conseqüentemente, o controle estomatal da transpiração é um processo dinâmico e dependente das condições ambientais e fisiológicas das plantas, não apresentado portanto, um comportamento estático como ocorre no atmômetro modificado.

\subsubsection{Avaliação do atmômetro modificado na estimativa da evapotranspiração.}

Altenhofen (1985) estudou o efeito de diferentes alturas de instalação do atmômetro modificado sobre as medidas de evaporação. Para tanto, diversos aparelhos foram instalados em suportes, possibilitando às superfícies evaporante alturas de 0,25 a $0,75 \mathrm{~m}$ sobre o dossel vegetativo de uma cultura de alfafa. Não foram encontradas diferenças significativas entre os tratamentos. Para verificar o efeito da advecção sobre a evaporação do atmômetro modificado foram instalados aparelhos em diversas condições de bordadura: próximos a estradas; áreas pavimentadas com construções; campos com solo não cultivado e no interior de uma lavoura de alfafa, que serviu como padrão nas comparações. A variação na evaporação dos aparelhos em relação ao padrão foi pequena ( 0 a $5 \%$ ). A maior variação ocorreu em relação aos aparelhos instalados próximos as áreas pavimentadas e com construções, apresentando valores cerca de $15 \%$ maiores que o padrão.

No ensaio descrito anteriormente não foram coletadas informações para quantificar o fluxo horizontal de energia (calor sensível) e assim, não 
podemos concluir nada em relação ao efeito da advecção sobre a evaporação do atmômetro modificado, pois não sabemos se realmente ocorreu esse fenômeno, mesmo nas condições mais favoráveis.

Altenhofen (1985) realizou estudos comparativos entre a evapotranspiração potencial estimada considerando a alfafa como cultura de referência (não foi citado qual foi o método empregado) e a evaporação medida pelo atmômetro modificado para períodos médios de cinco dias, durante os meses de junho a setembro, em Loveland, Colorado, EUA. Concluiu que a razão entre a evapotranspiração estimada e a evaporação dos aparelhos apresentou um valor médio de 0,92. Com um pequeno desvio padrão.

Blume et al. (1988) realizaram um experimento em condições de campo em Garden City, Kansas-EUA, envolvendo diversos métodos de medida da umidade do solo e consumo de água pelas plantas. A evaporação do atmômetro modificado e a evapotranspiração potencial estimada pelo método de Penman foram comparadas através de períodos acumulados de 6 dias. A variabilidade entre os dois métodos foi pequena e o atmômetro apresentou um desempenho satisfatório

Law \& Israeli (1988) em Fort Collins, Colorado, EUA verificaram pequena variação entre a evapotranspiração potencial estimada pelo método de Penman tomando-se a alfafa como cultura de referência e a evaporação do atmômetro modificado, utilizando os dados agrupados em períodos cumulativos de tempo (dia1 + dia2; dia1 + dia2 + dia3...). Resultados semelhantes foram obtidos por Broner (1988) em Loveland, Colorado, EUA.

Acreditamos que a utilização dos dados agrupados em períodos cumulativos de tempo, não é uma metodologia aceitável para as referidas análises. A acumulação dos valores pode gerar uma compensação dos erros (dias com subestimativas são compensados pelos dias com superestimativas). A forma adequada seria empregar os dados em escala diária ou valores médios em diferentes períodos de tempo. 
Em Piracicaba, SP, Pereira \& Coeiho (1992) conduziram um ensaio onde a evapotranspiração potencial estimada pelo método de Penman, utilizando a alfafa como cultura de referência, foi comparada evaporação do atmômetro modificado, durante os meses de maio a outubro. Definiu-se um coeficiente de ajuste "Ka" como sendo a razão entre a evapotranspiração potencial e a evaporação do atmômetro. Observou-se um valor médio de $\mathrm{Ka}$ igual a 1,04 , com um coeficiente de variação de $18 \%$. Constatou-se que nos dias chuvosos, o atmômetro modificado apresentou valores de evaporação inconsistentes, devido a entrada de água no interior do reservatório do aparelho via cápsula porosa. A escala de leitura do nível de água no reservatório, graduada em milímetros, não possibilitou uma quantificação precisa da evaporação, o que provavelmente, foi um dos fatores que gerou a grande variabilidade do coeficiente de ajuste "Ka".

Utilizando periodos médios de sete dias em Viçosa, MG, Erthal et al. (1995) não encontraram correlação linear satisfatória entre a evapotranspiração potencial estimada pelo método de Penman (cultura de referência: grama) e a evaporação do atmômetro modificado. Por outro lado, nas comparações com a evaporação do tanque classe e evapotranspiração potencial estimada pelo método do tanque classe "A" mostraram significativa correlação com as medidas do aparelho.

Pereira (1994) estudou o efeito de diferentes niveis do lençol freático na evapotranspiração e coeficientes de cultura da Alface (Lactuca sativa, L.) cultivada em lisímetros. Os coeficientes de cultura $(\mathrm{Kc})$ foram determinados em relação a evaporação do atmômetro modificado (Kc igual a razão entre a evapotranspiração da alface e a evaporação do atmômetro) e sobre a evapotranspiração potencial estimada pelo método do tanque classe "A" (Kc igual a razão entre a evapotranspiração da alface e a evapotranspiração calculada pelo método do tanque classe "A"). Concluiu que os coeficientes de 
cultura calculados pelas diferentes metodologias não se diferiram significativamente.

\subsubsection{Instalação do atmômetro modificado a nível de campo e seu emprego no controle da irrigação}

Broner (1990) indica os procedimentos adequados para a instalação e operação do atmômetro modificado:

1) Colocar o apareiho em posição vertical, com a superfície evaporante a cerca de $1,0 \mathrm{~m}$ da superfície do solo;

2) O atmômetro deve ser instalado em um local de fácil acesso próximo ao campo irrigado;

3) O local deve ser representativo das condições do campo;

4) Não instalar o atmômetro próximo a barreiras de vento ou insolação, tais como construções, árvores ou culturas altas;

5) Conservar a lona verde limpa, lavando-a periodicamente;

6) Instalação de uma bandeirola em um poste alto, próximo do aparelho, para que pássaros não pousem no mesmo;

7) Deve se manter a continuidade da água através da cerâmica e do tubo de sucção, eliminando-se totalmente as bolhas de ar;

8) Quando o nível de água do reservatório cair a aproximadamente dois terços, deve-se completar o nível novamente;

9) Maior segurança e representatividade da evaporação ser obtidas, instalando-se mais de um aparelho no mesmo local; no caso de diferenças significativas na leitura entre os instrumentos, as cerâmicas devem ser verificadas e limpas ou o fabricante contactado.

Broner (1990) apresenta uma metodologia para realizar o manejo da irrigação através de um balanço hídrico com o atmômetro modificado, utilizando as medidas do aparelho diretamente como o valor da evapotranspiração 
potencial e através de coeficientes de cultura, o consumo de água pelas plantas. 


\section{MATERIAL E MÉTODOS}

\subsection{Descrição geral}

O ensaio foi conduzido no interior do Posto Agrometeorológico do Departamento de Física e Meteorologia da Escola Superior de Agricultura "Luiz de Queiroz", Universidade de São Paulo, Piracicaba, SP, no período de junho a dezembro de 1992. As coordenadas geográficas locais são : $22^{\circ} 42^{\prime}$ de latitude sul, $47^{\circ} 38^{\prime}$ de longitude oeste, a 580 metros de altitude.

\subsection{Clima}

O clima da região é do tipo mesotérmico Cwa, pela classificação climática de Köeppen, ou seja, sub-tropical úmido, com estiagem no inverno, com temperatura média inferior a $18^{\circ} \mathrm{C}$ no mês mais frio e superior a $22^{\circ} \mathrm{C}$ no mês mais quente, também denominado de tropical de altitude (Camargo, 1974). O período chuvoso compreende os meses de outubro a março e o período seco os meses de abril a setembro (Ometto, 1981).

\subsection{Parâmetros meteorológicos}

As informações meteorológicas foram coletadas pelo corpo técnico do Departamento de Física e Meteorologia da ESALQ/USP no Posto 
Agrometeorológico do referido Departamento, onde também foram instalados os atmômetros modificados.

Foram empregados valores médios diários de Temperatura do ar, umidade relativa; velocidade do vento medida a $10 \mathrm{~m}$ de altura e totais diários de insolação, radiação solar global ao nível da superfície, precipitação pluviométrica e evaporação do tanque classe "A".

\subsection{Atmômetros modificados empregados}

Foram utilizados quatro atmômetros modificados da marca SEEI. Os aparelhos apresentam as seguintes características:

-Cápsula Porosa: cápsula de Bellani com diâmetro de 65 mm;

-Lona verde: fabricada com tecido especial, diâmetro de $170 \mathrm{~mm}$, com barbante de nylon para o seu amarrio sobre a cápsula porosa;

-Tubo de Sucção : tubo de plástico, com $42 \mathrm{~mm}$ de comprimento e 4 $\mathrm{mm}$ de diâmetro interno, tendo acoplada uma válvula de retenção de água para evitar o fluxo de água para o interior do reservatório em decorrência de chuvas. A extremidade superior do tubo apresenta uma rolha de borracha para fazer a ligação entre o tubo de sucção e a cápsula porosa.

-Reservatório de água: forma cilíndrica, em PVC, com $75 \mathrm{~mm}$ de diâmetro externo, $65 \mathrm{~mm}$ de diâmetro interno e altura de $45 \mathrm{~cm}$. Apresenta externamente, uma escala graduada em milímetros para a medida do nível de água ;

-Tubo de vidro transparente: diâmetro interno de $6 \mathrm{~mm}$, acoplado ao reservatório para a medida do nível de água

A Figura 2 apresenta a ilustração esquemática do aparelho.

Conforme relatado por Pereira \& Coelho (1992) o atmômetro modificado SEEI apresenta uma reduzida precisão para a medida da evaporação, devido às leituras do nível de água do reservatório serem medidas 
CAPSULA POROSA COBERTA COM LONA ESPECIAL VERDE

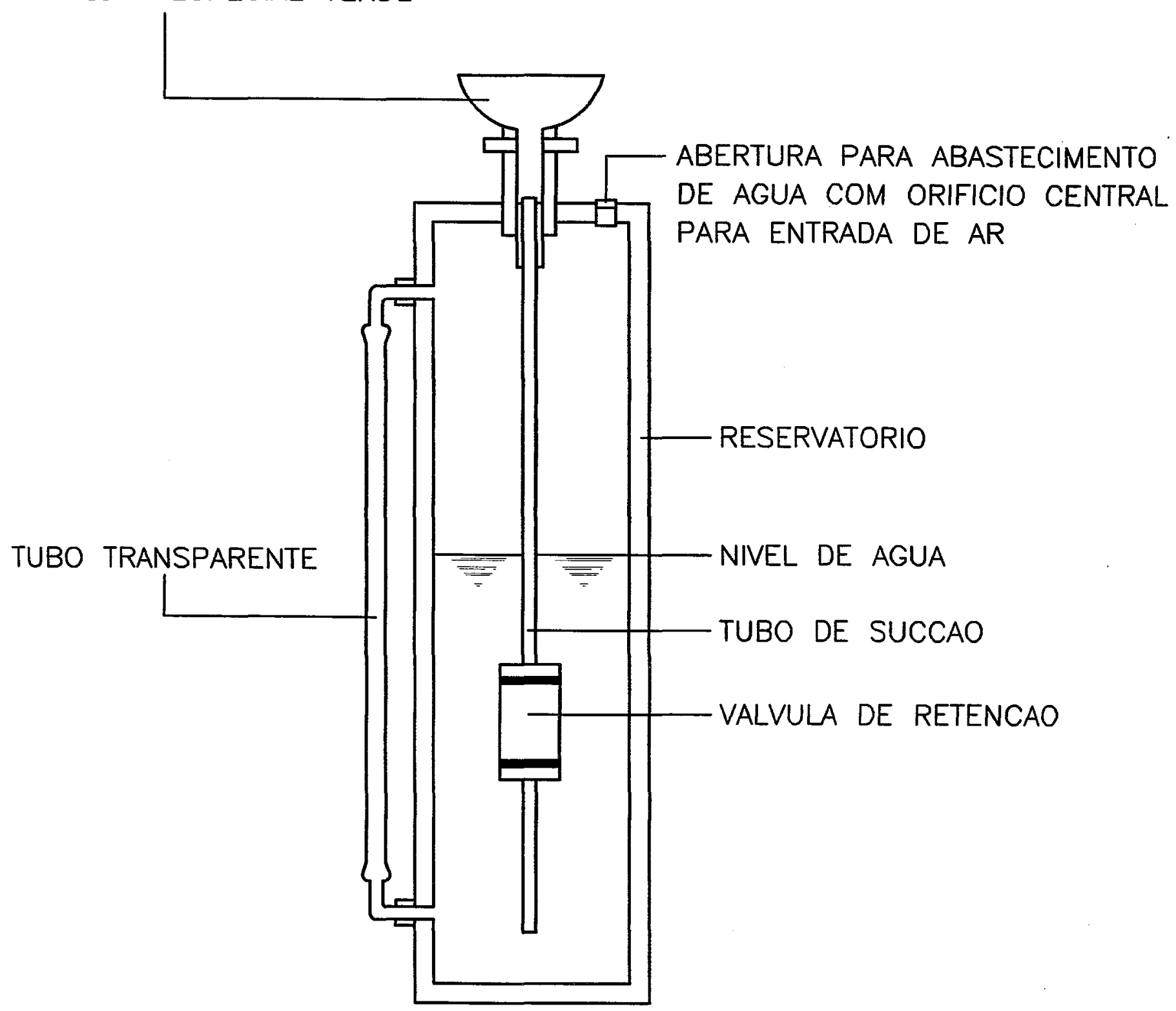

Figura 2 - Ilustração esquemática do atmômetro modificado. 
por uma escala graduada em milímetros. Em vista disso, três dos quatro aparelhos empregados tiveram sua escala de leitura ampliada, melhorando a precisão das medidas de evaporação.

\subsubsection{Procedimento para a ampliação da escala de leitura do atmômetro modificado}

Para a ampliação da escala de leitura do atmômetro modificado procurou-se um procedimento simples, de baixo custo e que não alterasse os componentes do aparelho. A evaporação do atmômetro modificado (EVAT) é quantificada através da razão entre o volume de água consumido no reservatório (VC) e a área da superfície evaporante (ASE):

$$
E V A T=\frac{V C}{A S E}
$$

O valor de VC é calculado por:

$$
V C=A S T R . \Delta H
$$

em que ASTR é a área molhada seção transversal do reservatório e $\Delta H$ é a variação da lâmina de água no reservatório, evaporada durante um período de tempo t.

Substituindo (2) em (1) temos:

$$
E V A T=\frac{A S T R}{A S E} \cdot \Delta H
$$

A relação (ASTR $\div$ ASE) é portanto, um coeficiente de ajuste entre a lâmina de água consumida no reservatório e a lâmina evaporada. No caso do atmômetro modificado estudado, com ASTR = ASE, essa relação é igual a 1, e assim a variação da lâmina de água no reservatório $(\Delta \mathrm{H})$ corresponde em igual valor a lâmina de água de evaporada (EVAT). Porém, para a medida do nivel de água no reservatório (e conseqüentemente da evaporação) utiliza-se uma 
escala graduada em milímetros, que não possibilita medidas com precisão menores que $1 \mathrm{~mm}$, devido a dificuldade em visualizar precisamente a posição do menisco de água no tubo de vidro, entre as marcas sucessivas da escala. Para empregarmos medidas de evaporação no controle da irrigação precisamos de medidas com precisão de décimos de milimetro.

Pelas equações 1, 2 e 3 observa-se que para um mesmo volume de água consumido, conforme se diminui o valor de ASTR ou aumenta ASE, o valor de $\Delta \mathrm{H}$ aumenta. Para o caso de $\Delta \mathrm{H}$ ser medido com escala graduada em milímetros, quanto maior for o valor desse parâmetro, para um mesmo volume de água evaporada, menores serão os erros na quantificação da evaporação devido a imprecisão das leituras na escala.

De acordo com o exposto, o procedimento adotado para o aumento da precisão na medida de evaporação do atmômetro modificado foi a redução da área da seção transversal do reservatório. Para tanto, foi instalado no interior dos reservatórios um tubo de PVC, com $60 \mathrm{~mm}$ de diâmetro, fechado em sua extremidade inferior através de uma chapa plástica, por onde através de um orifício, o tubo de sucção entra em contato com a água. Para que o conjunto não flutuasse no reservatório, ele foi preenchido com uma pequena quantidade de areia fina. A Figura 3 apresenta os detalhes construtivos do dispositivo.

Conforme pode ser visualizado na Figura 4, com a instalação do dispositivo, a área molhada da seção transversal do reservatório (ASTR) será aquela localizada entre a parede interna do reservatório de água e a parede externa do tubo de PVC, acrescida da área molhada da seção transversal do tubo transparente para a visualização do nível de água:

$$
A S T R=A S T I R+A S T T V-A S T E T
$$

em que ASTIR é a área molhada da seção transversal interna do reservatório de água; ASTTV é a área molhada da seção transversal interna do tubo de visualização e ASTET é a área total da seção transversal do tubo de PVC. 


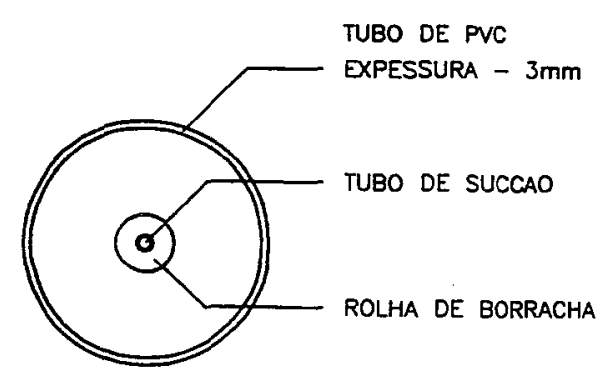

CORTE A-B

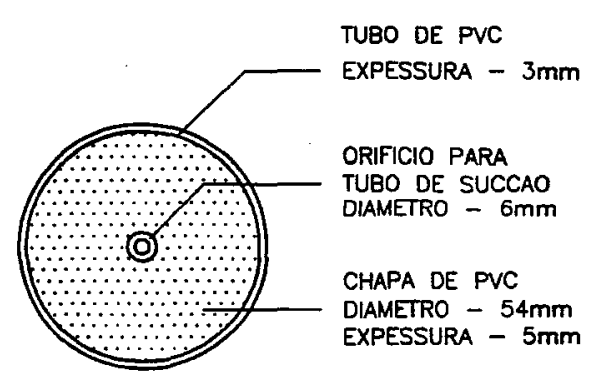

CORTE C-D

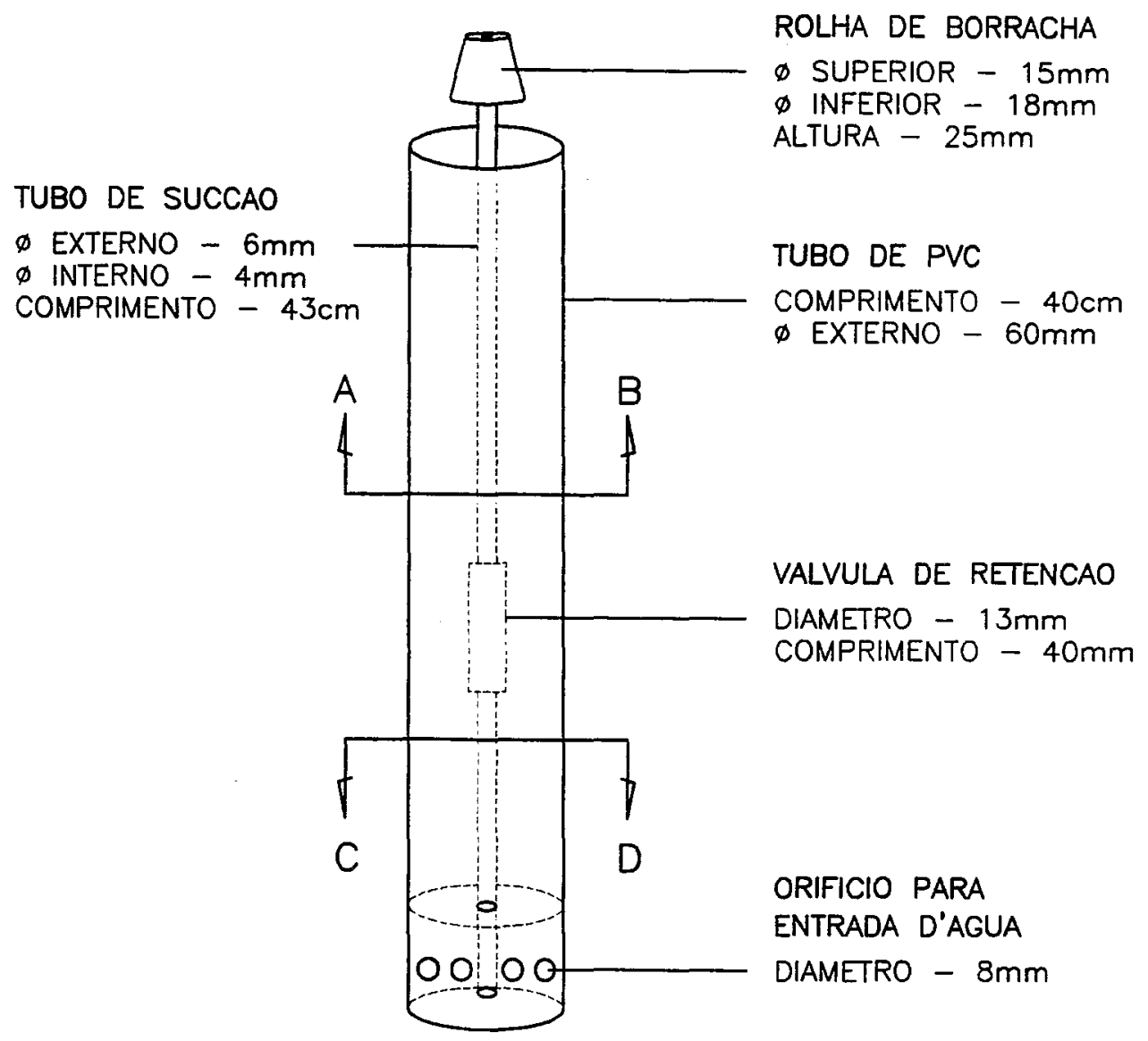

Figura 3 - Detalhes construtivos do dispositivo para ampliação da precisão nas medidas de evaporação pelo atmômetro modificado. 


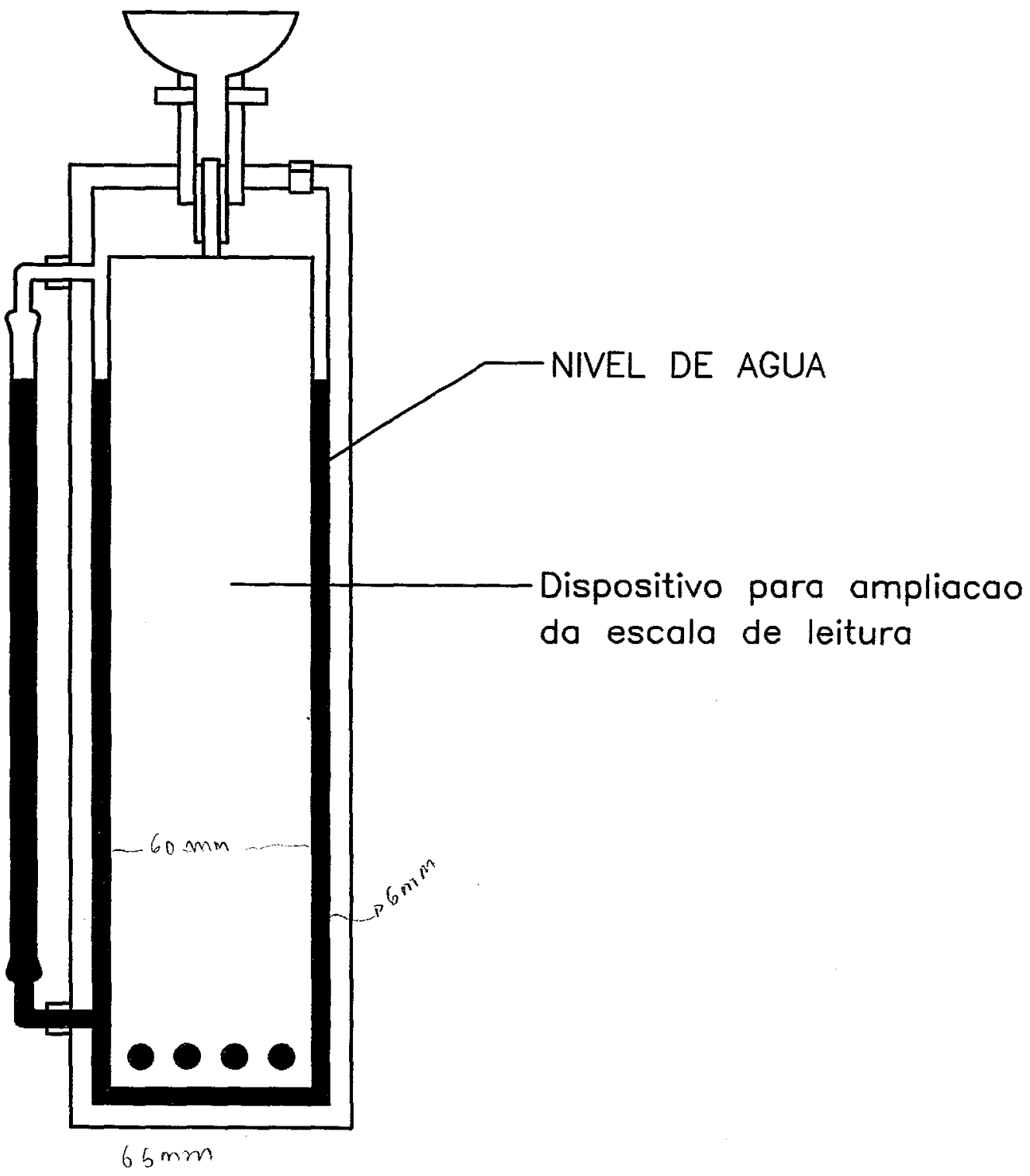

Figura 4 - llustração esquemática do atmômetro modificado com o dispositivo para aumentar a precisão de medida da evaporação. 
Considerando que o reservatório e o tubo de visualização apresentam diâmetro interno de $65 \mathrm{~mm}$ e $6 \mathrm{~mm}$ respectivamente, e o tubo de PVC $60 \mathrm{~mm}$ de diâmetro total, o valor de ASTR será de:

$$
\text { ASTR }=3318 \mathrm{~mm}^{2}+28 \mathrm{~mm}^{2}-2827 \mathrm{~mm}^{2}=519 \mathrm{~mm}^{2}
$$

A superfície evaporante possui $65 \mathrm{~cm}$ de diâmetro, portanto a sua área (ASE) será de $3318 \mathrm{~mm}^{2}$. Aplicando-se a equação (3) temos que a lâmina de água evaporada em função da variação do nível de água no reservatório será dada por:

$$
E V A T=\frac{519 \mathrm{~mm}^{2}}{3318 \mathrm{~mm}^{2}} \cdot \Delta H=0,16 \cdot \Delta H
$$

Assim, o valor de evaporação do atmômetro modificado com o aparelho para a ampliação da escala de leitura será obtido multiplicando-se a variação do nivel de água no reservatório $(\Delta \mathrm{H})$ durante um período t pelo fator 0,16 . Considerando uma precisão de leitura do nível de água de $1,0 \mathrm{~mm}$, o atmômetro com escala de medida ampliada possibilita uma precisão de $1,0 \mathrm{~mm} \times 0,16=$ $0,16 \mathrm{~mm}$ na medida da evaporação, contra o valor de $1,0 \mathrm{~mm}$ no aparelho com escala de medida comercial.

\subsection{Instalação dos atmômetros modificados e procedimentos de ensaio.}

Os atmômetros modificados foram instalados no interior do posto agrometerológico do Departamento de Física e Meteorologia da ESALQ/USP, sobre terreno cultivado com grama batatais (Paspalum Notatum L.). Foram empregados suportes que possibilitaram às superfícies evaporante dos aparelhos ficarem a uma altura de $1 \mathrm{~m}$ da superfície gramada, conforme as recomendações de Altenhofen (1985) e Broner (1990). A Figura 5 ilustra a localização dos aparelhos no interior do posto agrometeorológico. 


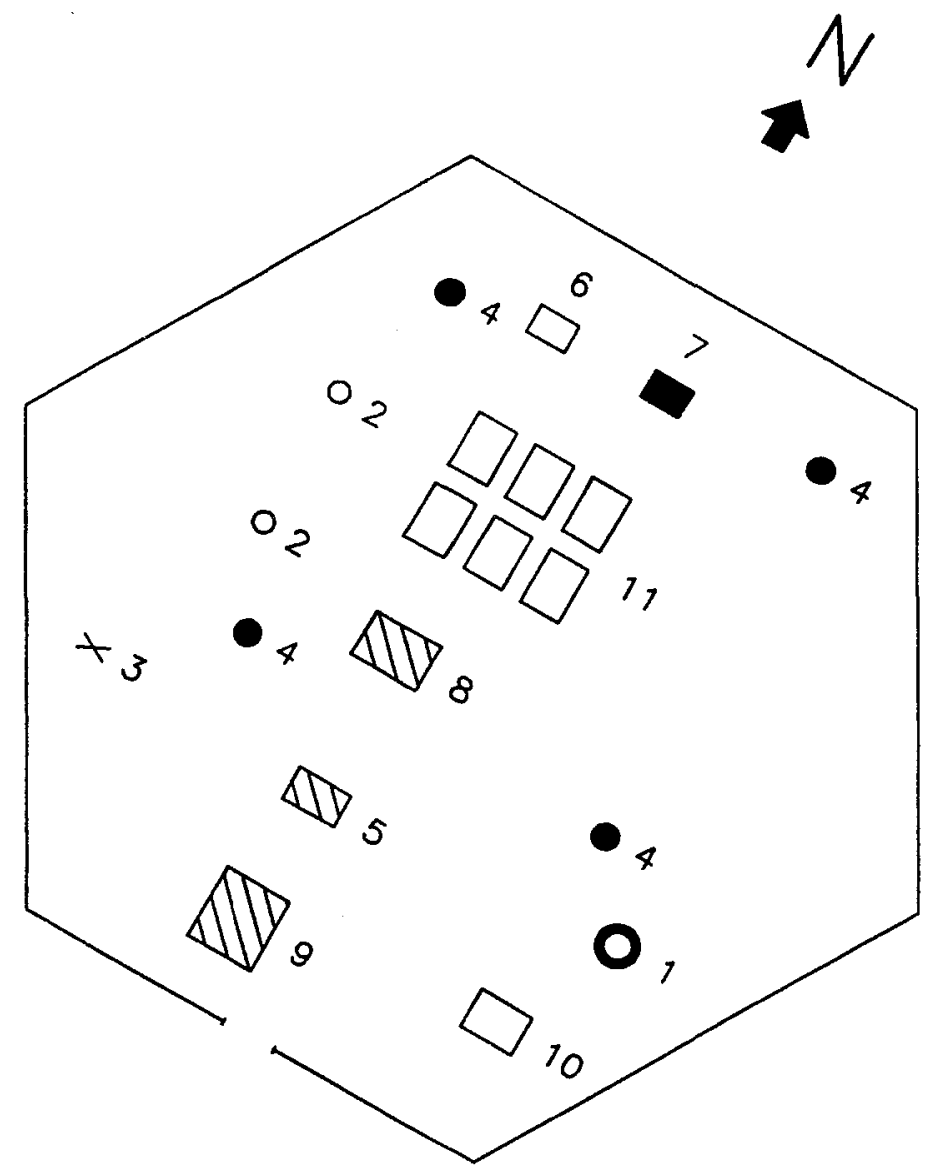

\section{LEGENDA}

1 - TANQUe ClASSE "A"

2 - PLUVIOMETRO

3 - PLUVIOGRAFO

4 - ATMOMETRO MODIFICADO

5 - ANEMOGRAFO

6 - ACTINOGRAFO

7 - HELIOGRAFO

8 - ABRIGO METEOROLOGICO

9 - CASA DO OBSERVADOR

10 - PLATAFORMA HORIZONTAL

11 - TANQUES DE ALVENARIA PARA EVAPOTRANSPIROMETROS

Figura 5 - llustração esquemática das posições de instalação dos atmômetros modificados no posto agrometeorológico do Departamento de Física e Meteorologia da ESALQ/USP. 
As leituras foram realizadas diariamente, no horário entre 7:00 e 7:30h. Para evitar a obstrução da cápsula porosa com sais ou a proliferação de algas no aparelho foi utilizada água destilada com uma pequena concentração de algicida, reposta quando o nível de água no reservatório era reduzido a 2/3 do nível máximo, conforme recomenda Broner (1990). As lonas verde foram mantidas limpas durante todo o período. Durante o ensaio, os aparelhos foram revezados em seus locais de instalação, com o objetivo de evitar um possível efeito de localização nas medidas.

\subsection{Estimativa da evapotranspiração potencial pelo método de Penman- Monteith.}

A equação original de Penman-Monteith pode ser escrita como:

$$
\lambda E T o=\frac{s(R n-G)+\rho \cdot c p(e s-e a) / r a}{s+\gamma(1+r c / r a)}
$$

em que: ETo é o fluxo de calor latente de evaporação ( $M J m^{-2}{d i a^{-1}}$ ); Rn é a radiação líquida ( $\mathrm{MJ} \mathrm{m}^{-2} \mathrm{dia}^{-1}$ ); $\mathrm{G}$ é o fluxo de calor no solo ( $\mathrm{MJ} \mathrm{m}^{-2}$ dia $^{-1}$ ); $\rho$ é a massa especifica do ar atmosférico $\left(\mathrm{kg} \mathrm{m}^{-3}\right)$; $\mathrm{cp}$ é o calor específico do ar (MJ $\left.\mathrm{kg}^{-1} \cdot \mathrm{C}^{-3}\right)$; es é a pressão de saturação de vapor à temperatura do ar ( $\left.\mathrm{kPa}\right)$; ea é o pressão atual de vapor $(\mathrm{kPa})$; rc é o resistência da cobertura vegetal $\left(\mathrm{s} \mathrm{m}^{-1}\right)$; ra é a resistência aerodinâmica $\left(\mathrm{s} \mathrm{m}^{-1}\right)$; $\gamma$ é o constante psicrométrica $\left(\mathrm{kPa}^{\circ} \mathrm{C}^{-1}\right)$; s é o inclinação da curva de pressão de saturação à temperatura do ar $\quad(\mathrm{kPa}$ $\left.{ }^{\circ} \mathrm{C}^{-1}\right)$ e $\lambda$ é o calor latente de vaporização $\left(\mathrm{MJ} \mathrm{kg}^{-1}\right)$.

Para a estimativa da evapotranspiração potencial pelo método de Penman-Monteith utilizou-se a padronização proposta por Smith (1991), que consiste basicamente em utilizar a grama como cultura de referência a uma altura de 0,12 m; albedo igual a $23 \% ; r a=69 \mathrm{~s} / \mathrm{m} ; \mathrm{rc}=\left(208 \div \mathrm{U}_{2}\right)$, em que U2 é a velocidade média do vento a 2 metros de altura $\left(\mathrm{m} . \mathrm{s}^{-1}\right)$. Para condições 
ambientais padrões com $\lambda=2,45 \mathrm{MJ} \mathrm{kg}^{-1}$ e $\mathrm{G}=0 \mathrm{MJ} \mathrm{m}$, Smith (1991) apresenta a seguinte expressão, utilizada também por Peres (1994):

$E T o=0,408 \frac{s}{s+\gamma(1+r c / r a)} R n+\left(\frac{900}{T+275}\right) \frac{\gamma}{s+\gamma(1+r c / r a)}(e s-e a) U_{2}$

em que ETo é a evapotranspiração potencial em mm.dia-1

\subsubsection{Radiação líquida (Rn)}

Para a estimativa da radiação líquida utilizou-se a seguinte expressão:

$$
R n=0,041686\{R S G(1-)-R L\} \text {. }
$$

em que 0,041686 é o fator de conversão de unidades (cal. $\mathrm{cm}^{-2} \mathrm{dia}^{-1} \mathrm{em} \mathrm{MJ} \mathrm{m}{ }^{-2}$ $\left.\mathrm{dia}^{-1}\right)$; RSG é a radiação solar global ao nível da superfície (cal.cm $\mathrm{cm}^{-2} \mathrm{dia}^{-1}$ ); é a fração média diária da radiação solar refletida (albedo), assumido como 0,23 (23\%), conforme recomenda Smith (1991) e RL é o balanço de ondas longas (cal. $\mathrm{cm}^{-2} \mathrm{dia}^{-1}$ ), determinado pela seguinte expressão, representativa para a região de Piracicaba, SP, obtida por Ometto (1995):

$$
R L=\sigma(T+273)^{4}\left(0.233+0.0204 \sqrt{e a}+0.209 \frac{n}{N}\right)
$$

em que é a constante de Stefan-Boltzman (11,9 .10-8 $\left.\mathrm{cal}^{\mathrm{cm}} \mathrm{cm}^{-2} \mathrm{dia}^{-1} \mathrm{~K}^{-4}\right)$; T é a temperatura média do ar $\left({ }^{\circ} \mathrm{C}\right)$; $n$ é número de horas de Brilho solar e $\mathrm{N}$ é a dura-

ção máxima de horas de brilho solar, calculado através da metodologia proposta por Holtslag \& Ulden (1993):

$$
N=0,1333 h
$$

em que h é o ângulo horário em graus decimais:

$$
h=\arccos -(\operatorname{tg} \phi \operatorname{tg} \delta)
$$

em que $\phi$ é a latitude do local em graus $\left(-22,7^{\circ}\right.$ para Piracicaba,SP) e $\delta$ é a declinação solar , estimada por: 


$$
\delta=\operatorname{arcsen}(0,398 \operatorname{sen} S L)
$$

em que:

$$
S L=0,0175\{4,871+0,175 p+0,033 \operatorname{sen}(0,175 p)\}
$$

sendo:

$$
\mathrm{p}=30(M-1)+D M
$$

em que: $\mathrm{M}$ é o número do mês (1-12) e DM o dia do mês (1-31)

\subsubsection{Pressão de saturação do vapor d'água}

A pressão de saturação do vapor d'água (es, $\mathrm{kPa}{ }^{\circ} \mathrm{C}^{-1}$ ) foi estimada pela seguinte expressão:

$$
\text { es }=0,6108 \exp \left(\frac{17,27 T}{T+237,3}\right)
$$

\subsubsection{Pressão atual do vapor d’água}

A pressão atual do vapor d'água $\left(e a, \mathrm{kPa}^{\circ} \mathrm{C}^{-1}\right)$ foi estimada por:

$$
\text { ea }=\text { es } \frac{\mathrm{UR}}{100}
$$

em que UR é o umidade relativa média do ar (\%)

\subsubsection{Tangente a curva de pressão de saturação de vapor}

A tangente a curva de pressão de saturação de vapor $\left(\mathrm{s}, \mathrm{kPa}{ }^{\circ} \mathrm{C}^{-1}\right)$ foi calculada pela seguinte expressão:

$$
s=\frac{4098}{(237,3+T)} e s
$$




\subsubsection{Constante psicrométrica}

A constante psicrométrica $\left(\gamma, \mathrm{kPa}{ }^{\circ} \mathrm{C}^{-1}\right)$ foi estimada por:

$$
\gamma=10^{-3} \frac{c p . P}{\varepsilon \lambda}
$$

em que: $c p$ é o calor específico do ar à pressão constante $(c p=1,013 \mathrm{MJ}$ $\left.\mathrm{kg}^{-1} \mathrm{C}^{-1}\right)$; $\mathrm{P}$ é o pressão atmosférica $(\mathrm{kPa})$; é o razão entre o peso molecular do vapor d'água e do ar atmosférico seco igual a 0,622. Para Piracicaba com valor médio de pressão atmosférica de $94,9 \mathrm{kPa}$ (Ometto, 1995) tem-se, pela equação (18) $\gamma=0,0623 \mathrm{kPa} \cdot{ }^{\circ} \mathrm{C}^{-1}$.

\subsubsection{Velocidade do vento a $\mathbf{2} \mathbf{m}$ de alltura}

Devido ao posto agrometeorológico da ESALQ/USP não medir a velocidade do vento na altura de 2 metros no ano de 1992, ela foi estimada através da velocidade do vento medida a 10 metros de altura pela seguinte relação:

$$
U 2=U z \frac{\ln \left(\frac{2-d p z}{Z o m}\right)}{\ln \left(\frac{Z-d p z}{Z o m}\right)}
$$

em que Uz é a velocidade do vento na altura Z; dpz é o deslocamento do plano zero $(m)$, estimado por:

$$
d p z=0,667 h c
$$

em que hc é a altura média da vegetação $(\mathrm{m})$ e Zom é comprimento da rugosidade equivalente para a transferência de momento $(\mathrm{m})$, estimado pela relação:

$$
\text { Zom }=0,123 \mathrm{hc}
$$

Considerando o valor de 0,12 m para a altura da grama (Smith, 1991) e a altura de medida da velocidade do vento igual a 10 metros temos $d=0,080 \mathrm{~m}$ 
e Zom $=0,015 \mathrm{~m}$. Aplicando-se a equação (18) tem-se que $\mathrm{U}_{2}$ estimado a partir de $U_{10}$ é estimado pela seguinte relação:

$$
U_{2}=0,75 U_{10}
$$

\subsection{Análise dos dados}

\subsubsection{Variabilidade da evaporação medida com os atmômetros modificados}

Para verificar a significância da variação entre as medidas de evaporação coletadas nos atmômetros foi utilizado o teste de KolmogorovSmirnov, aplicado para a análise de duas amostras independentes. As análises foram feitas através da combinação entre as medidas dos atmômetros com escala de leitura ampliada e entre esses com o atmômetro com escala de leitura comercial, gerando um total de 6 combinações. Preferimos o emprego do teste de Kolmogorov-Smirnov ao invés de uma análise de variância convencional, para melhor visualização da variabilidade nas medidas de evaporação pelos aparelhos. Segundo CAMPOS (1983), esse teste verifica se duas amostras independentes se diferem estatisticamente entre na si na representação de um evento. O processo analítico do teste envolve inicialmente a ordenação conjunta das observações das duas amostras "A" e "B", gerando um conjunto com "X" elementos. Posteriormente, dentro dessa série conjunta associamos para cada ponto " $X$ " os respectivos estimadores:

$$
\begin{aligned}
& S 1(X)=\frac{k 1}{m} \\
& S 2(X)=\frac{k 2}{n}
\end{aligned}
$$

em que k1 é o número de observações da amostra "A" com valores menores ou iguais a X; k2 é o número de observações da amostra "B" com valores menores 
ou iguais a "X", n o número total de observações da amostra "A" e m o número de observações da amostra "B", ou seja: $S 1(X)$ e $S 2(X)$ consistem da distribuição empírica acumulada das variáveis no conjunto global de dados. Para verificar se a diferença entre as amostras é significativa define-se o valor "D" do teste de Kolmogorov-Smirnov, especificado como a maior divergência entre os valores de $S 1(X)$ e $S 2(X)$ :

$$
D=\sup _{X}|S 1(X)-S 2(X)|
$$

Se o valor de $D$ encontrado for inferior ao valor tabelado (em função de n e m observações) ao nivel de $5 \%$ de probabilidade, considera-se as duas amostras como estatisticamente iguais, ou seja: a diferença entre elas não é significativa. Uma melhor visualização da divergência entre as amostras é feita através de gráficos correlacionando $S 1(X)$ e $S 2(X)$ com os valores das observações.

\subsubsection{Correlações entre os valores de evapotranspiração potencial e evapotranspiração}

Foram realizadas as seguintes correlações:

-Evaporação do atmômetro modificado com escala de leitura ampliada versus atmômetro modificado com escala de leitura comercial;

-Evapotranspiração potencial (ETo) versus evaporação do atmômetro modificado com escala de leitura comercial, evaporação dos atmômetros modificados com escala de leitura ampliada e evaporação do tanque classe " $A$ ";

-Evaporação do tanque classe " $A$ " (ECA) versus evaporação do atmômetro modificado com escala de leitura comercial, evaporação dos atmômetros modificados com escala de leitura ampliada.

As análises foram realizadas para os seguintes períodos de tempo:

-Período diário; 
-Períodos médios de 2, 3 e 4 dias;

-Todos os períodos (1, 2, 3 e 4 dias), com objetivo de encontrar uma expressão global que representa-se os eventos analisados em qualquer período médio de tempo.

\subsubsection{Procedimentos estatísticos para ajuste dos dados e testes das correlações.}

Inicialmente, foram verificadas as relações funcionais entre as variáveis através de diagramas de dispersão, ou seja, utilizando gráficos de pontos relacionando as variáveis dependentes e independentes.

Após verificada a correlação linear entre as variáveis, foi empregada a seguinte expressão:

$$
Y=a+b X
$$

em que $Y$ é a variável dependente; $X$ a variável independente, "a" o coeficiente linear de ajuste e "b" o coeficiente angular de ajuste.

Teoricamente, quando de correlacionam valores de evapotranspiração e evaporação considera-se que quando a demanda evaporativa da atmosfera é infinitamente pequena, ambas as variáveis tendem a zero. Assim, considerouse o valor do coeficiente linear neste trabalho como nulo, ficando portanto a expressão 25 reescrita como:

$$
Y=b X
$$

isolando-se o coeficiente angular da expressão acima temos:

$$
b=\frac{Y}{X}
$$

Dessa forma, quando analisamos ETo como variável dependente e ECA como variável independente, o coeficiente "b" na equação 27 corresponderá ao valor médio do coeficiente de tanque $\mathrm{Kp}$, que é por definição a relação ETo $\div$ ECA (Doorenbos \& Pruitt, 1977). De forma análoga, também 
foram definidos os valores médios de "Ka", como sendo as razões ETo $\div$ EVAT ou ECA : EVAT, onde EVAT corresponde a evaporação dos atmômetros modificados.

Para o ajuste do modelo adotado (equação 26) às variáveis estudadas empregou-se o método dos mínimos quadrados, conforme descrito por ZAR (1974) e GOMES (1970). Para verificar as medidas de dependência entre as variáveis empregou-se o coeficiente de correlação $\left(r^{2}\right)$. Na análise de adequação dos modelos na previsibilidade das variáveis dependentes, foram construídos diagramas de dispersão entre os valores observados e respectivos valores estimados, traçando-se uma reta teórica que representa a correlação perfeita entre os citados valores, conhecida na literatura como reta 1:1 (um para um) ou de $45^{\circ}$. Quanto menor a dispersão dos pontos ao redor da reta 1:1, melhor é a previsibilidade do modelo. Para se quantificar a homogeneidade da dispersão em relação a reta 1:1 empregou-se o teste de concordância de Willmott (1981):

$$
d=\left\{1-\left[\frac{\sum(P i-O i)^{2}}{\sum\left(\left|P^{\prime} i\right|+\left|O^{\prime} i\right|\right)^{2}}\right]\right\}
$$

em que $\mathrm{Pi}$ são os valores previstos, $\mathrm{Oi}$ os valores observados; $\mathrm{P}^{\prime} \mathrm{i}=\mathrm{Pi}-\mathrm{Om}$; O'i=Oi-Om; sendo Om a média dos valores observados. $O$ valor "d" varia de 0 a 1 , sendo o valor 1 indicador de uma dispersão nula ou perfeitamente uniforme dos dados previstos em relação aos estimados, ao redor da reta 1:1.

Após obtidas as equações de ajuste para os diferentes períodos médios isoladamẹte, observou-se que os coeficientes angulares apresentaram valores similares. Para verificar se uma expressão global, envolvendo todos os períodos ( 1 a 4 dias) , pudesse ser empregada, aplicou-se o teste F apresentado por Zar (1984): 


$$
F=\frac{\frac{S Q r u-\sum_{i=1}^{K} S Q R i}{2(K-1)}}{\frac{\sum_{i=1}^{K} S Q R i}{\sum_{i=1}^{K} G L i}}
$$

em que SQru é o somatório dos quadrados dos desvios da regressão global empregando todos os períodos, SQRi é o somatório dos quadrados dos resíduos da regressão ajustada a um determinado período i ; K é o número de regressões índice i empregadas e GLi é o grau de liberdade das regressões índice i empregadas, que corresponde no presente estudo, com uma variável independente, a ( $n-2)$; onde $n$ é o número de dados no período i. Se o valor de $F$ calculado pela expressão (29) não exceder o valor de $F$ tabelado para $2(\mathrm{~K}-1)$ e $\Sigma$ Gli graus de liberdade (nível de significância de $5 \%$ ) considera-se que a expressão global não se difere significativamente das expressões parciais, referentes a cada período de tempo.

Para verificar se os coeficientes de ajuste "b" se diferiram estatisticamente entre si nas estimativas envolvendo o atmômetro com escala de leitura comercial e o atmômetro com escala de leitura ampliada, aplicou-se o teste $t$ apresentado por Zar (1984):

$$
\begin{aligned}
& t=\frac{b 1-b 2}{s b} \\
& s b=\sqrt{\frac{S x y}{\sum(X 1-\bar{X} 1)^{2}}+\frac{S x y}{\sum(X 2-\bar{X} 2)^{2}}} \\
& S x y=\frac{S Q R 1+S Q R 2}{G L r 1+G L r 2}
\end{aligned}
$$

em que b1 e b2 são respectivamente os coeficientes de ajuste dos dois modelos testados ( 1 e 2), X1 e X2 são os valores das variáveis dois modelos testados, $\mathrm{X} 1$ e $\mathrm{X} 2$ os valores médios das variáveis independentes, SQR1 e 
SQR2 a somatória dos quadrados dos resíduos dos ajustes para o cálculo de b1 e b2 e GLr1,GLr2 os graus de liberdade dos resíduos das regressões.

Considera-se que não há diferença significativa entre b1 e b2 se o valor de $t$ calculado for inferior ao tabelado para (GLr1+GLr2) graus de liberdade.

Em todas as análises realizadas,os dados foram divididos em dois grupos: com um grupo de efetuou o ajuste do modelo de regressão e com o outro a verificação da previsibilidade dos respectivos modelos ajustados. Esse procedimento visa um maior rigor estatístico nas análises, empregando na verificação do modelo dados independentes, ou seja: que não foram empregados no ajuste do modelo, conforme recomendações de Efron e Gong (1983), Schreuder et al. (1987) e Jones \& Carberry (1994) 


\section{RESULTADOS E DISCUSSÃO}

\subsection{Parâmetros meteorológicos, evaporação dos atmômetros modificados, evaporação do tanque classe "A" e evapotranspiração potencial}

$\mathrm{Na}$ Tabela 1 (apêndice) são apresentados os valores diários dos parâmetros meteorológicos, evaporação do tanque classe "A" e evapotranspiração potencial estimada pelo método de Penman-Monteith, em escala diária coletados durante o ensaio. $\mathrm{Na}$ Tabela 2 (apêndice) são apresentados os valores de evaporação medidos pelo atmômetro modificado com escala de leitura comercial e pelos três atmômetros modificados com escala de leitura ampliada coletados durante o mesmo período. Os valores apresentados para os aparelhos com escala de leitura ampliada foram determinados utilizando o coeficiente de ajuste entre a variação de água no reservatório e a lâmina evaporada pela cápsula porosa, igual a 0,15 , conforme descrito no ítem 3.4.1, equação (5). Nas Tabelas 3, 4, 5, 6, 7, 8, 9, e 10 (apêndice) são apresentados os valores de evaporação e evapotransiração utilizados nos ajustes e nas verificações dos modelos de regressão analisados para o período diário e médios de 2, 3 e 4 dias.

Observou-se durante o ensaio que nos dias de ocorrência de chuva os aparelhos apresentaram resultados inconsistentes, devido a entrada de água nos reservatórios, o que evidencia o mal funcionamento das válvulas de retenção. Em alguns dias, ocorreu pousio de pássaros nos aparelhos, constatado pela presença de marcas de barro ou fezes nas lonas verde, o que 
ocasionou uma grande redução nas leituras, quando comparado aos aparelhos sem pousio de pássaros naqueles dias. Assim, os dias com ocorrência de chuvas ou pousio de pássaros foram descartados nas análises realizadas, bem como os períodos médios calculados envolvendo esses dias. Para pesquisas visando contornar os problemas citados sugerimos o desenvolvimento e teste de válvulas de retenção mais sensíveis ao fluxo de água da cápsula porosa ao reservatório de água, como também a colocação de pequenas aguihas na parte superior do atmômetro modificado, próximas à superfície evaporante, com o objetivo de dificultar o pousio de pássaros.

\subsection{Verificação da variabilidade das leituras dos atmômetros}

Na Tabela 11 são apresentados os contrastes realizados entre as medidas dos atmômetros modificados com escala de leitura ampliada (ATMEA) e do atmômetro modificado com escala de leitura comercial (ATMEC), para a aplicação do teste não paramétrico de Kolmogorov-Smirnov, do valor da máxima divergência (D) e a significância dos contrastes. A Figura 6 ilustra os valores de evaporação para diferentes contrastes, em função de suas freqüências empíricas acumuladas.

Tabela 11 - Contrastes entre as medidas dos atmômetros modificados com escala de leitura ampliada (ATMEA-1; ATMEA-2 e ATMEA-3) e com atmômetro modificado com escala de leitura comercial (ATMEA), valor da máxima divergência do teste de Kolmogorov-Smirnov (D) e a significância dos contrastes ao nivel de $5 \%$ de probabilidade.

\begin{tabular}{ccc}
\hline CONTRASTES & VALOR "D" & $\begin{array}{c}\text { SIGNIFICÂNCIA } \\
\text { (5 \% de probabilidade) }\end{array}$ \\
\hline ATMEA-1 x ATMEA-2 & & não significativo \\
ATMEA-1 x ATMEA-3 & 0,070 & não significativo \\
ATMEA-1 x ATMEC & 0,054 & significativo \\
ATMEA-2 $\times$ ATMEA-3 & 0,219 & não significativo \\
ATMEA-2 ATMEC & 0,063 & significativo \\
ATMEA-3 ATMEC & 0,227 & significativo \\
\hline
\end{tabular}



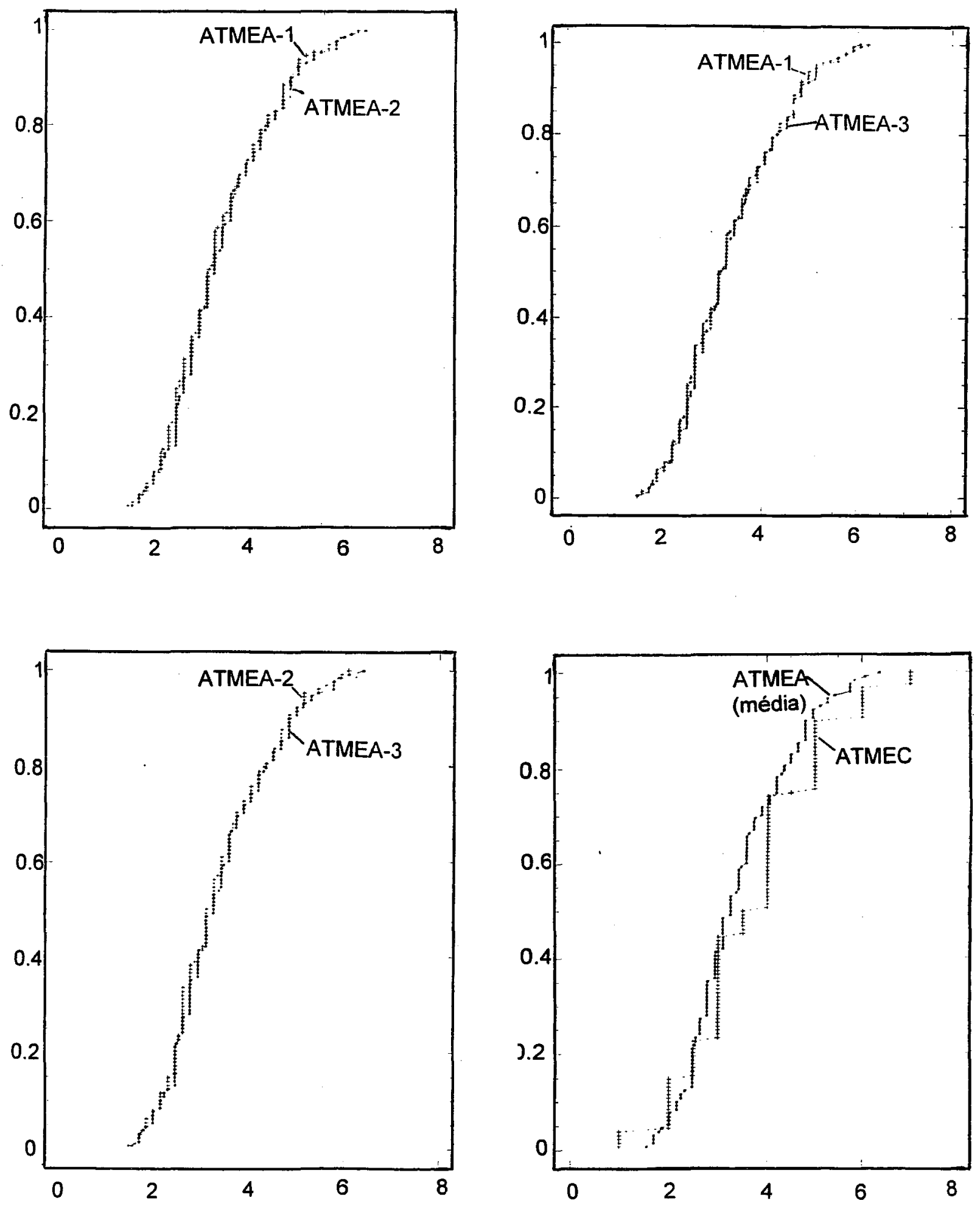

Figura 6 - llustração dos constrastes entre os atmômetros modificados com escala de leitura ampliada (ATMEA-1; ATMEA-2 e ATMEA-3) e entre a evaporação do atmômetro modificado com escala de leitura comercial (ATMEC) e o valor médio dos atmômetros com escala ampliada (ATMEA), em função de suas freqüências empíricas acumuladas nos contrastes. 
Verifica-se que os contrastes entre os atmômetros com escala de leitura ampliada (ATMEA) não foram significativos, ou seja, foram estatisticamente iguais. De maneira oposta, os contrastes envolvendo os atmômetros modificados com escala de leitura ampliada (ATMEA) em relação ao atmômetro com escala de leitura comercial (ATMEC) foram significativos, comprovando o efeito do tratamento da ampliação da escala nas medidas de evaporação dos aparelhos. Na Figura 6 podemos visualizar a grande similaridade entre as curvas de evaporação dos atmômetros com escala ampliada. Nos contrastes envolvendo o atmômetro com escala comercial observam-se grandes diferenças entre as curvas, apresentando formas diferenciadas e com grande divergência.

Em vista do exposto, devido aos atmômetros com escala de leitura ampliada não apresentarem diferença significativa em suas medidas, decidimos trabalhar com o valor médio da evaporação desses aparelhos nas análises, representado genericamente por ATMEA. 


\subsection{Curso dos elementos meteorológicos durante o período de ensaio}

$\mathrm{Na}$ Tabela 12 são apresentados os valores médios quinzenais dos parâmetros meteorológicos, calculados com base na Tabela 1 Na Figura 7 são ilustrados os cursos desses parâmetros ao longo do periodo de ensaio. Utilizamos períodos quinzenais ao invés de diários para uma melhor visualização das tendências.

Tabela 12 - Valores médios quinzenais de umidade relativa do ar (UR), Temperatura do ar $(\mathrm{T})$, precipitação pluviométrica total (PP), Radiação solar global ao nível da superfície (RSG), velocidade do vento a 2 metros de altura (U2) e insolação (INS).

\begin{tabular}{cccccccc}
\hline \multirow{2}{*}{ PERIODO } & MEES & UR & T & PPL & RSG & U2 & INS \\
& & $\%$ & ${ }^{\circ} \mathrm{C}$ & $\mathrm{mm}$ & $\mathrm{MJ} \mathrm{m}^{-2} \mathrm{dia}^{-1}$ & $\mathrm{~m} / \mathrm{s}$ & horas \\
\hline 1 & JUN & 76,3 & 20,3 & 0,0 & 11,5 & 1,4 & 6,7 \\
2 & JUN & 72,8 & 19,1 & 0,6 & 11,7 & 1,6 & 7,3 \\
3 & JUL & 75,6 & 18,7 & 36,6 & 11,2 & 1,8 & 6,8 \\
4 & JUL & 71,8 & 17,5 & 0,0 & 12,1 & 1,8 & 6,3 \\
5 & AGO & 69,0 & 18,8 & 0,0 & 13,3 & 1,9 & 6,1 \\
6 & AGO & 74,3 & 19,4 & 10,4 & 13,6 & 1,6 & 6,7 \\
7 & SET & 83,9 & 18,4 & 59,4 & 9,5 & 2,0 & 3,1 \\
8 & SET & 78,1 & 20,7 & 28,1 & 14,1 & 1,8 & 5,5 \\
9 & OUT & 78,7 & 21,2 & 98,6 & 14,6 & 2,0 & 5,6 \\
10 & OUT & 77,0 & 23,1 & 134,5 & 16,9 & 2,0 & 6,9 \\
11 & NOV & 77,4 & 23,2 & 99,6 & 17,0 & 1,8 & 6,3 \\
12 & NOV & 77,7 & 22,9 & 132,7 & 17,1 & 2,2 & 6,0 \\
13 & DEZ & 79,0 & 22,5 & 134,4 & 17,1 & 2,0 & 6,8 \\
\hline MÉDIA & & 76.3 & 20,4 & 56.5 & 13.8 & 1,8 & 6.2 \\
\hline
\end{tabular}



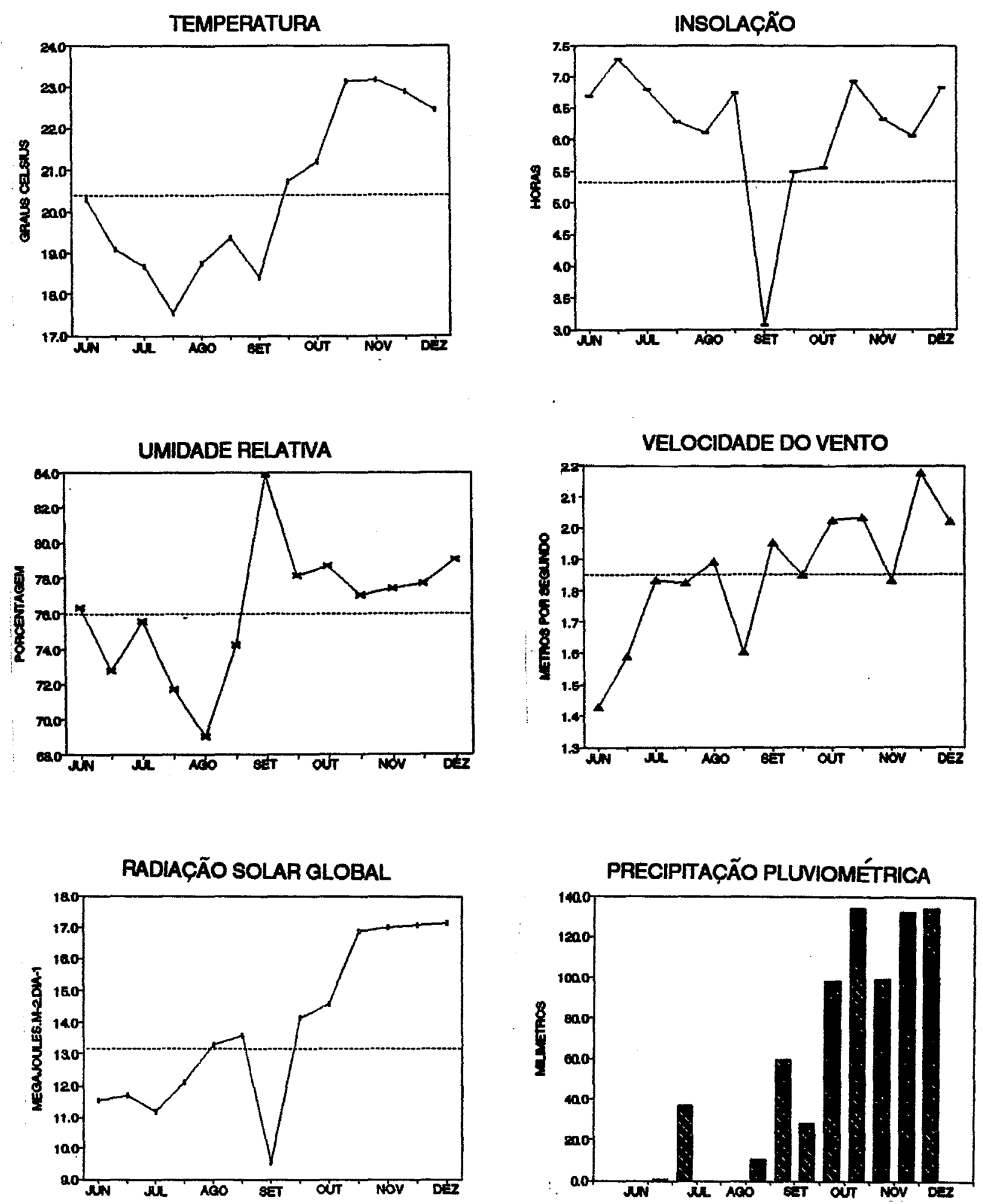

Figura 7 - Cursos dos elementos meteorológicos em períodos quinzenais durante os meses de junho a dezembro de 1992 
O ensaio foi conduzido durante os quatro últimos meses do período seco (junho a setembro) e os três primeiros meses do período chuvoso (outubro, novembro, até a primeira quinzena de dezembro). Pela Figura 7 observa-se que no período seco (junho-setembro) a temperatura, umidade relativa e radiação solar global apresentaram tendência antagônica em relação ao período chuvoso (outubro-dezembro). No primeiro período, os parâmetros apresentaram valores abaixo da média geral (linha tracejada) com comportamento inicial de decréscimo até o mês de agosto, quando ocorre tendência de elevação desses valores. No segundo período, os referidos parâmetros apresentam valores acima da média geral, com tendência de acréscimo da temperatura e da umidade relativa até o mês de outubro, quando então se observa uma pequena variação até o mês de dezembro. $A$ insolação apresenta comportamento de decréscimo até o mês de setembro quando temos uma relativa tendência de acréscimo nos meses seguintes.

A velocidade do vento apresentou comportamento geral crescente ao longo dos meses do ensaio, com menores valores nos meses de junho-julho e maiores valores nos meses de novembro-dezembro. A precipitação pluviométrica aumentou consideravelmente a partir dos meses de outubro, caracterizando o período chuvoso.

De maneira geral, com as tendências de aumento gradativo da temperatura do ar, da velocidade do vento e decréscimo da umidade relativa caracterizam condições potenciais de aumento do poder evaporante do ar. Esse fato, associado a elevação da radiação solar sugere um aumento gradativo nas medidas de evaporação e evapotranspiração durante o ensaio, conforme verificaremos a seguir. 
4.4 Curso da evapotranspiração potencial, da evaporação dos atmômetros modificados e do tanque classe "A".

A Figura 8 apresenta os cursos da evapotranspiração potencial estimada pelo método de Penman Monteith, em escala diária, em relação a evaporação dos atmômetros modificados e do tanque classe "A"

Observa-se aumento gradativo dos valores de evaporação e evapotranspiração durante os meses, confirmando a tendência esperada em relação aos parâmetros do clima, conforme descrito no ítem anterior. Verificamos que conforme ocorre o acréscimo da evapotranspiração potencial, ocorre concomitantemente o acréscimo dos valores de evaporação em igual proporção, porém assumindo valores sempre maiores, ou seja: as variáveis diferem em uma proporção relativamente constante ao longo do tempo. Em relação ao atmômetro com escala de leitura comercial, essa tendência não é tão evidente devido a sua grande dispersão quando comparado aos demais dados. A evaporação do atmômetro com escala de leitura ampliada (ATMEA) apresentou tendência semelhante ao tanque classe "A", porém, com valores menores. 


\section{ETO $\odot$ ATMEC}

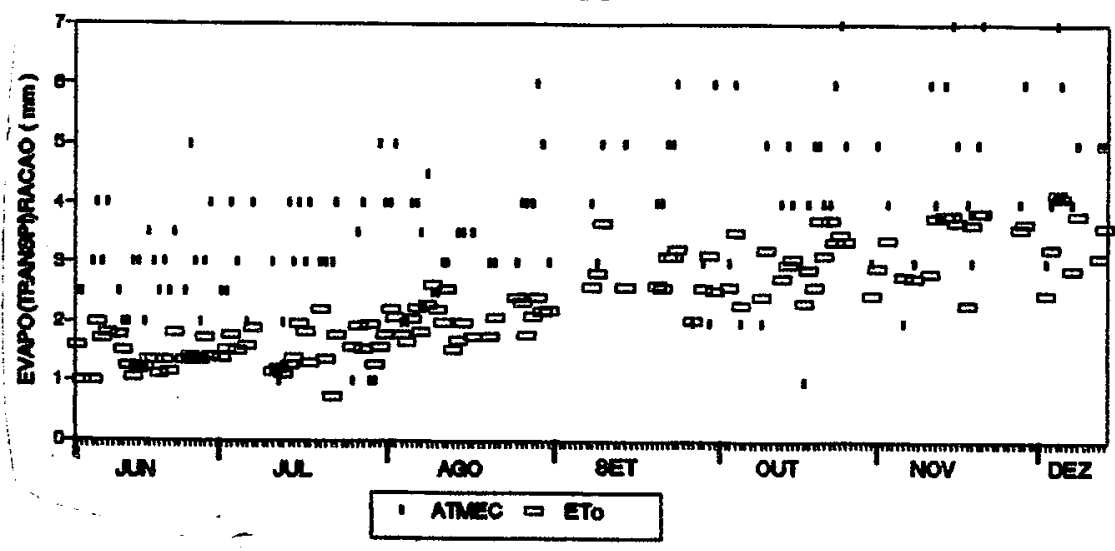

ETO \& ATMEA

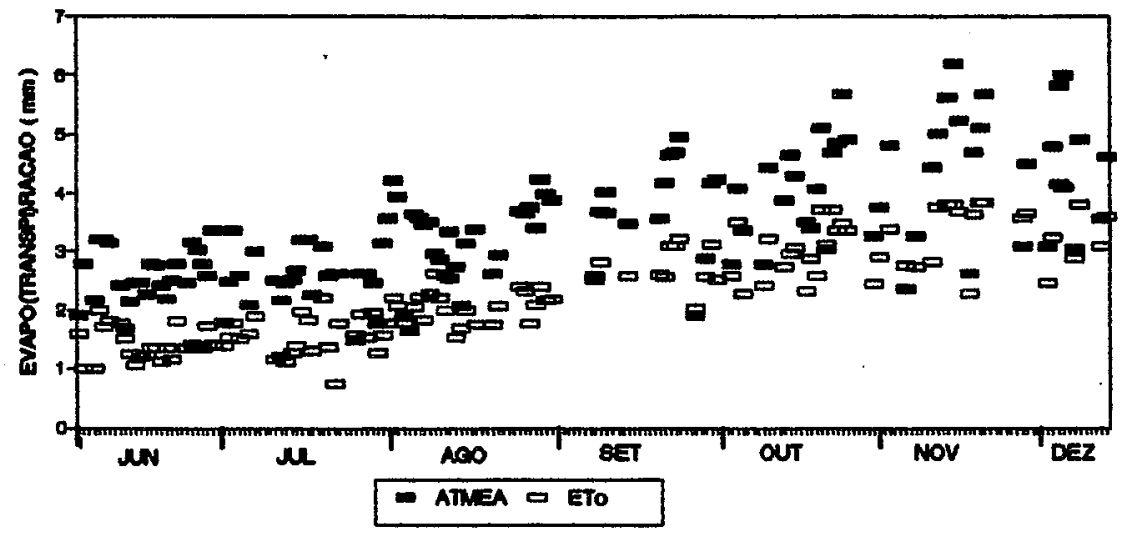

\section{ETO $\theta$ ECA}

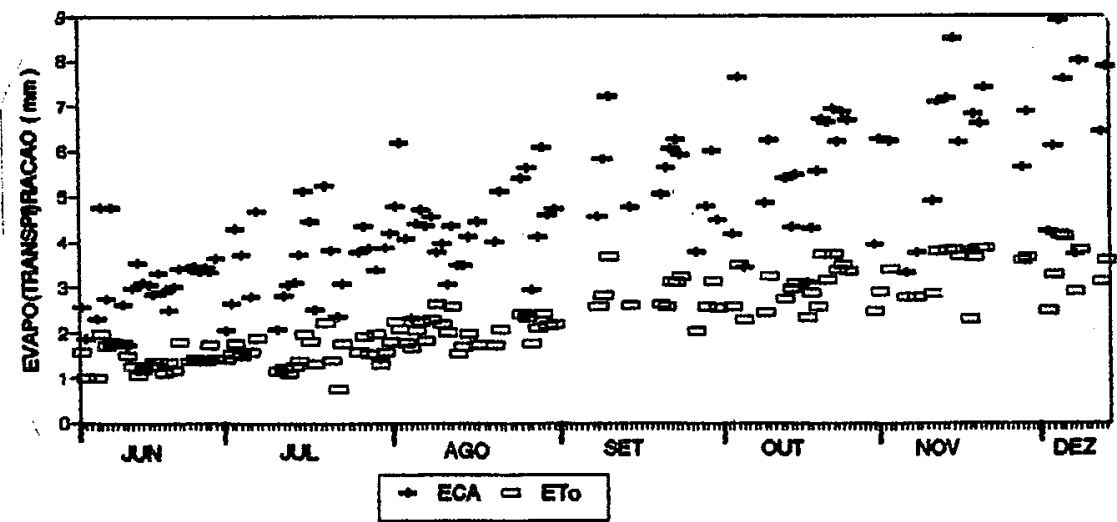

Figura 8 - Cursos da Evapotranspiração potencial (ETo); da evaporação do atmômetro modificado com escala de leitura comercia (ATMEC); do atmômetro modificado com escala de leitura ampliada (ATMEA) e da evaporação do tanque classe "A". 


\subsection{Relação entre o Atmômetro modificado com escala de leitura ampliada (ATMEA) e o atmômetro modificado com escala de leitura comercial (ATMEC).}

A Tabela 13 apresenta os parâmetros estatísticos referentes aos ajustes do modelo linear entre os valores de evaporação do atmômetro modificado com escala de leitura ampliada e a evaporação do atmômetro modificado com escala de leitura comercial. A Figura 9 ilustra os diagramas de dispersão e as retas de ajuste das variáveis nos diferentes período, a Figura 10 apresenta os diagramas de dispersão entre os valores de evaporação medida e estimada do atmômetro modificado com escala de leitura ampliada.

Tabela 13. Número de dados ( $n$ ), coeficiente de ajuste (b), coeficiente de correlação $\left(r^{2}\right)$ e índice de concordância de Willmott (d) determinados para as correlações entre a evaporação do atmômetro modificado com escala de leitura ampliada (ATMEA) e a evaporação do atmômetro modificado com escala de leitura comercial (ATMEC) nos diversos períodos de tempo

\begin{tabular}{ccccc}
\hline $\begin{array}{c}\text { PERIODO MÉDIO } \\
\text { (DIAS) }\end{array}$ & $\mathrm{n}$ & $\mathrm{b}$ & $\mathrm{r}^{2}$ & $\mathrm{~d}$ \\
\hline 1 & 33 & 0,91 & 0,59 & 0,90 \\
2 & 20 & 0,88 & 0,79 & 0,90 \\
3 & 12 & 0,92 & 0,94 & 0,98 \\
4 & 9 & 0,97 & 0,91 & 0,97 \\
\hline
\end{tabular}

Observa-se um aumento gradual do coeficiente de ajuste "b", se aproximando do valor 1 (valor que indica perfeita relação entre as leituras dos aparelhos) como também 0 aumento dos valores dos coeficientes de correlação $\left(r^{2}\right)$ e de Willmott (d). Isso se deve ao fato que conforme o período 
1 DIA

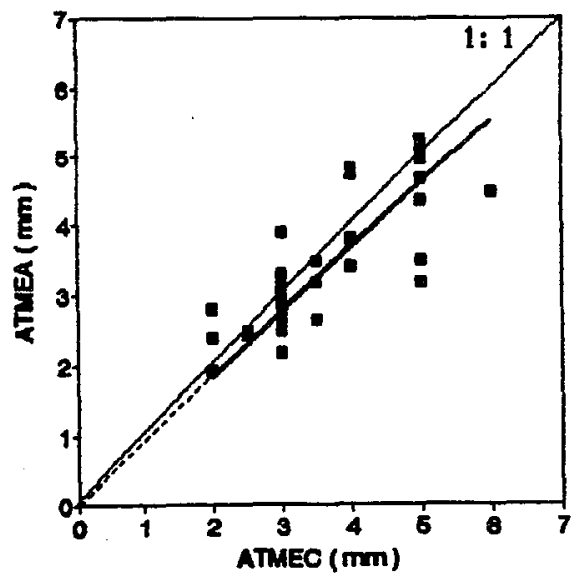

3 DIAS

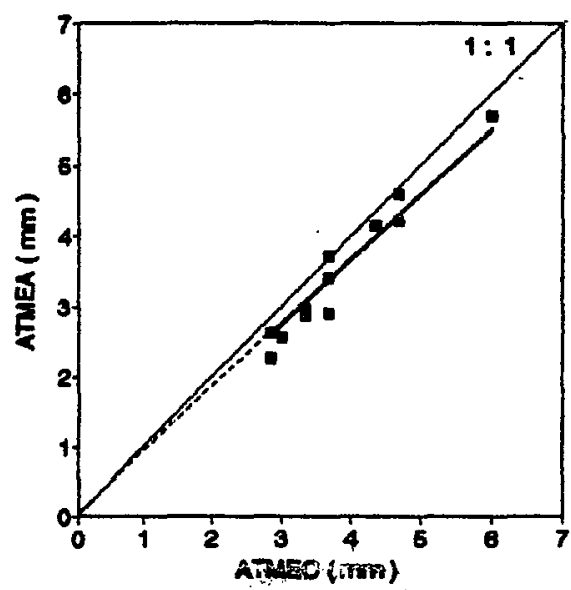

2 DIAS

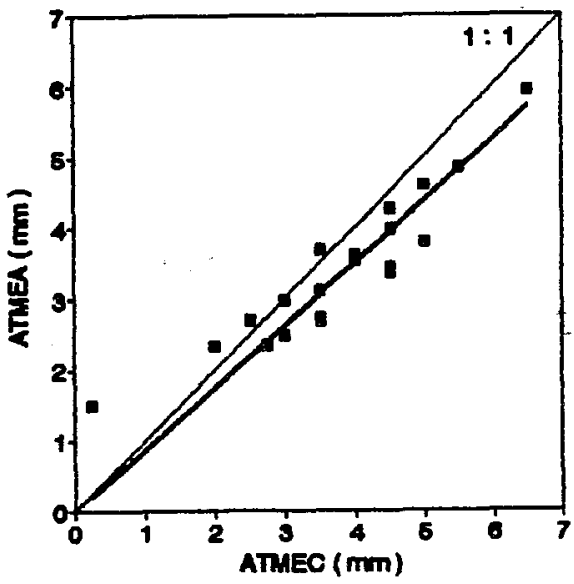

4 DIAS

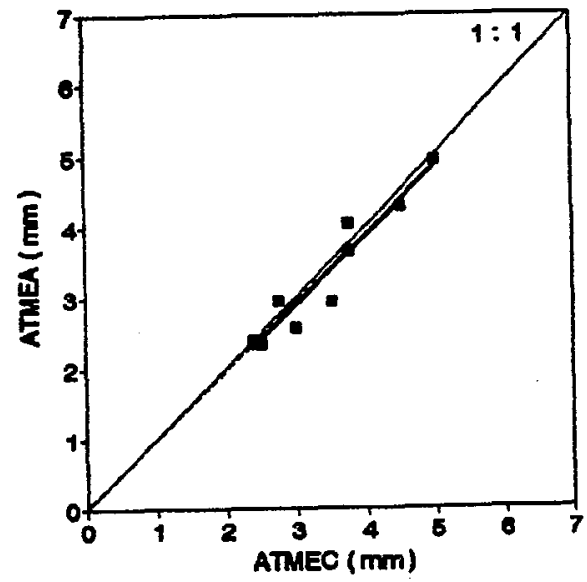

Figura 9 - Diagramas de dispersão e retas de ajuste entre a evaporação do atmômetro modificado com escala de leitura ampliada (ATMEA) e a evaporação do atmômetro modificado com escala de leitura comercial (ATMEC) 
1 DIA

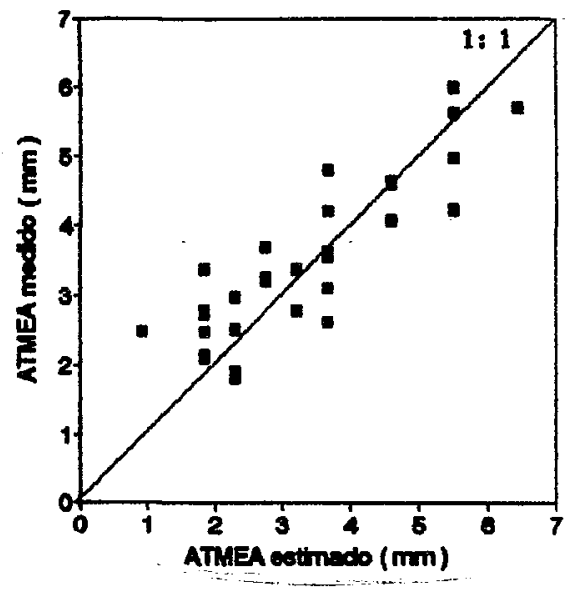

3 DIAS

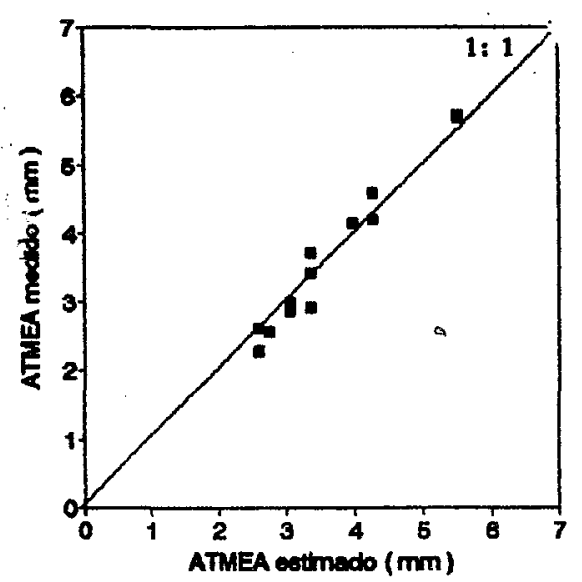

2 DIAS

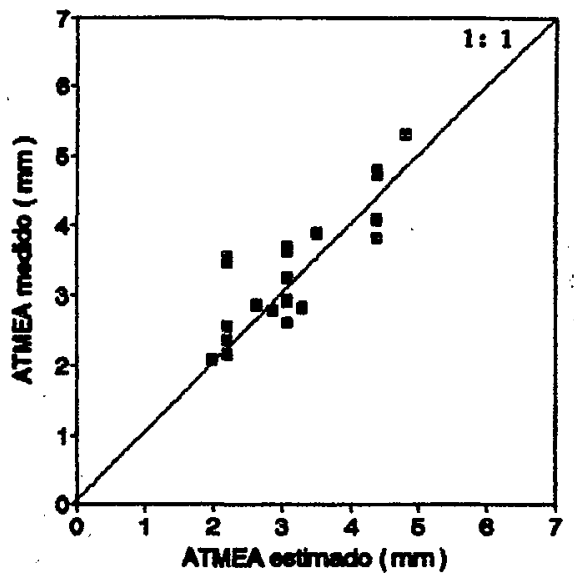

4 DIAS

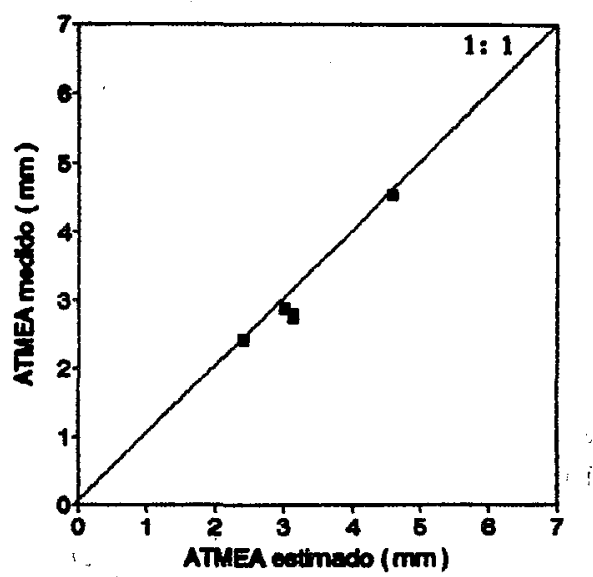

Figura 10 - Diagramas de dispersão entre os valores da evaporação medida no atmômetro modificado com escala de leitura ampliada (ATMEA) e estimada através do modelo linear utilizando a evaporação do atmômetro modificado com escala de leitura comercial (ATMEC) 
médio, menor é o efeito da ampliação da escala de leitura sobre a evaporação medida entre os aparelhos. Para o período de um dia não há correlação satisfatória, conforme pode ser visualizado nas Figuras 9 e 10, onde se tem grande dispersão entre as variáveis nesse período. Para o período de dois dias a correlação aumenta, porém ainda temos uma relativa dispersão. No período médio de três dias tem-se uma boa correlação entre as medidas, evidenciado pelo alto valor, como também do valor do coeficiente de ajuste "b", com valor igual a 0,92. Para o período de quatro dias a correlação é ainda mais consistente.

Concluimos assim que a evaporação medida no atmômetro modificado com escala de leitura comercial apresenta precisão equivalente ao atmômetro modificado com escala de leitura ampliada para períodos maiores ou iguais a três dias, ou seja, o efeito da ampliação da escala de leitura do atmômetro modificado é significativo para períodos de tempo de 1 a 2 dias.

\subsection{Correlações entre a evapotranspiração potencial, a evaporação dos atmômetros modificados e a evaporação do tanque classe "A"}

As Tabelas 14, 15 e 16 apresentam respectivamente, os parâmetros de ajuste $e$ índices de correlação entre a evapotranspiração potencial e a evaporação do atmômetro modificado com escala de leitura comercial, o atmômetro modificado com escala de leitura ampliada e a evaporação do tanque classe "A". As Figuras 11, 13 e 15 ilustram os diagramas de dispersão e as retas de ajuste entre entre as citadas variáveis. As Figuras 12, 14 e 16 apresentam os diagramas de dispersão entre a evapotranspiração potencial estimada pelo método de Penman-Monteith (ETo) e estimada pelos ajustes obtidos.

Observa-se que a evaporação do atmômetro modificado com escala de leitura comercial (ATMEC) não se correlacionou consistentemente com ETo 
para o período diário e médio de de 2 dias, constatado através dos baixos valores dos coeficientes de determinação $\left(r^{2}\right)$, apresentando ajuste consistente durante os períodos de três e quatro dias. Nas Figuras 11 e 12 observa-se alta dispersão entre as variáveis nos períodos de 1 e 2 dias e uma menor dispersão durante os períodos médios de 3 e 4 dias. No caso do atmômetro modificado com escala de leitura ampliada (ATMEA), verifica-se que para o período de um dia já temos uma correlação satisfatória com ETo, correlação esta que vai se elevando conforme os períodos médios aumentam. Verifica-se nas Tabelas 14 e 15 que para o períodos de três dias, os coeficientes de correlação $r^{2}$ e d para os ajustes de ETo em função de ATMEC e ATMEA apresentam valores muito próximos, conforme pode ser visualizado nas 11 e 13, onde as citadas correlações apresentam dispersão muito similar. Esse fato evidencia o que foi discutido no ítem 4.5, onde verificou-se que ATMEC e ATMEA apresentavam precisão similar em suas medidas para períodos iguais ou superiores a 3 dias.

Tabela 14 - Número de dados ( $n$ ), coeficiente de ajuste (b), coeficiente de correlação $\left(r^{2}\right)$, índice de concordância de Willmott (d), somatório dos quadrados dos resíduos (SQR) e valor de $F$ para o ajuste global referentes às correlações entre a evapotranspiração potencial (ETo) e a evaporação do atmômetro modificado com escala de leitura comercial (ATMEC) nos diversos períodos de tempo

\begin{tabular}{cccccc}
\hline $\begin{array}{c}\text { PERIOODO MÉDIO } \\
\text { (DIAS) }\end{array}$ & $\mathrm{n}$ & (b) & $\mathrm{r}^{2}$ & $\mathrm{~d}$ & $\mathrm{SQR}$ \\
\hline 1 & 33 & 0,61 & $0,21^{\star *}$ & 0,84 & 17,04 \\
2 & 20 & 0,60 & $0,55^{\star *}$ & 0,80 & 6.26 \\
3 & 12 & 0,61 & $0,81^{\star *}$ & 0,94 & 1,297 \\
4 & 9 & 0,64 & $0,70^{* *}$ & 0,89 & 1,408 \\
\hline TODOS OS & & 0,61 & $0,45^{\star *}$ & 0,94 & 26,12 \\
PERIODOS & $\mathrm{F}=0,0478 \mathrm{~ns}$ & & & & \\
\hline
\end{tabular}

ns - não significativo

** - significativo ao nível de $5 \%$ de probabilidade 
Tabela 15 - Número de dados ( $n$ ), coeficiente de ajuste (b), coeficiente de correlação $\left(r^{2}\right)$, indice de concordância de Willmott (d), somatório dos quadrados dos resíduos (SQR) e valor de $F$ para o ajuste global referentes às correlações entre a evapotranspiração potencial (ETo) e a evaporação do atmômetro modificado com escala de leitura ampliadal (ATMEA) nos diversos períodos de tempo

\begin{tabular}{|c|c|c|c|c|c|}
\hline $\begin{array}{l}\text { PERÍODO MÉDIO } \\
\text { (DIAS) }\end{array}$ & $n$ & (b) & $r^{2}$ & d & SQR \\
\hline 1 & 33 & 0,68 & $0,66^{\star \star}$ & 0,91 & 7,32 \\
\hline 2 & 20 & 0,69 & $0,70^{\star \star}$ & 0,95 & 4,23 \\
\hline 3 & 12 & 0,67 & $0,88^{\star \star}$ & 0,96 & 0,86 \\
\hline 4 & 9 & 0,67 & $0,88^{* *}$ & 0,92 & 0,57 \\
\hline $\begin{array}{l}\text { TODOS OS } \\
\text { PERIODOS }\end{array}$ & $\mathrm{F}=0,05 \mathrm{~ns}$ & 0,68 & $0,72^{* *}$ & 0,92 & 13,04 \\
\hline
\end{tabular}

Tabela 16 - Número de dados (n), coeficiente de ajuste (b), coeficiente de correlação $\left(r^{2}\right)$, índice de concordância de Willmott (d), somatório dos quadrados dos resíduos (SQR) e valor de $F$ para o ajuste global referentes às correlações entre a evapotranspiração potencial (ETo) e a evaporação do tanque classe "A" (ECA) nos diversos períodos de tempo

\begin{tabular}{cccccc}
\hline $\begin{array}{c}\text { PERIOODO MÉDIO } \\
\text { (DIAS) }\end{array}$ & $\mathrm{n}$ & (b) & $\mathrm{r}^{2}$ & $\mathrm{~d}$ & $\mathrm{SQR}$ \\
\hline 1 & 33 & 0,51 & $0,76^{* *}$ & 0,84 & 17,04 \\
2 & 20 & 0,51 & $0,89^{* *}$ & 0,80 & 6,26 \\
3 & 12 & 0,50 & $0,94^{* *}$ & 0,94 & 1,297 \\
4 & 9 & 0,51 & $0,88^{* *}$ & 0,89 & 1,408 \\
\hline TODOS OS & & 0,51 & $0,84^{* *}$ & 0,94 & 26,12 \\
PERIODOS & $\mathrm{F}=0,033 \mathrm{~ns}$ & & & \\
\hline
\end{tabular}

ns - não significativo

** - significativo ao nível de $5 \%$ de probabilidade 
1 DIA

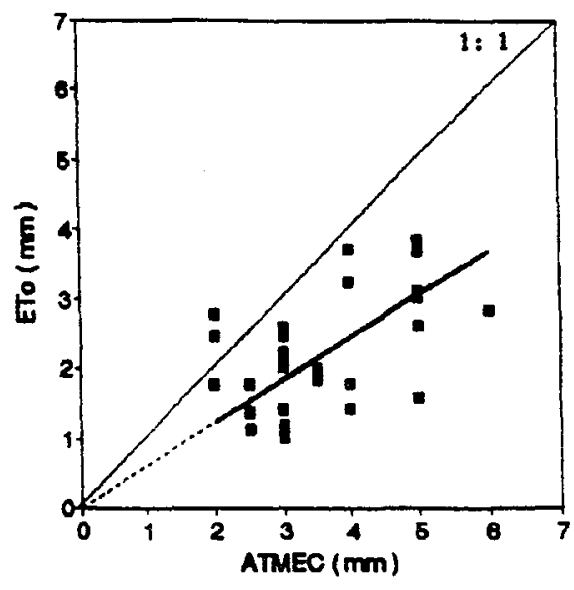

3 DIAS

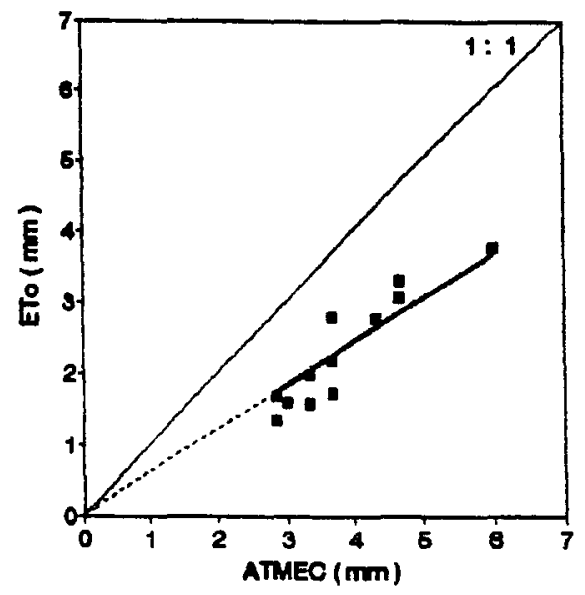

2 DIAS

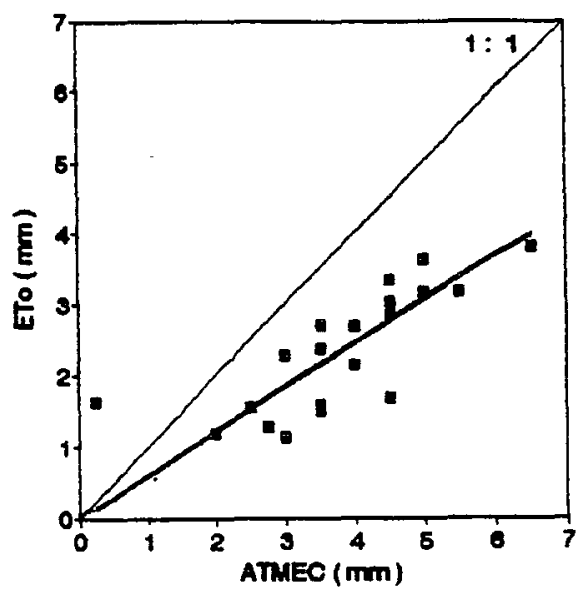

4 DIAS

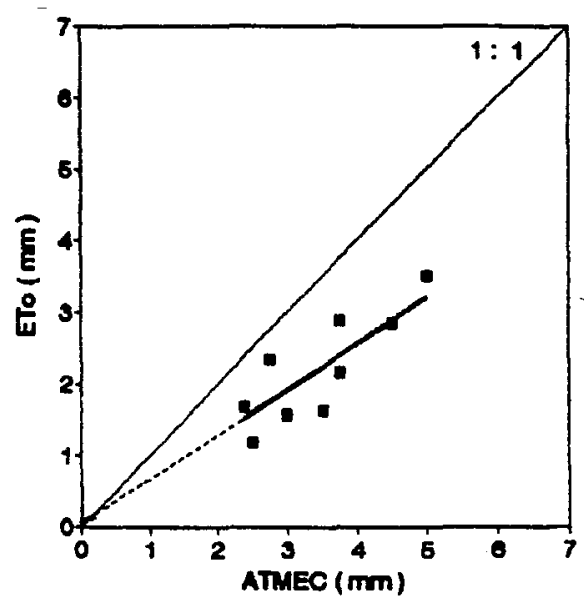

TODOS OS PERIODOS

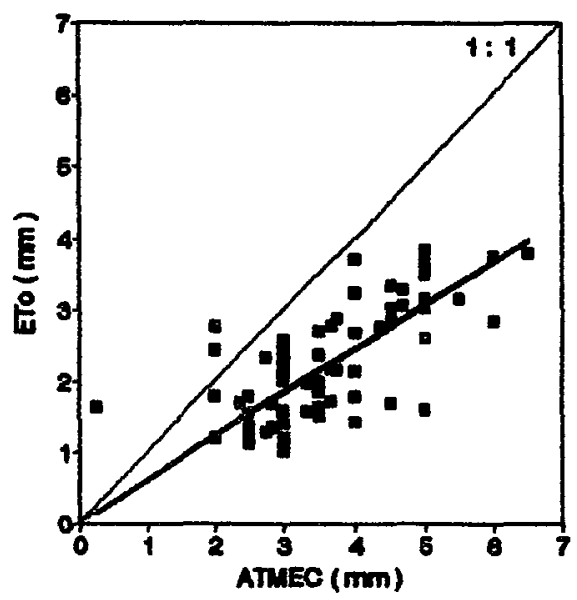

Figura 11 - Diagramas de dispersão e retas de ajuste entre a evapotranspiração potencial (ETo) e a evaporação do atmômetro modificado com escala de leitura comercial (ATMEC) 
1 DIA

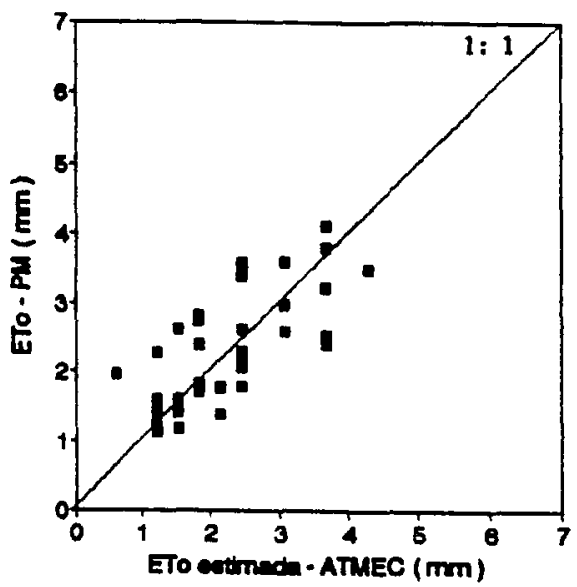

3 DIAS

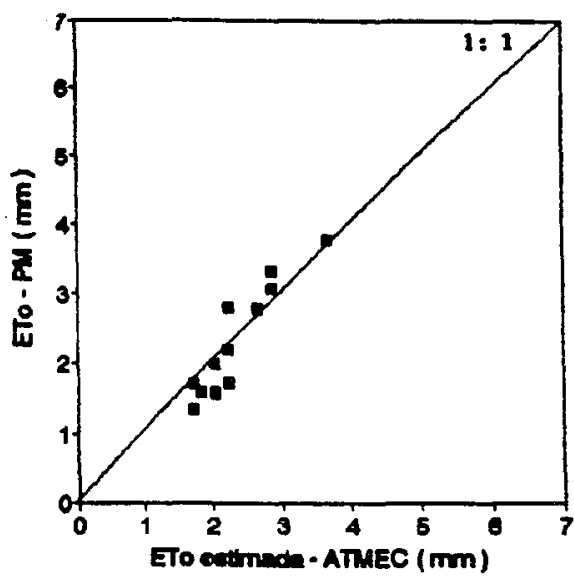

2 DIAS

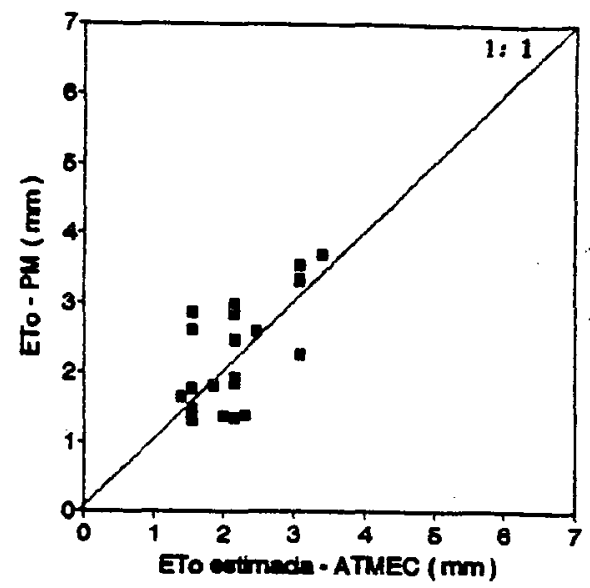

4 DIAS

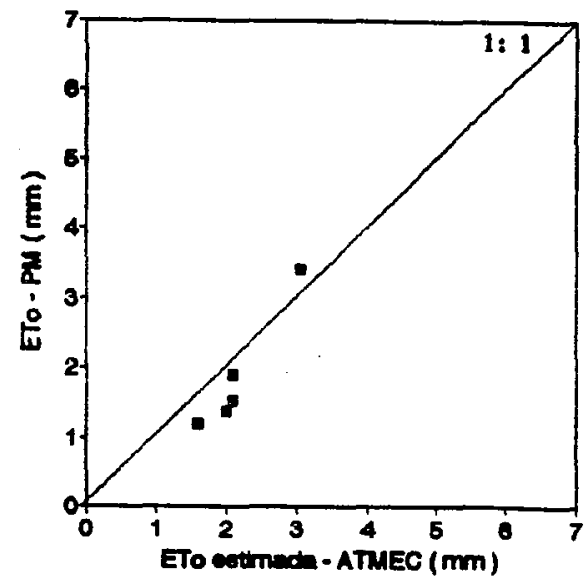

TODOS OS PERIODOS

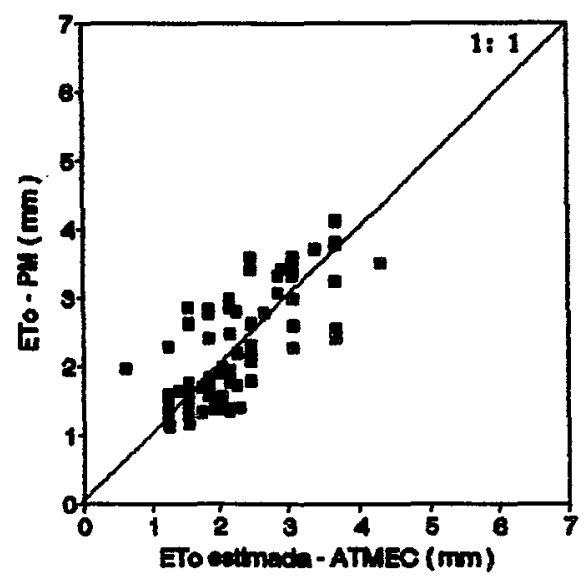

Figura 12 - Diagramas de dispersão e retas 1:1 entre os valores da evapotranspiração potencial estimada pelo método de Penman Monteith (ETo-PM) e estimada através do modelo linear utilizando a a evaporação do atmômetro modificado com escala de leitura comercial (ATMEC) 
1 DIA

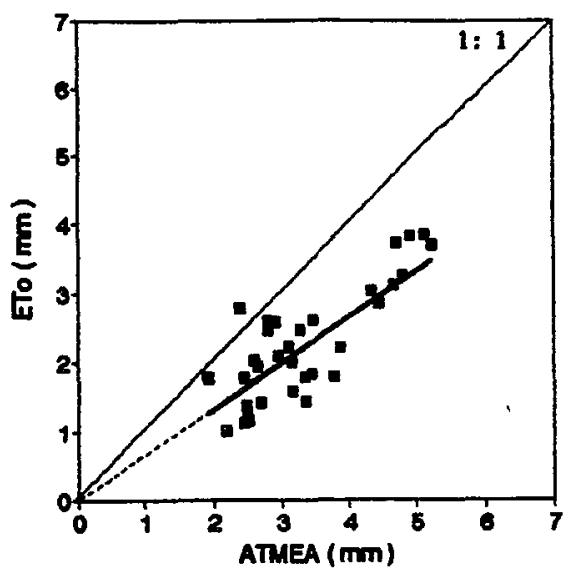

3 DIAS

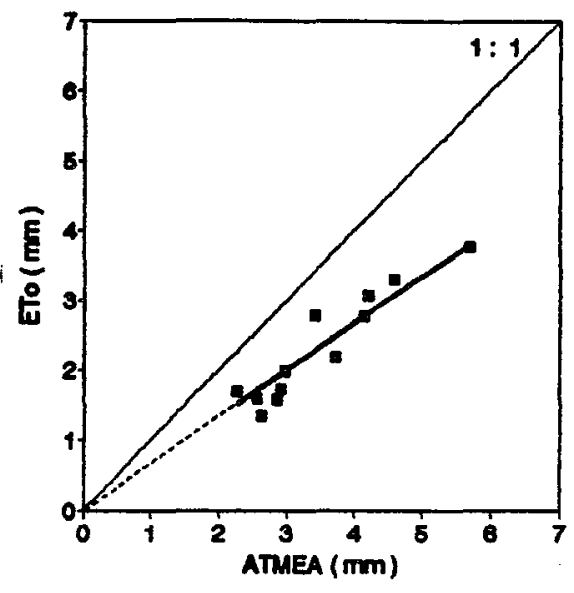

2 DIAS

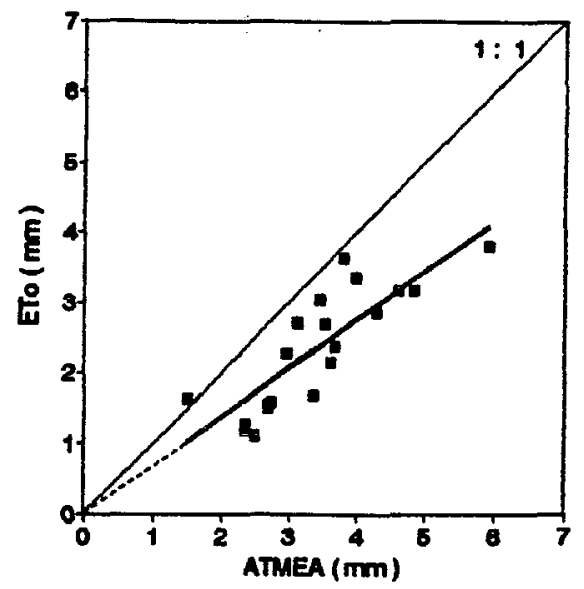

4 DIAS

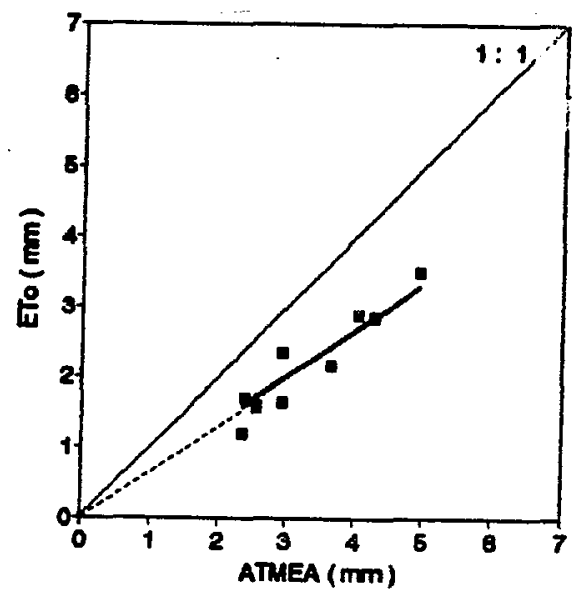

TODOS OS PERIODOS

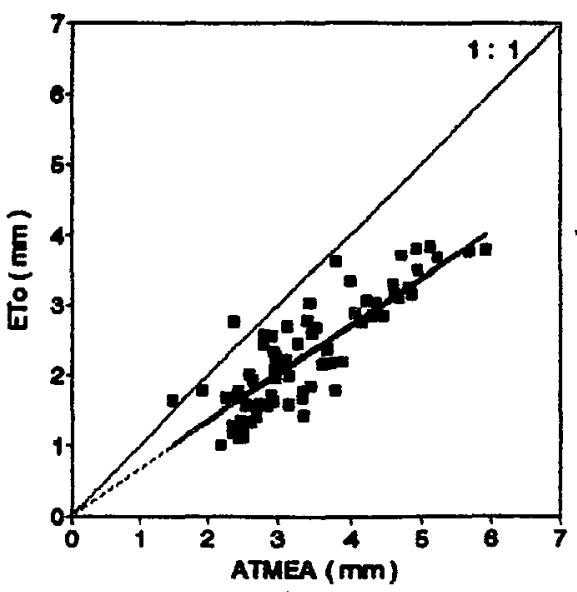

Figura 13 - Diagramas de dispersão e retas de ajuste entre a evapotranspiração potencial (ETo) e a evaporação do atmômetro modificado com escala de leitura ampliada (ATMEA) 
1 DIA

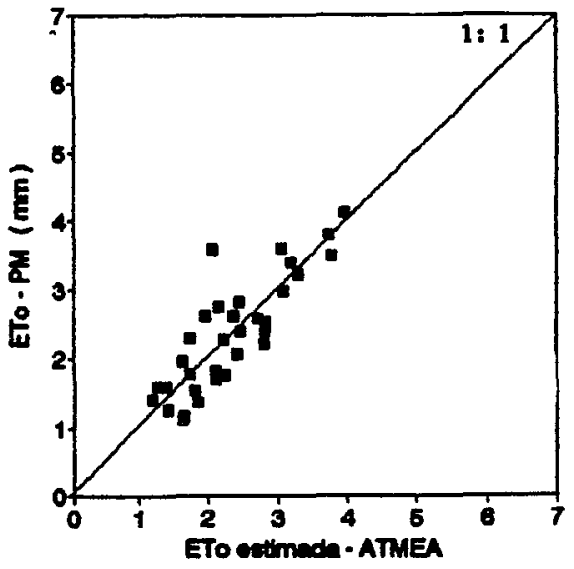

3 DIAS

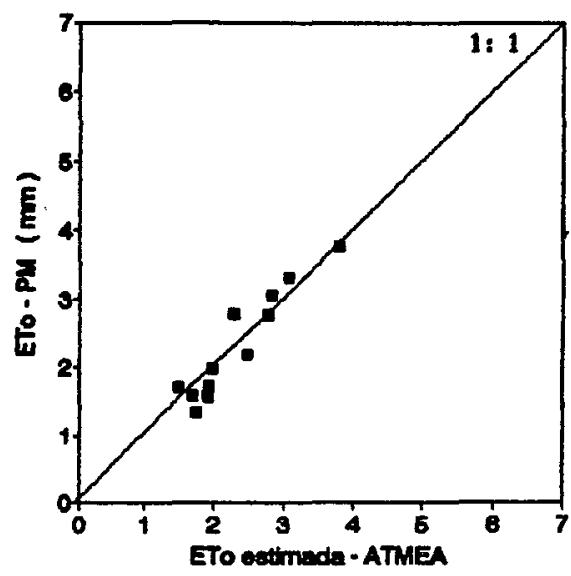

2 DIAS

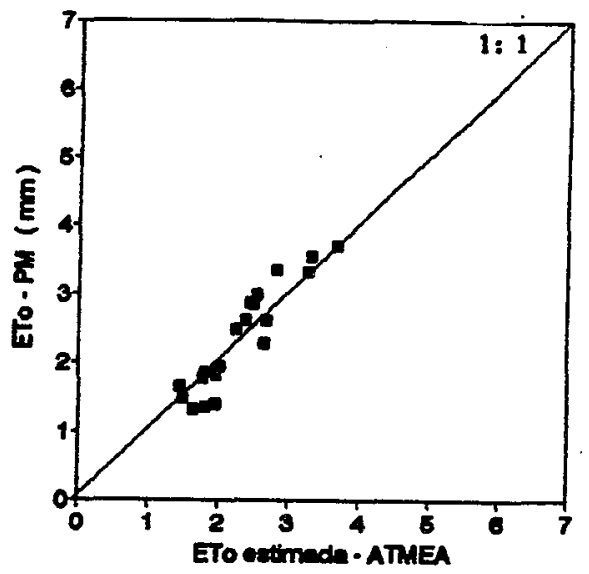

4 DIAS

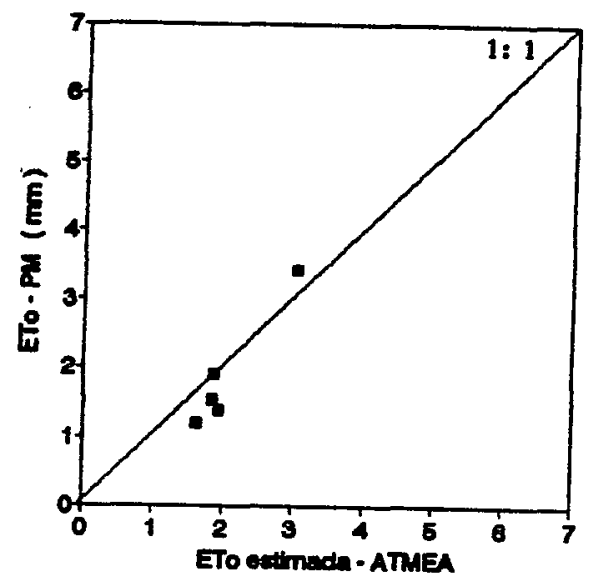

\section{TODOS OS PERIODOS}

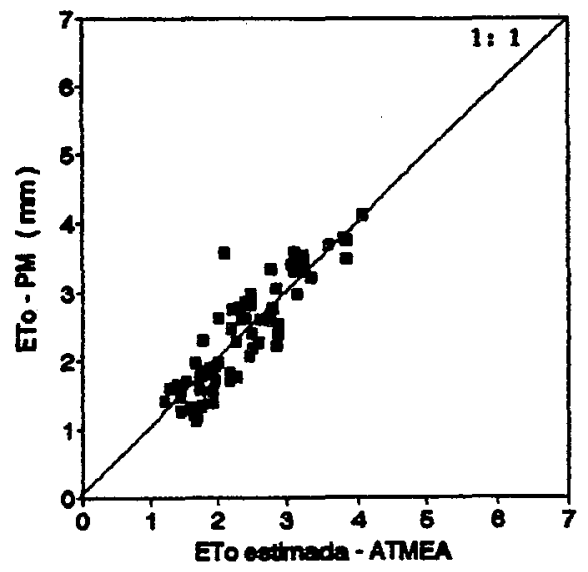

Figura 14 - Diagramas de dispersão e retas 1:1 entre os valores da evapotranspiração potencial estimada pelo método de Penman Monteith (ETo-PM) e estimada através do modelo linear utilizando a a evaporação do atmômetro modificado com escala de leitura ampliada (ATMEA) 
1 DIA

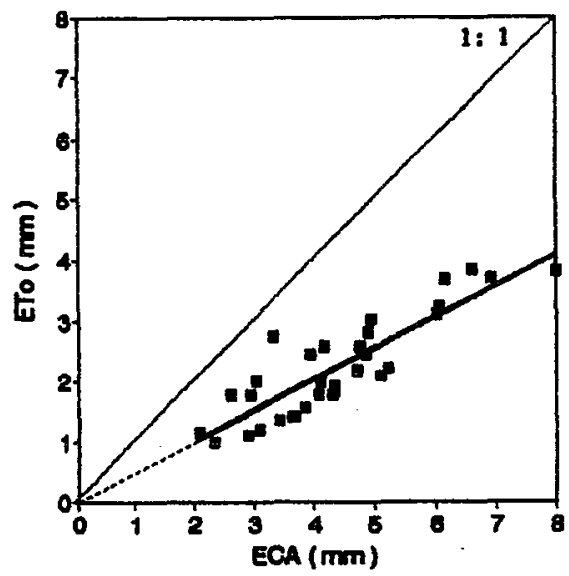

3 DIAS

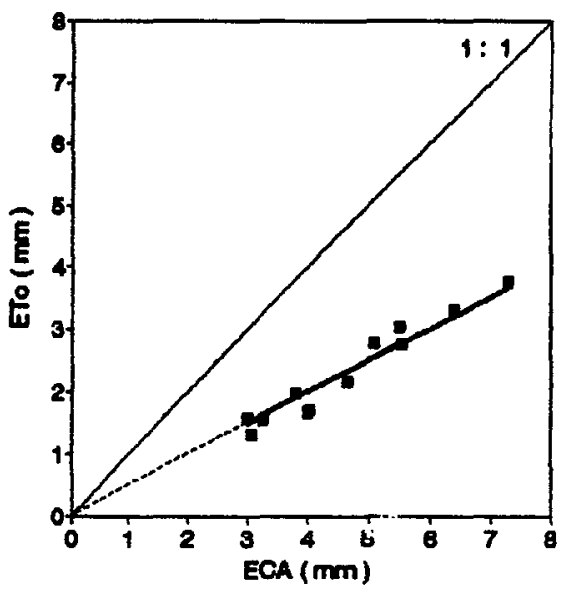

2 DIAS

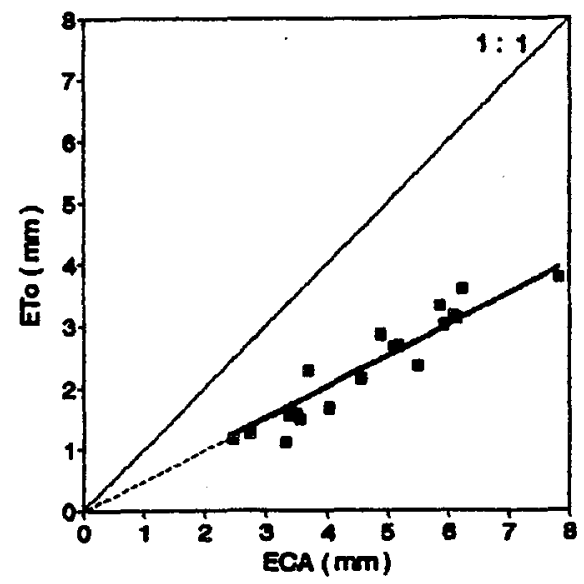

4 DIAS

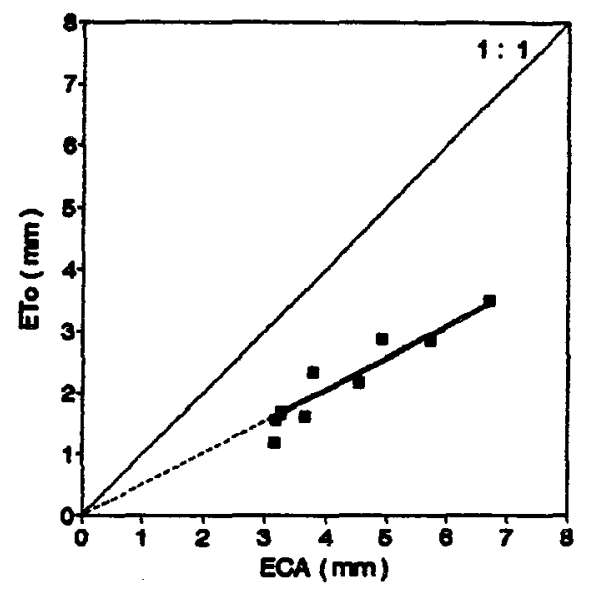

TODOS OS PERIODOS

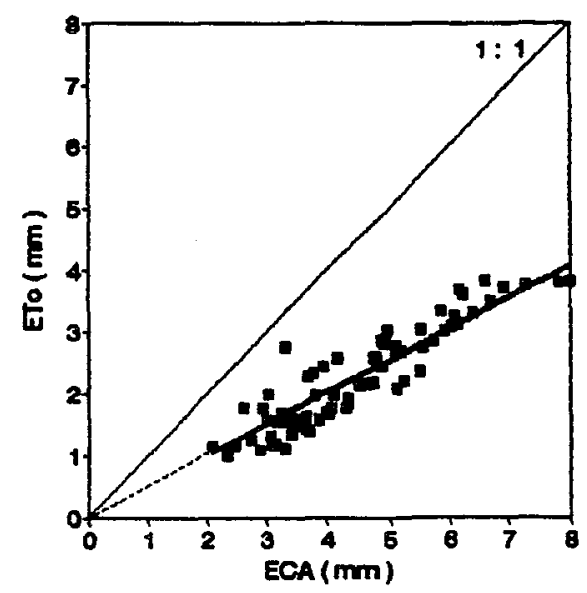

Figura 15 - Diagramas de dispersão e retas de ajuste entre a evapotranspiração potencial (ETo) e a evaporação do tanque classe "A" (ECA). 
1 DIA

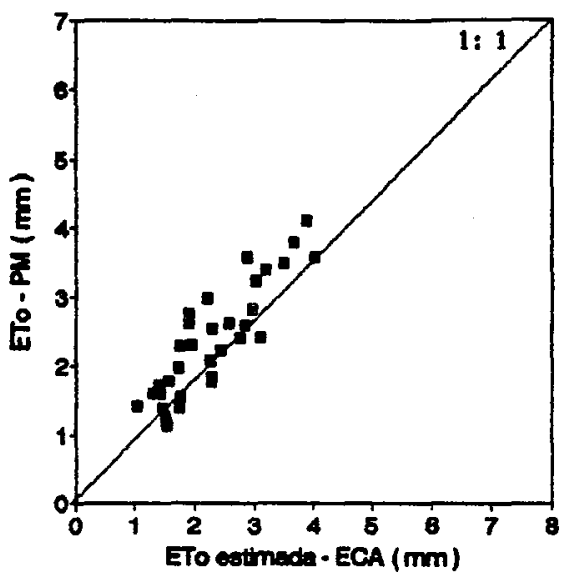

3 DIAS

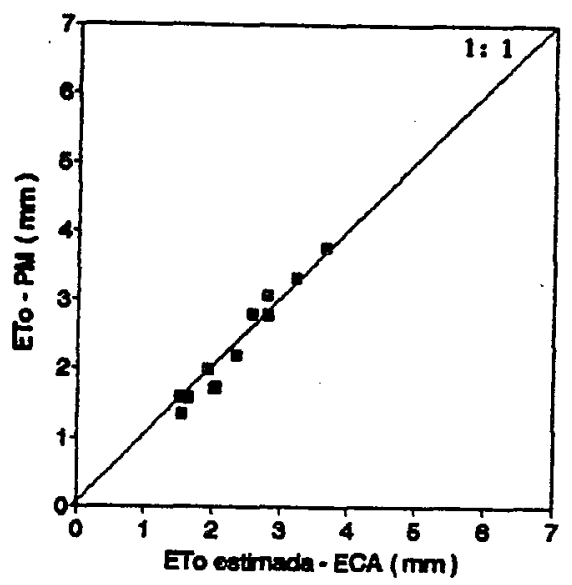

2 DIAS

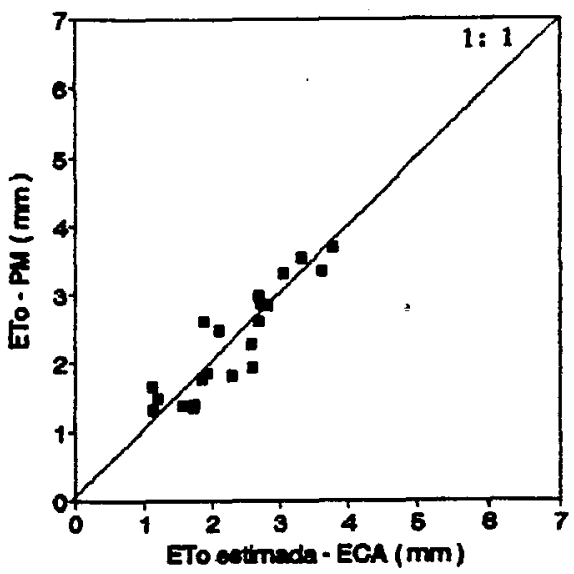

4 DIAS

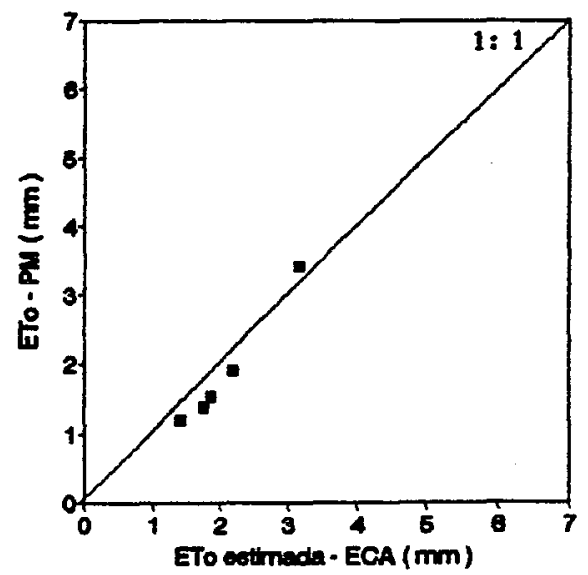

\section{TODOS OS PERIOODOS}

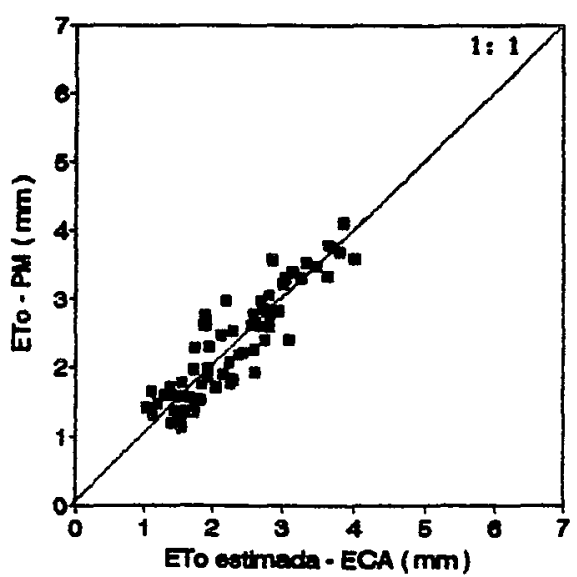

Figura 16 - Diagramas de dispersão e retas 1:1 entre os valores da evapotranspiração potencial estimada pelo método de Penman Monteith (ETo-PM) e estimada através do modelo linear utilizando a a evaporação do tanque classe "A" (ECA) 
Observa-se que os coeficientes de ajuste "b" para ATMEC e ATMEA apresentaram valores muito próximos, porém com um valor ligeiramente maior para ATMEA. Esse fato se justifica devido aos aparelhos serem iguais, diferenciando-se somente na precisão das medidas de evaporação. A tendência da evaporação de ATMEC e ATMEA se correlacionar com ETo é similar, porém em relação a ATMEC as dispersões são maiores devido a sua menor precisão nas leituras, conforme podemos visualizar nas Figuras 11 e 13.

Tanto para ATMEC como para ATMEC a equação global envolvendo todos os períodos apresentou-se não significativa pelo teste $F$ em relação aos períodos individualizados, ou seja: a relação entre ETo com ATMEC e ATMEA para qualquer período de tempo pode ser expressa por :

$$
\begin{aligned}
& \text { ETo }=0,61 \text { ATMEC } \\
& \text { ETo }=0,68 \text { ATMEA }
\end{aligned}
$$

Aplicando-se o teste $t$ (equações 29, 30 e 31) para as equações acima encontramos $t=0,825$. $O$ valor de $t$ tabelado para $n=144$ (número total de graus de liberdade das comparações) para um nível de significância de $5 \%$ é de 1,976 (Zar, 1984). Como o valor de de $t$ tabelado é superior ao calculado conclui-se que as equaçōes 33 e 34 não diferem estatisticamente entre si. Em termos práticos podemos recomendar o uso da equação 34 por ela ser obtida empregando dados de evaporação com maior precisão. Convém lembrar que para correlacionar ETo com o atmômetro modificado com escala de leitura comercial devemos empregar períodos médios iguais ou superiores a três dias.

Em relação aos ajustes de ETo com a evaporação do tanque classe "A" verificamos que para o período de um dia já se obtem uma boa correlação entre as variáveis, aumentando conforme se elevam os períodos acumulados. Através do teste $F$ verifica-se também a representatividade da equação global na estimativa de ETo em todos os períodos de tempo. Assim podemos escrever a seguinte expressão:

$$
\mathrm{ETo}=0,51 \mathrm{ECA}
$$


Observa-se que as correlações entre ETo e ECA apresentaram ajustes superiores àqueles realizados com os atmômetros modificados. Isso se deve provavelmente a maior precisão nas medidas de ECA através do parafuso micrométrico, que possibilita uma precisão de $0,1 \mathrm{~mm}$ nas medidas, contra 0,16 $\mathrm{mm}$ do atmômetro modificado com escala de leitura ampliada e $1 \mathrm{~mm}$ do atmômetro com escala de leitura comercial.

$O$ fato das relações entre ETo versus evaporação dos atmômetros modificados e evaporação do tanque classe " $\mathrm{A}$ " apresentarem tendência linear pode ser explicado pelo curso dessas variáveis ao longo do período do ensaio, conforme discutido no ítem 4.4 onde se observa que a tendência dessas variáveis se diferirem por uma razão constante ao longo do tempo.

\subsection{Correlação entre a evaporação do tanque classe "A"e a evaporação dos atmômetros}

As Tabelas 17 e 18 apresentam os resultados referentes as análises de correlação entre a evaporação do tanque classe e a evaporação dos atmômetros modificados para os diferentes períodos de tempo. As Figuras 17 e 19 apresentam os diagramas de dispersão e as retas de ajuste entre as variáveis. As Figuras 18 e 20 apresentam os diagramas de dispersão entre os valores de ECA medidos e respectivos valores de ECA estimados pelos atmômetros modificados.

Da mesma forma como em relação a evapotranspiração potencial, o atmômetro modificado com escala de leitura comercial (ATMEC) não apresentou correlação satisfatória para os períodos médios de 1 e 2 dias, apresentando bons resultados somente para os períodos médios de 3 e 4 dias. Por outro lado, o atmômetro modificado com escala de leitura ampliada (ATMEA) apresentou bons resultados em todos os períodos. Pelas Figuras 17 e 19 observa-se que para os períodos de 3 e 4 dias as dispersões entre as 
relações ECA × ATMEC e ECA $\times$ ATMEA são muito semelhantes, sugerindo, da mesma forma com visto nos ítens anteriores, que o efeito da ampliação da escala dos atmômetros modificados tem efeito significativo para períodos de tempo de 1 e 2 dias.

Tanto para ATMEC como para ATMEC a equação global envolvendo todos os períodos apresentou-se não significativa pelo teste $F$ em relação aos períodos individualizados, ou seja: a relação entre ECA com ATMEC e ATMEA para qualquer periodo de tempo pode ser expressa por :

$$
\begin{aligned}
& \mathrm{ECA}=1,20 \text { ATMEC } \\
& \mathrm{ECA}=1,33 \text { ATMEA }
\end{aligned}
$$

Aplicando-se o teste $t$ (equações 29, 30 e 31) para as equações acima encontramos $t=0,877$. O valor de $t$ tabelado para $n=144$ (número total de graus de liberdade das comparações) para um nível de significância de $5 \%$ é de 1,976 (Zar, 1984). Como o valor de de $t$ tabelado é superior ao calculado conclui-se que as equações 36 e 37 não diferem estatisticamente entre si. Em termos práticos podemos recomendar o uso da equação 37 por ela ser obtida empregando dados de evaporação com maior precisão. Convém lembrar que para correlacionar ECA com o atmômetro modificado com escala de leitura comercial devemos empregar períodos médios iguais ou superiores a três dias.

Comparativamente com as correlações de ETo versus evaporação dos atmômetros, as correlações de ECA versus evaporação dos atmômetros foram similares em relação a dispersão dos dados e coeficientes de correlação ( $r^{2}$ e d). 
Tabela 17 - Número de dados ( $n$ ), coeficiente de ajuste (b), coeficiente de correlação $\left(r^{2}\right)$, índice de concordância de Willmott (d), somatório dos quadrados dos resíduos (SQR) e valor de $F$ para o ajuste global referentes às correlações entre a evaporação do tanque classe "A" (ECA) e a evaporação do atmômetro modificado com escala de leitura comercial (ATMEC) nos diversos períodos de tempo

\begin{tabular}{|c|c|c|c|c|c|}
\hline $\begin{array}{l}\text { PERIOODO MÉDIO } \\
\text { (DIAS) }\end{array}$ & $n$ & (b) & $r^{2}$ & $d$ & SQR \\
\hline 1 & 33 & 1,19 & $0,15^{\star *}$ & 0,86 & 50,68 \\
\hline 2 & 20 & 1,19 & $0,56^{* *}$ & 0,87 & 16,94 \\
\hline 3 & 12 & 1,22 & $0,86^{\star \star}$ & 0,96 & 2,78 \\
\hline 4 & 9 & 1,25 & $0,89^{\star \star}$ & 0,97 & 1,34 \\
\hline TODOS OS & & 1,20 & $0,45^{\star \star}$ & 0,93 & $\overline{72,17}$ \\
\hline \multicolumn{6}{|c|}{$F=0,064 n s$} \\
\hline
\end{tabular}

Tabela 18 - Número de dados ( $n$ ), coeficiente de ajuste (b), coeficiente de correlação $\left(\mathrm{r}^{2}\right)$, índice de concordância de Willmott (d), somatório dos quadrados dos resíduos (SQR) e valor de $F$ para 0 ajuste global referentes às correlações entre a evaporação do tanque classe " $A$ " (ECA) e a evaporação do atmômetro modificado com escala de leitura ampliada (ATMEA) nos diversos períodos de tempo

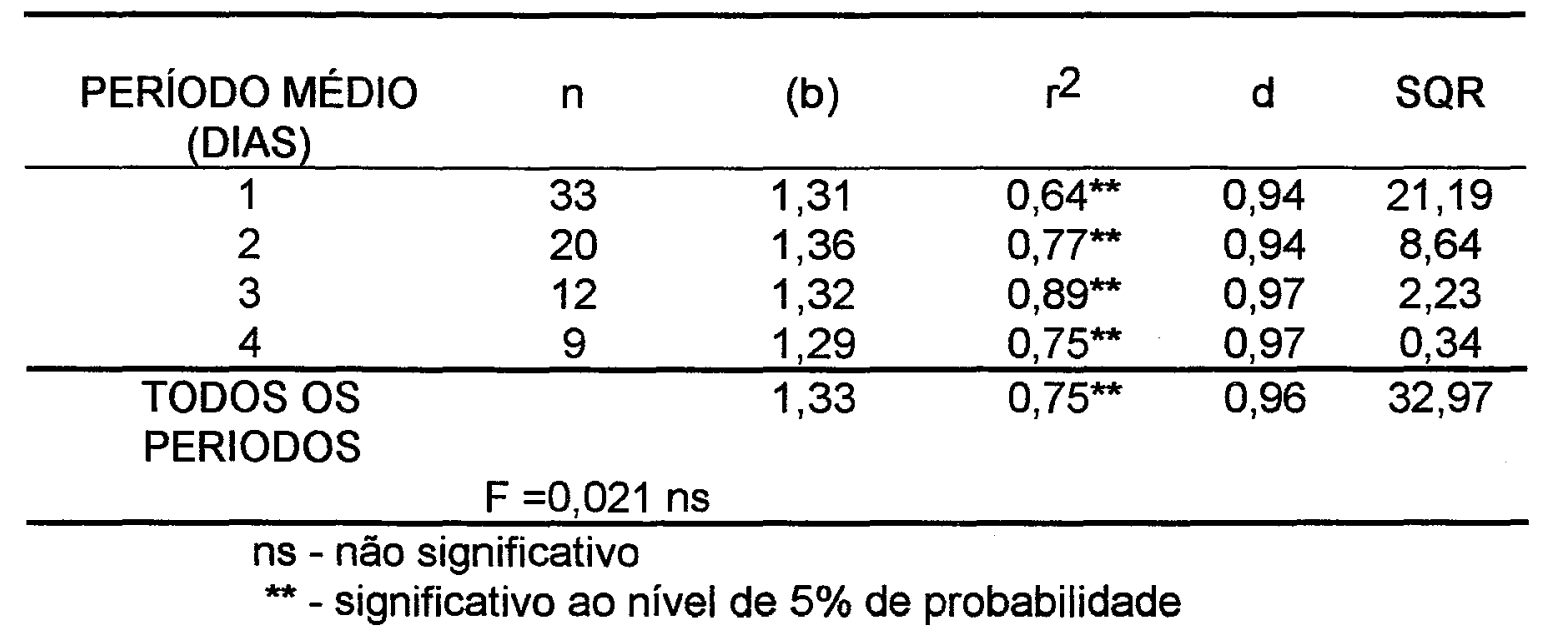


1 DIA

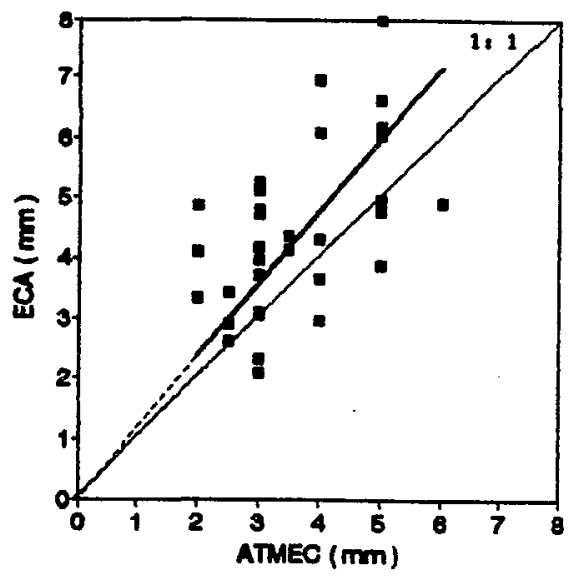

3 DIAS

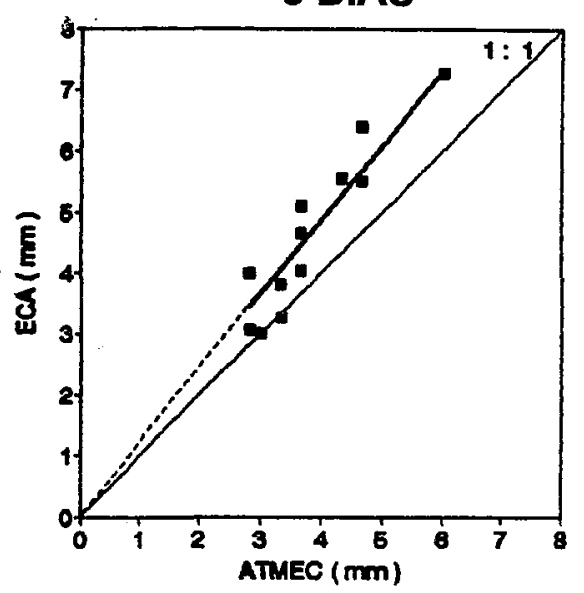

2 DIAS

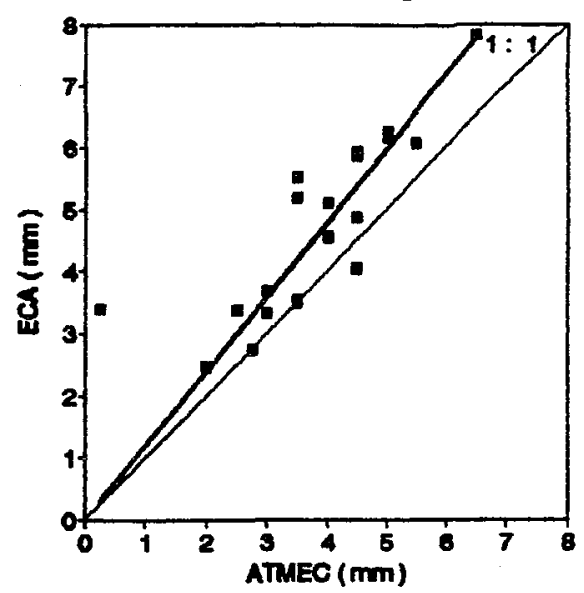

4 DIAS

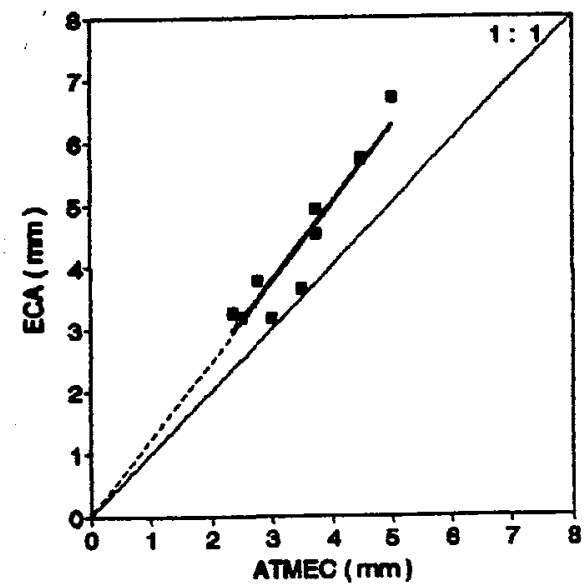

TODOS OS PERIODOS

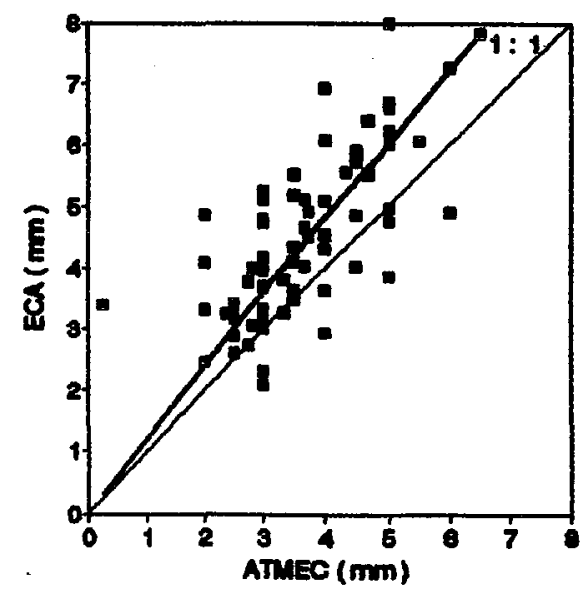

Figura 17 - Diagramas de dispersão e retas de ajuste entre a evaporação do tanque classe " $A$ " (ECA) e a evaporação do atmômetro modificado com escala de leitura comercial (ATMEC) 
1 DIA

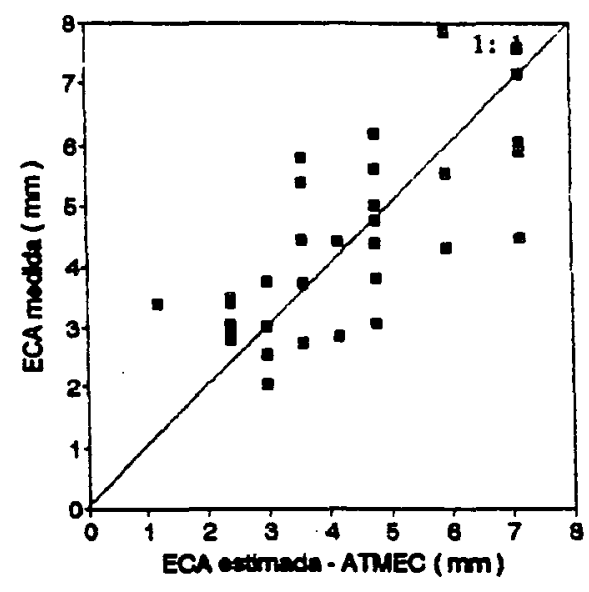

3 DIAS

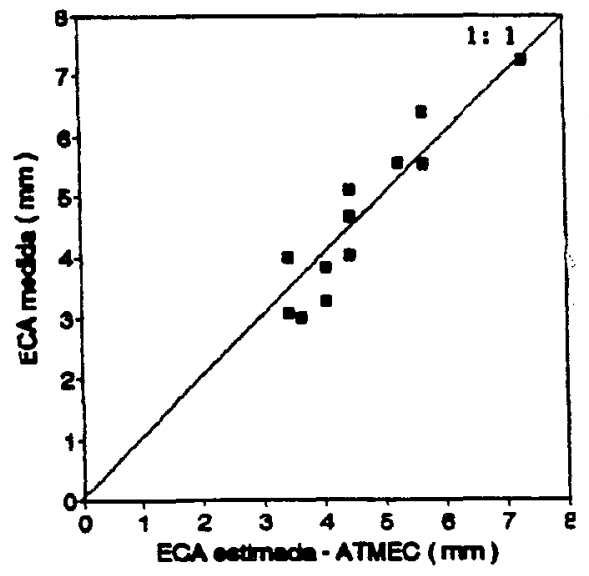

2 DIAS

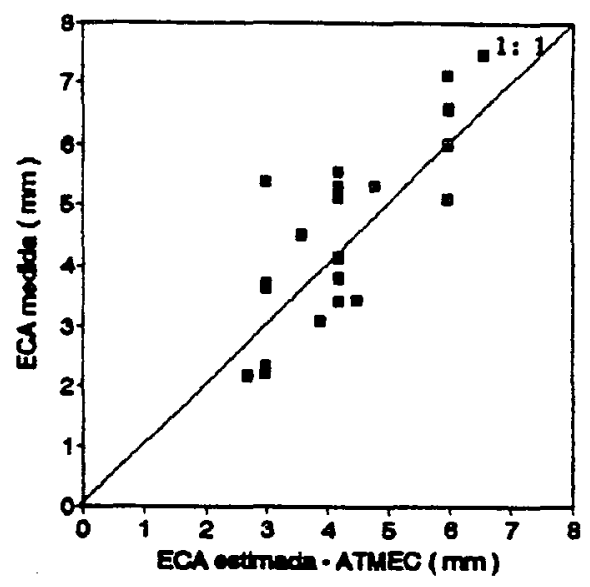

4 DIAS

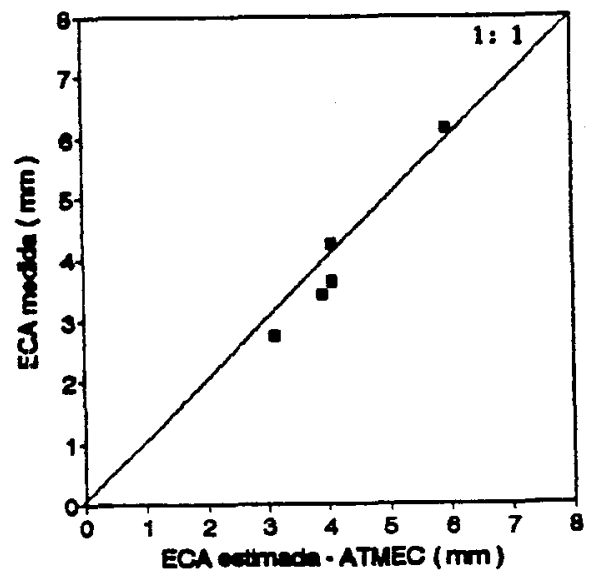

TODOS OS PERIODOS

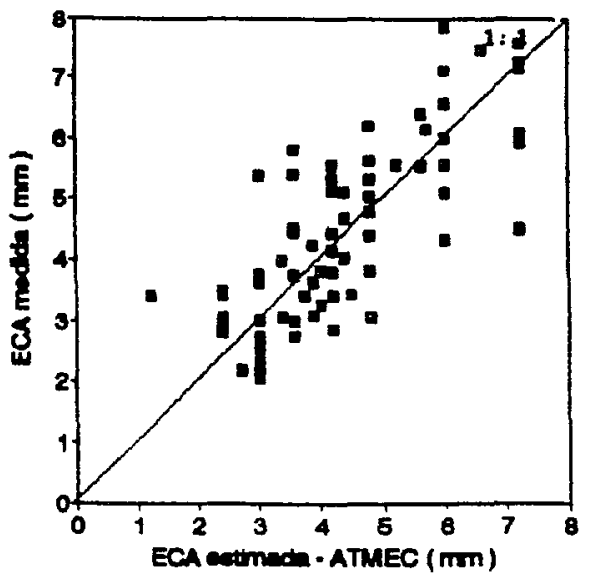

Figura 18 - Diagramas de dispersão e retas 1:1 entre os valores da evaporação medida no tanque classe "A" e estimada através do modelo linear utilizando a a evaporação do atmômetro modificado com escala de leitura comercial (ATMEC) 
1 DIA

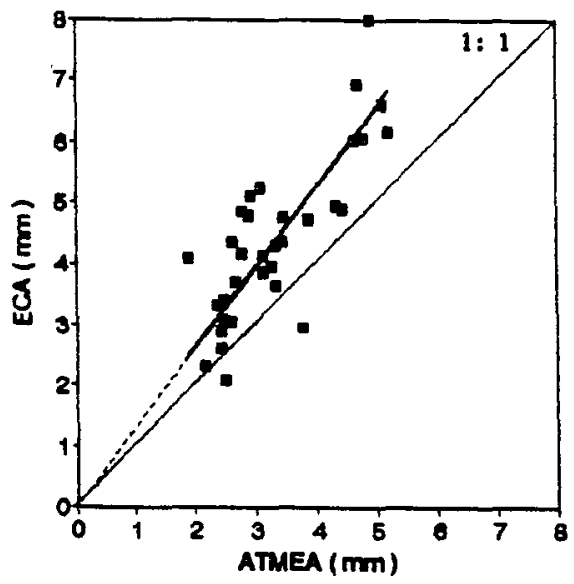

3 DIAS

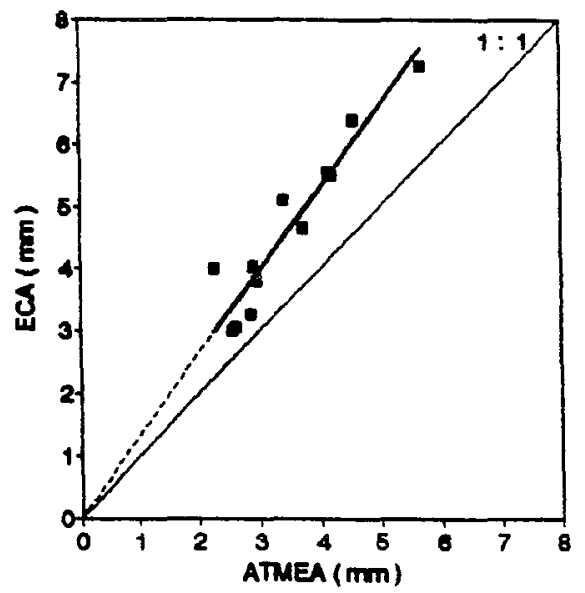

2 DIAS

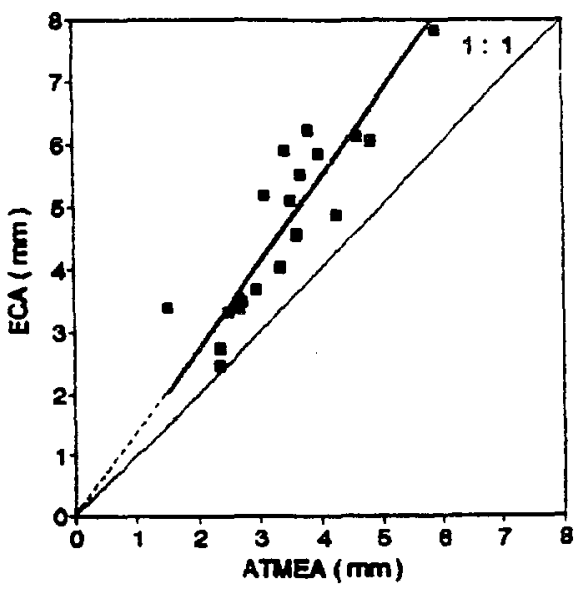

\section{DIAS}

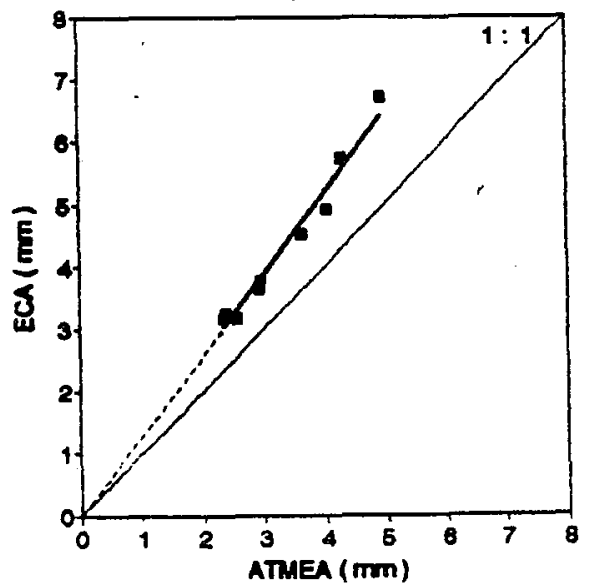

TODOS OS PERIODOS

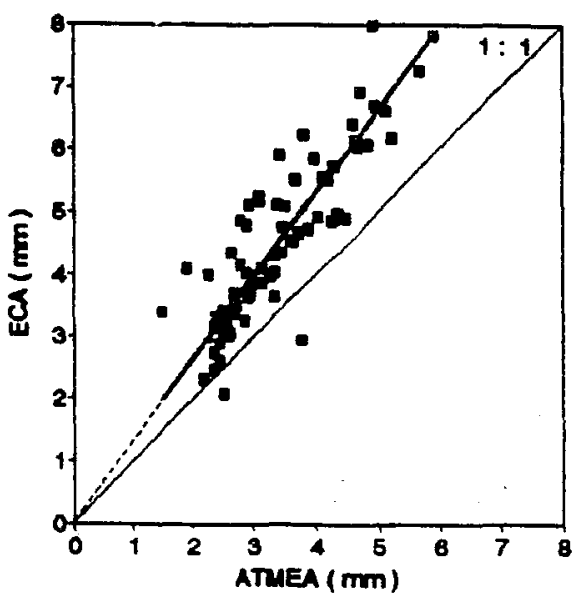

Figura 19 - Diagramas de dispersão e retas de ajuste entre a evaporação do tanque classe "A" (ECA) e a evaporação do atmômetro modificado com escala de leitura ampliada (ATMEA) 
1 DIA

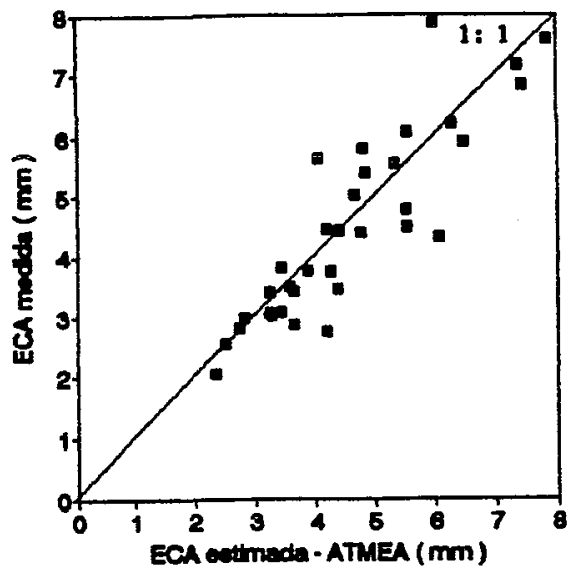

3 DIAS

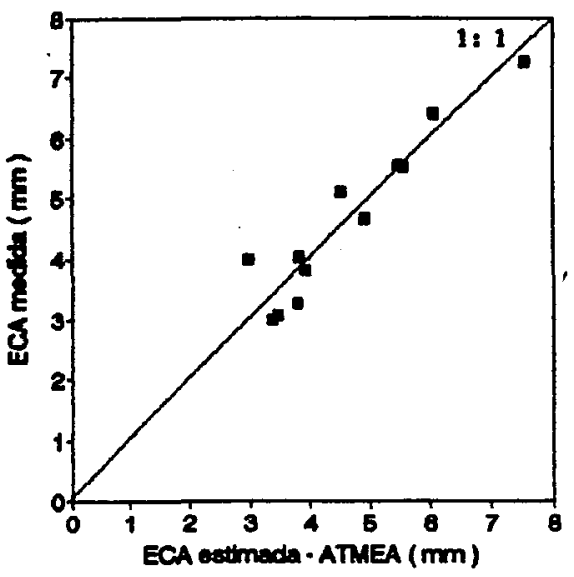

2 DIAS

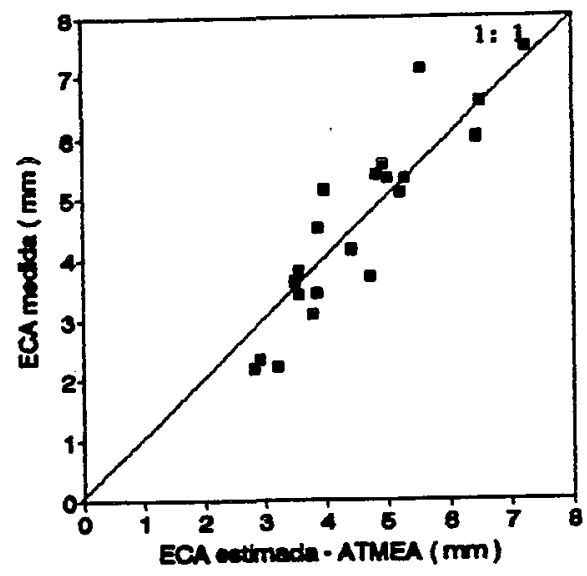

4 DIAS

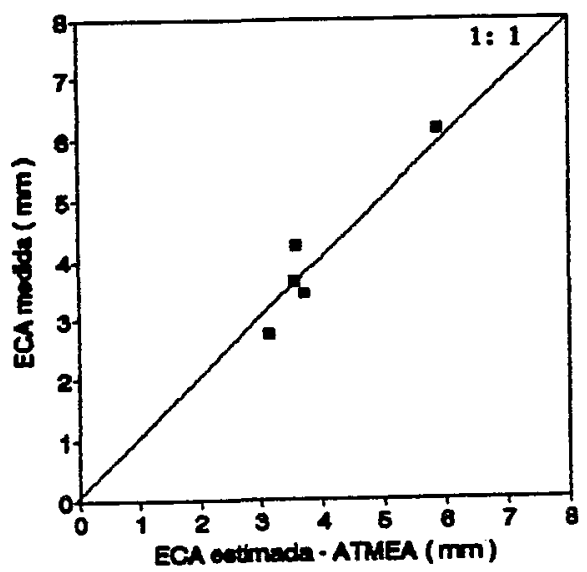

TODOS OS PERIOODOS

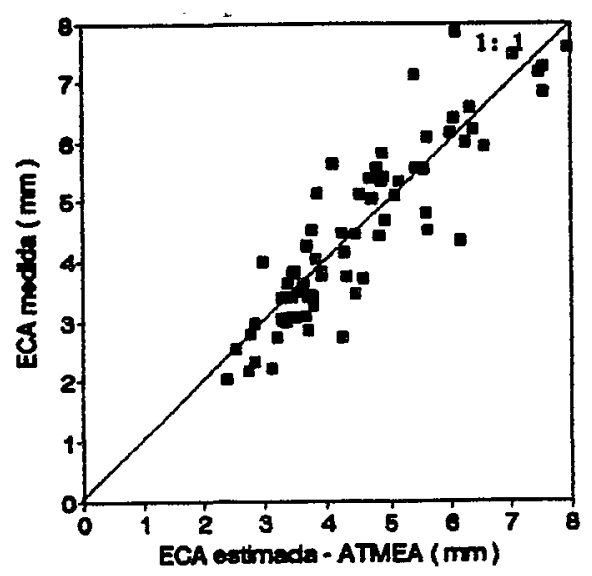

Figura 20 - Diagramas de dispersão e retas 1:1 entre os valores da evaporação medida no tanque classe "A" e estimada através do modelo linear utilizando a a evaporação do atmômetro modificado com escala de leitura ampliada (ATMEA) 


\section{CONCLUSÕES}

A partir das informações coletadas e da metodologia empregada foram estabelecidas as seguintes conclusões:

a) o atmômetro modificado comercializado apresenta boa correlação com a evapotranspiração potencial estimada pelo método de Penman-Monteith e a evaporação do tanque classe "A" para períodos médios de tempo maiores ou iguais a três dias;

b) a ampliação da escala de leitura do aparelho através do dispositivo idealizado na presente pesquisa, possibilitou ao atmômetro modificado, uma boa correlação com a evapotranspiração potencial estimada pelo método de Penman-Monteith e a evaporação do tanque classe " $A$ " em escala diária e em períodos médios de 2, 3 e 4 dias.

c) as correlações entre a evapotranspiração potencial estimada pelo método de Penman-Monteith (ETo) e a evaporação do atmômetro modificado com escala de leitura ampliada apresentaram dispersões semelhantes às comparações de ETo versus evaporação do tanque classe "A" para todos os períodos de tempo analisados, diferindo-se apenas em relação ao coeficiente de ajuste. As relações ETo versus atmômetro modificado com escala de leitura comercial apresentaram as mesmas tendências citadas anteriormente em relação a ETo versus ECA, para períodos de tempo acumulados de 3 e 4 dias. 
d) $\mathrm{O}$ atmômetro modificado com escala de leitura ampliada apresentou semelhante sensibilidade aos parâmetros de clima quando comparado ao tanque classe "A". 


\section{REFERÊNCIAS BIBLIOGRÁFICAS}

ALTENHOFEN, J. A modified atmometer for on-farm evapotranspiration determination. In: Conference on Advances in Evapotranspiration. Chicago: ASAE, 1985, p. 177-184.

BLUME; H.R.; JANTZ, D.R.; KUDER, L.J.; SHAW, A.D. Methods in determining crop usage. St Joseph: ASAE, 1988. 20p.

BRONER, I. Irrigation sheduling with atmometers. In: INTERNATIONAL CONFERENCE ON IRRIGATION, 5., Tel-Aviv, 1990. Proceedings. TelAviv: 1988. p 99-107.

BURMAN, R.D.; NIXON, P.R.; WRIGHT, J.L.; PRUITT, W.O. Water requirements. In: Design and Operation of farm irrigation systems. St. Joseph: ASAE, 1983. p.189-232.

CAMARGO, A.P; PEREIRA, A.R. Prescrição de rega suplementar por modelo climatológico. 1.ed. Campinas: Fundação Cargill, 1990. 27p. 
CAMARGO, A.P; PINTO, H.S.; BRUNINI, O. PEDRO JUNIOR, M.J.; ORTOLANI, A.A.; ALFONSI, R.R. Clima do estado de São Paulo. In: SÃO PAULO (Estado). Secretaria da Agricultura. Zoneamento agrícola do Estado de São Paulo. São Paulo: Secretaria da Agricultura, 1974. v1, cap.2, p.51-87.

CAMPOS, H. Estatística experimental não paramétrica. 4.ed. Piracicaba: ESALQ/USP, 1983. 349 p.

DEVLIN. R. M. Plant Physiology. 2.ed. New York: Van Nostrand Reinhold, 1969. $446 p$.

DOORENBOS, J.; PRUITT, W.O. Guidelines for predicting crop water requirements. Rome: FAO, 1977. 144p. (FAO. Irrigation and Drainage Paper, 24:revised)

DOORENBOS, J.; KASSAN,A.H. Efeito da água no rendimento das culturas. Campina Grande: FAO, 1994. 305p. (FAO. Boletim 33)

EFRON, B.; GONG, G. A leisurely look at the boostrap, the jackknife end cross-validation. The American Statiscian, v.37, n.1, p.36-48, 1983.

ERTHAL, V. J. T.; BERNARDO, S.; RAMOS;M.M.;SEDIYAMA, G.C. Avaliação da estimativa da evapotranspiração de referência para a região de Viçosa MG, utilizando o atmômetro modificado. Revista Ceres, v.4, n.4, p.1-9, 1996.

GOMES, F. P. Curso de estatística experimental. 2. ed. São Paulo: Nobel, 1970. 431p. 
HOLTSLAG, A.A.M.; ULDEN, P. V. A simple scheme for day time estimates of the surface fluxes from routine weather data. Journal of Climate and Applied Meteorology, v. 22, n.4, 1983.

JONES; P.N.; CARBERRY, P.S. A technique to develop and validade simulation models. Agricultural Systems. v.46, p.427-442, 1994.

KLUTE, A Methods of soil analysis - Physical and Mineralogical Methods. 2.ed. Madison: ASA, 1986. 1188p.

LAW, R.A.P.; ISRAELI, I. Evaluation of atmometer performance as a toll for irrigation scheduling. San Joseph: ASAE, 1988. 26p.

MEIDER, H.; MANSFIELF, T.A. Physiology of stomata. 1.ed. London: McGraw-Hill, 1968. 179p.

MONTEITH, J.L. Evaporation and enviroment. In: Symp. Soc. Exp. Biology. London: 1965, v.19, p.205-34.

MONTEITH, J.L. Principles of enviromental physics. New York: American Elsevier, 1973. 241p.

OMETTO, J.C. Bioclimatologia Vegetal. 1.ed. São Paulo: Editora Agronômica Ceres, 1981. 440p.

OMETTO, J.P.H. Medidas e estimativas do balanço de ondas longas, para a região de Piracicaba, SP. Piracicaba,1995. 87p. Dissertação (Mestrado) Escola Superior de Agricultura "Luiz de Queiroz", Universidade de São Paulo. 
PENMAN, H.L. Natural evaporation from open water, bare soil and grass. Proceedings Royal Society of London, v.A193, p.120-146, 1948.

PEREIRA, A. R. Apontamentos da disciplina LFM 704 - Evapo(transpi)ração. Piracicaba: Departamento de Física e Meteorologia, ESALQ/USP, 1992, $52 p$.

PEREIRA, A.S.; COELHO,R.D. Determinação da evapotranspiração de referência (ETo) através de atmômetros modificados em condições tropicais. In: CONGRESSO BRASILEIRO DE ENGENHARIA AGRÍCOLA, 21., Santa Maria, 1992. Anais. Santa Maria: 1992. p.637-647.

PEREIRA, F.A.C. Efeitos de diferentes profundidades do lençol freático sobre a evapotranspiração, o coeficiente de cultura, a produção e os componentes de produção da alface (Lactuca sativa L). Viçosa, 1994. 55p. Dissertação (Mestrado) - Universidade Federal de Viçosa.

PERES, J. G. Avaliação do modelo de Penman-Monteith, padrão FAO, para estimar a evapotranspiração de referência nas condições do estado de São Paulo. Piracicaba, 1994. 116p. Tese (Doutorado) - Escola Superior de Agricultura "Luiz de Queiroz", Universidade de São Paulo.

SCHREUDER, H.T.; LI, H.G.; SCOTT, C.T. Jackkinife and bootstrap estimation for sampling with partial replacement. Forest Science, v.33, n.33, p.677$689,1987$.

SHANNON, J. W. Use of atmômeters in estiming evapotranspiration. Journal of irrigation and drainage division. v.94, p.309-321, 1968. 
SILVA, F.C Uso de dispositivos lisimétricos na medida da evapotranspiração de referência. Piracicaba, 1996. 68p. Dissertação (Mestrado) - Escola Superior de Agricultura "Luiz de Queiroz", Universidade de São Paulo.

SMITH, M. Report on the expert consultation on procedures for revision of FAO guidelines for prediction of crop water requirements. Rome: FAO, 1991. $45 p$.

VILLA NOVA, N.A.; REICHARDT, K. Evaporação e Evapotraspiração. In: RAMOS, F.; OCCHIPINTI, VILLA NOVA, N.A.; REICHARDT, K.; MAGALHÃES, P.C.; CLEARY,R.W. Engenharia Hidrológica. Rio de Janeiro: Associação Brasileira de Recursos Hídricos (ABRH), 1989, v.2,, 84p.

WILLMOTT, C. J. On the validation of models. Physical geography, v.2, n.2, p.184-94, 1981.

ZAR, J.H. Biostatistical analysis. 2.ed. New Jersey: Prentice-Hall Inc., 1984. $620 p$.

ZELITCH, I. Stomata and water relations in plants. 1.ed. New Haven: The connecticut Agricultural Esperiment Station, 1963. 116p. 
APÊNDICE 
Tabela 1 - Valores de Radiação Solar Global ao nível da superfície (RSG), insolação (INS), Precipitação pluviométrica (PP); Umidade Relativa do ar (UR); Evaporação do Tanque Classe (ECA) e Evapotranspiração potencial (ETo) estimada pelo método de Penman-Monteith, para o período de 01/06 a 14/12/1992 em Piracicaba, SP.

\begin{tabular}{|c|c|c|c|c|c|c|c|c|}
\hline DATA & RSG & INS & PP & UR & $\mathrm{U} 2$ & $T$ & $\overline{E C A}$ & ETo \\
\hline & $\mathrm{MJ} \mathrm{m}^{-2} \mathrm{dia}^{-1}$ & HORAS & $\mathrm{mm}$ & $\%$ & $\mathrm{~m} \cdot \mathrm{s}^{-1}$ & ${ }^{\circ} \mathrm{C}$ & $\mathrm{mm}$ & $\mathrm{mm}$ \\
\hline $1 / 6$ & 9,7 & 3,2 & 0,0 & 83,0 & 1,7 & 19,9 & 2,6 & 1,6 \\
\hline $2 / 6$ & 12,1 & 8,8 & 0,0 & 79,0 & 0,9 & 21,4 & 1,9 & 1,0 \\
\hline $3 / 6$ & 11,8 & 7,3 & 0,0 & 80,0 & 1,5 & 20,8 & 4,3 & 1,3 \\
\hline $4 / 6$ & 10,8 & 7,7 & 0,0 & 82,0 & 1,3 & 20,6 & 2,3 & 1,0 \\
\hline $5 / 6$ & 12,5 & 9,6 & 0,0 & 63,0 & 2,6 & 21,3 & 4,8 & 2,0 \\
\hline $6 / 6$ & 10,9 & 6,2 & 0,0 & 71,0 & 1,3 & 24,1 & 2,7 & 1,7 \\
\hline $7 / 6$ & 12,2 & 7,2 & 0,0 & 73,0 & 1,6 & 23,5 & 4,8 & 1,8 \\
\hline $8 / 6$ & 12,2 & 6,7 & 0,0 & 71,0 & 1,6 & 22,7 & 3,2 & 1,9 \\
\hline $9 / 6$ & 10,5 & 3,5 & 0,0 & 75,0 & 1,1 & 21,2 & 2,6 & 1,8 \\
\hline $10 / 6$ & 8,0 & 1,3 & 0,0 & 82,0 & 0,7 & 20,8 & 1,7 & 1,5 \\
\hline $11 / 6$ & 10,3 & 5,4 & 0,0 & 83,0 & 1,1 & 20,7 & 3,0 & 1,3 \\
\hline $12 / 6$ & 12,8 & 9,5 & 0,0 & 77,0 & 1,5 & 18,4 & 3,5 & 1, \\
\hline $13 / 6$ & 13,7 & 9,0 & 0,0 & 77,0 & 1,5 & 16,6 & 3,1 & 1,2 \\
\hline $14 / 6$ & 12,3 & 7,0 & 0,0 & 76,0 & 1,5 & 16,1 & 3,0 & 1, \\
\hline $15 / 6$ & 13,3 & 0 & 0,0 & 73,0 & 1,6 & 16,6 & 2,9 &, 4 \\
\hline $16 / 6$ & 14,1 & ,3 & 0,0 & 70,0 & 1,6 & 16,6 & 3 & 1,4 \\
\hline $17 / 6$ & 13,4 & 9,2 & 0,0 & 75,0 & 1.5 & 15,7 & 2,9 & 1, \\
\hline $18 / 6$ & 12,4 & 6,6 & 0,0 & 74,0 & 1,6 & 15,7 & 2,5 & 1, \\
\hline $19 / 6$ & 12,8 & 9,1 & 0,0 & 71,0 & 1,7 & 16,3 & 3,0 & 1, \\
\hline $20 / 6$ & 11,9 & 7,1 & 0,0 & 71,0 & 2,4 & 19,5 & 3,4 & 1,8 \\
\hline $21 / 6$ & 12,6 & 9,2 & 0,0 & 73,0 & 1,5 & 20,2 & 3,2 & 1,2 \\
\hline $22 / 6$ & 12,1 & 7,8 & 0,0 & 75,0 & 1,5 & 20,4 & 3,4 & 1, \\
\hline $23 / 6$ & 12,8 & 9,1 & 0,0 & 71,0 & 1,7 & 20,4 & 3,5 & 1, \\
\hline $24 / 6$ & 12,4 & 8,7 & 0,0 & 72,0 & 1,6 & 20,9 & 3,3 & 1, \\
\hline $25 / 6$ & 12,8 & 8,6 & 0,0 & 71,0 & 1,5 & 19,7 & 3,4 & 1, \\
\hline $26 / 6$ & 12,1 & 6,8 & 0,0 & 68,0 & 1,8 & 19,3 & 3,3 & 1 \\
\hline $27 / 6$ & 12,9 & 9,2 & 0,0 & 66,0 & 1,5 & 20,2 & 3,6 & 1, \\
\hline $28 / 6$ & 5,3 & 0,6 & 0,6 & 83,0 & 1,0 & 18,6 & 1,1 & 1, \\
\hline $29 / 6$ & 7,2 & 2,6 & 0,0 & 77,0 & 1,5 & 21,3 & 2,0 & 1 \\
\hline $30 / 6$ & 10,3 & 5,3 & 0,0 & 75,0 & 1,4 & 21,9 & 2,6 & 1, \\
\hline $1 / 7$ & 12,3 & 8,2 & 0,0 & 63,0 & 1,8 & 21,8 & 4,3 & 1, \\
\hline $2 / 7$ & 11,0 & 6,3 & 0,0 & 76,0 & 1,8 & 20,5 & 3,7 & 1, \\
\hline $3 / 7$ & 11,9 & 6,9 & 0,0 & 79,0 & 2,0 & 20,3 & 4,2 & 1, \\
\hline $4 / 7$ & 9,0 & 3,0 & 0,0 & 78,0 & 1,5 & 20,4 & 2,8 & 1, \\
\hline
\end{tabular}


Tabela 1 - Valores de Radiação Solar Global ao nivel da superfície (RSG), insolação (INS), Precipitação pluviométrica (PP); Umidade Relativa do ar (UR); Evaporação do Tanque Classe (ECA) e Evapotranspiração potencial (ETo) estimada pelo método de Penman-Monteith, para o período de 01/06 a 14/12/1992 em Piracicaba, SP. (Continuação)

\begin{tabular}{|c|c|c|c|c|c|c|c|c|}
\hline DATA & $\begin{array}{c}\text { RSG } \\
\mathrm{MJ} \mathrm{m}^{-2} \mathrm{dia}^{-1}\end{array}$ & HORAS & $\begin{array}{l}\mathrm{PP} \\
\mathrm{mm}\end{array}$ & $\begin{array}{l}\text { UR } \\
\% \\
\end{array}$ & $\begin{array}{c}\mathrm{U} 2 \\
\mathrm{~m} \cdot \mathrm{s}^{-1}\end{array}$ & ${ }^{\circ} \mathrm{C}$ & $\begin{array}{l}\text { ECA } \\
\mathrm{mm}\end{array}$ & $\begin{array}{l}\text { ETo } \\
\mathrm{mm}\end{array}$ \\
\hline $5 / 7$ & 13,1 & 9,0 & 0,0 & 63,0 & 2,1 & 20,8 & 4,7 & 1,9 \\
\hline $6 / 7$ & 11,2 & 7,2 & 5,7 & 77,0 & 2,4 & 20,4 & 4,0 & 1,5 \\
\hline 717 & 2,8 & 0,0 & 11,0 & 85,0 & 2,8 & 13,3 & 3,4 & 0,6 \\
\hline 817 & 2,6 & 0,1 & 19,9 & 96,0 & 2,0 & 13,8 & 2,2 & 0,2 \\
\hline $9 / 7$ & 13,9 & 8,6 & 0,0 & 82,0 & 1,0 & 17,0 & 2,1 & 1,2 \\
\hline $10 / 7$ & 11,6 & 6,3 & 0,0 & 81,0 & 1,7 & 16,0 & 2,8 & 1,2 \\
\hline $11 / 7$ & 13,6 & 9,7 & 0,0 & 75,0 & 1,2 & 18,3 & 3,0 & 1,1 \\
\hline $12 / 7$ & 13,3 & 8,3 & 0,0 & 76,0 & 1,1 & 18,9 & 3,1 & 1,3 \\
\hline $13 / 7$ & 13,6 & 9,4 & 0,0 & 74,0 & 1,8 & 18,8 & 3,7 & 1,4 \\
\hline $14 / 7$ & 13,9 & 9,4 & 0,0 & 63,0 & 2,2 & 20,1 & 5,1 & 2,0 \\
\hline $15 / 7$ & 13,8 & 9,4 & 0,0 & 66,0 & 2,1 & 20,0 & 4,5 & 1,8 \\
\hline $16 / 7$ & 11,8 & 6,9 & 0,0 & 80,0 & 1,2 & 20,1 & 2,5 & 1,3 \\
\hline $17 / 7$ & 8,4 & 3,5 & 0,0 & 87,0 & 0,9 & 17,7 & 1,4 & 1,0 \\
\hline $18 / 7$ & 13,5 & 8,0 & 0,0 & 69,0 & 2,6 & 21,1 & 5,2 & 2,2 \\
\hline $19 / 7$ & 14,4 & 9,2 & 0,0 & 65,0 & 1,3 & 16,3 & 3,8 & 1,4 \\
\hline $20 / 7$ & 12,6 & 9,3 & 0,0 & 75,0 & 0,7 & 17,1 & 2,4 & 0,7 \\
\hline $21 / 7$ & 12,5 & 5,3 & 0,0 & 72,0 & 1,4 & 18,5 & 3,1 & 1,8 \\
\hline $22 / 7$ & 10,9 & 4,9 & 0,0 & 75,0 & 1,7 & 19,4 & 3,6 & 1,7 \\
\hline $23 / 7$ & 9,0 & 0,9 & 0,0 & 78,0 & 3,1 & 13,7 & 3,0 & 1,7 \\
\hline $24 / 7$ & 5,9 & 0,3 & 0,0 & 73,0 & 3,7 & 13,1 & 3,8 & 1,6 \\
\hline $25 / 7$ & 13,0 & 5,6 & 0,0 & 75,0 & 2,8 & 16,2 & 4,3 & 1,9 \\
\hline $26 / 7$ & 15,2 & 9,3 & 0,0 & 69,0 & 1,5 & 16,0 & 3,9 & 1,5 \\
\hline $27 / 7$ & 14,5 & 6,5 & 0,0 & 70,0 & 1,7 & 16,7 & 3,4 & 2,0 \\
\hline $28 / 7$ & 8,1 & 2,0 & 0,0 & 79,0 & 1,5 & 16,3 & 1,4 & 1,3 \\
\hline $29 / 7$ & 14,4 & 9,6 & 0,0 & 65,0 & 1,5 & 18,2 & 3,9 & 1,6 \\
\hline $30 / 7$ & 14,3 & 9,4 & 0,0 & 58,0 & 1,6 & 19,4 & 4,2 & 1,8 \\
\hline $31 / 7$ & 15,2 & 9,8 & 0,0 & 58,0 & 1,9 & 21,2 & 4,8 & 2,2 \\
\hline $1 / 8$ & 14,3 & 9,4 & 0,0 & 63,0 & 2,1 & 20,7 & 6,2 & 2,1 \\
\hline $2 / 8$ & 8,8 & 1,5 & 0,0 & 79,0 & 3,1 & 16,5 & 4,1 & 1,8 \\
\hline $3 / 8$ & 9,0 & 0,3 & 0,0 & 78,0 & 1,9 & 14,9 & 2,3 & 1,7 \\
\hline $4 / 8$ & 14,6 & 8,3 & 0,0 & 63,0 & 1,7 & 20,1 & 4,4 & 2,1 \\
\hline $5 / 8$ & 14,5 & 7,0 & 0,0 & 70,0 & 1,8 & 20,6 & 4,7 & 2,2 \\
\hline $6 / 8$ & 15,0 & 8,9 & 0,0 & 68,0 & 1,5 & 19,1 & 4,4 & 1,8 \\
\hline
\end{tabular}


Tabela 1 - Valores de Radiação Solar Global ao nivel da superfície (RSG), insolação (INS), Precipitação pluviométrica (PP); Umidade Relativa do ar (UR); Evaporação do Tanque Classe (ECA) e Evapotranspiração potencial (ETo) estimada pelo método de Penman-Monteith, para o período de 01/06 a 14/12/1992 em Piracicaba, SP. (Continuação)

\begin{tabular}{|c|c|c|c|c|c|c|c|c|}
\hline DATA & $\begin{array}{c}\text { RSG } \\
\mathrm{MJ} \mathrm{m}^{-2} \mathrm{dia}^{-1}\end{array}$ & $\begin{array}{c}\text { INS } \\
\text { HORAS }\end{array}$ & $\begin{array}{l}\mathrm{PP} \\
\mathrm{mm} \\
\end{array}$ & $\begin{array}{l}\text { UR } \\
\% \\
\end{array}$ & $\begin{array}{c}\mathrm{U} 2 \\
\mathrm{~m} \cdot \mathrm{s}^{-1} \\
\end{array}$ & $\begin{array}{l}\mathrm{T} \\
{ }^{\circ} \mathrm{C} \\
\end{array}$ & $\begin{array}{c}\text { ECA } \\
\mathrm{mm} \\
\end{array}$ & $\begin{array}{l}\text { ETo } \\
\mathrm{mm} \\
\end{array}$ \\
\hline $7 / 8$ & 14,8 & 7,4 & 0,0 & 62,0 & 1,9 & 19,0 & 4,6 & 2,3 \\
\hline $8 / 8$ & 11,2 & 2,9 & 0,0 & 67,0 & 2,1 & 21,8 & 3,8 & 2,6 \\
\hline $9 / 8$ & 12,5 & 4,6 & 0,0 & 72,0 & 2,1 & 19,1 & 4,0 & 2,2 \\
\hline $10 / 8$ & 12,1 & 3,8 & 0,0 & 70,0 & 1,0 & 20,1 & 3,0 & 2,0 \\
\hline $11 / 8$ & 12,9 & 4,1 & 0,0 & 58,0 & 1,8 & 19,2 & 4,3 & 2,6 \\
\hline $12 / 8$ & 12,3 & 7,6 & 0,0 & 73,0 & 1,6 & 19,9 & 3,5 & 1,5 \\
\hline $13 / 8$ & 12,6 & 5,8 & 0,0 & 75,0 & 1,9 & 16,8 & 3,5 & 1,7 \\
\hline $14 / 8$ & 17,6 & 10,2 & 0,0 & 69,0 & 1,7 & 17,0 & 4,1 & 2,0 \\
\hline $15 / 8$ & 17,2 & 9,7 & 0,0 & 68,0 & 2,1 & 16,5 & 4,7 & 2,1 \\
\hline $16 / 8$ & 16,5 & 9,3 & 0,0 & 72,0 & 1,3 & 16,5 & 4,4 & 1,8 \\
\hline $17 / 8$ & 15,2 & 8,2 & 0,3 & 61,0 & 1,8 & 20,0 & 4,5 & 2,3 \\
\hline $18 / 8$ & 8,8 & 1,7 & 0,3 & 77,0 & 1,4 & 20,4 & 2,5 & 1,8 \\
\hline $19 / 8$ & 10,6 & 5,0 & 0,0 & 78,0 & 1,8 & 21,4 & 4,0 & 1,8 \\
\hline $20 / 8$ & 14,7 & 7,8 & 0,0 & 76,0 & 2,2 & 20,0 & 5,1 & 2,1 \\
\hline $21 / 8$ & 7,7 & 2,0 & 3,2 & 88,0 & 1,4 & 19,3 & 1,3 & 1,3 \\
\hline $22 / 8$ & 6,0 & 1,2 & 2,8 & 95,0 & 1,5 & 19,3 & 0,7 & 1,0 \\
\hline $23 / 8$ & 10,0 & 4,3 & 2,8 & 86,0 & 2,5 & 21,3 & 3,7 & 1,7 \\
\hline $24 / 8$ & 19,0 & 10,3 & 0,0 & 61,0 & 1,5 & 18,3 & 5,4 & 2,4 \\
\hline $25 / 8$ & 18,8 & 10,1 & 0,0 & 63,0 & 1,7 & 16,5 & 5,6 & 2,3 \\
\hline $26 / 8$ & 17,4 & 10,1 & 0,0 & 66,0 & 1,1 & 15,9 & 3,0 & 1,8 \\
\hline $27 / 8$ & 16,9 & 8,3 & 0,0 & 71,0 & 1,2 & 18,3 & 4,1 & 2,1 \\
\hline $28 / 8$ & 16,2 & 9,2 & 0,0 & 66,0 & 2,0 & 20,8 & 6,1 & 2,4 \\
\hline $29 / 8$ & 17,6 & 9,6 & 0,0 & 74,0 & 1,4 & 19,7 & 4,6 & 2,2 \\
\hline $30 / 8$ & 16,3 & 9,4 & 0,0 & 68,0 & 1,5 & 21,2 & 4,7 & 2,2 \\
\hline $31 / 8$ & 5,8 & 1,2 & 1,7 & 86,0 & 1,3 & 21,2 & 1,6 & 1,2 \\
\hline $1 / 9$ & 6,7 & 0,3 & 1,2 & 94,0 & 1,4 & 19,9 & 1,5 & $1 ; 3$ \\
\hline $2 / 9$ & 2,1 & 0,0 & 1,0 & 98,0 & 0,7 & 17,8 & 0,1 & 0,3 \\
\hline $3 / 9$ & 9,4 & 2,6 & 0,0 & 82,0 & 1,5 & 19,9 & 2,6 & 1,7 \\
\hline $4 / 9$ & 10,9 & 3,0 & 2,5 & 82,0 & 1,5 & 21,3 & 2,9 & 2,0 \\
\hline $5 / 9$ & 4,4 & 0,0 & 1,6 & 95,0 & 1,2 & 17,6 & 1,0 & 0,7 \\
\hline $6 / 9$ & 3,5 & 0,0 & 2,2 & 96,0 & 2,6 & 16,7 & 0,2 & 0,5 \\
\hline $7 / 9$ & 13,9 & 2,4 & 0,0 & 79,0 & 3,3 & 17,4 & 4,6 & 2,6 \\
\hline $8 / 9$ & 18,6 & 9,8 & 0,0 & 67,0 & 3,0 & 18,0 & 5,8 & 2,8 \\
\hline $9 / 9$ & 20,6 & 9,0 & 0,0 & 65,0 & 3,9 & 18,7 & 7,2 & 3,7 \\
\hline
\end{tabular}


Tabela 1 - Valores de Radiação Solar Global ao nível da superfície (RSG), insolação (INS), Precipitação pluviométrica (PP); Umidade Relativa do ar (UR); Evaporação do Tanque Classe (ECA) e Evapotranspiração potencial (ETo) estimada pelo método de Penman-Monteith, para o período de 01/06 a 14/12/1992 em Piracicaba, SP. (Continuação)

\begin{tabular}{|c|c|c|c|c|c|c|c|c|}
\hline DATA & RSG & INS & PP & $\overline{U R}$ & U2 & $\bar{T}$ & $\overline{E C A}$ & ETo \\
\hline & $M J m^{-2} \mathrm{dia}^{-1}$ & HORAS & $\mathrm{mm}$ & $\%$ & $\mathrm{~m} \cdot \mathrm{s}^{-1}$ & ${ }^{\circ} \mathrm{C}$ & $\mathrm{mm}$ & $\mathrm{mm}$ \\
\hline $10 / 9$ & 20,2 & 9,4 & 0,0 & 63,0 & 2,9 & 19,7 & 6,8 & 3,5 \\
\hline $11 / 9$ & 3,0 & 0,0 & 4,8 & 87,0 & 1,8 & 16,1 & 0,1 & 0,6 \\
\hline $12 / 9$ & 2,3 & 0,0 & 5,2 & 99,0 & 1,5 & 15,1 & 0,1 & 0,2 \\
\hline $13 / 9$ & 17,7 & 8,4 & 0,0 & 75,0 & 1, & 21,4 & 4,8 & 2,6 \\
\hline $14 / 9$ & 7,9 & 0,9 & 15,3 & 79,0 & 1, & 19,6 & 1,6 & 1,6 \\
\hline $15 / 9$ & 2,0 & 0,0 & 25,6 & 97,0 & 1,3 & 16,9 & & 0,2 \\
\hline $16 / 9$ & 7,9 & 1,5 & 0,0 & 87,0 & 0,8 & 19,9 & 2,3 & 1,4 \\
\hline $17 / 9$ & 13,6 & 4,2 & 9,6 & 87,0 & 1,7 & 20,4 & 4,2 & 2,2 \\
\hline $18 / 9$ & 11,3 & 2,9 & 0,0 & 86,0 & 2,0 & 21,1 & 3,4 & 2,1 \\
\hline $19 / 9$ & 15,3 & 5,0 & 0,0 & 79,0 & 1,6 & 21,1 & 5,0 & 2,6 \\
\hline $20 / 9$ & 18,7 & 9,5 & 0,0 & 77,0 & 1,8 & 20,6 & 5,6 & 2,6 \\
\hline $21 / 9$ & 19,8 & 10,3 & 0,0 & 69,0 & 2,2 & 22,0 & 6,0 & 3,1 \\
\hline $22 / 9$ & 19,2 & 9,5 & 0,0 & 65,0 & 1,7 & 22,9 & 6,2 & 3,1 \\
\hline $23 / 9$ & 19,7 & 9,1 & 0,0 & 61,0 & 1,4 & 23,4 & 5,9 & 3,2 \\
\hline $24 / 9$ & 13,8 & 5,5 & 3,5 & 69,0 & 2,8 & 24,1 & 6,9 & 3,2 \\
\hline $25 / 9$ & 3,6 & 0,6 & 14,8 & 95,0 & 1,8 & 22,6 & 1,9 &, 0 \\
\hline $26 / 9$ & 9,0 & 0,5 & 0,0 & 82,0 & 3 & 18,2 & 3,8 & 2,0 \\
\hline $27 / 9$ & 4,4 & 0,1 & 0,2 & 92,0 & 1,2 & 17,3 & 0,5 & 0,7 \\
\hline $28 / 9$ & 16,7 & 5,9 & 0,0 & 79,0 & 2,0 & 18,7 & 4,8 & 2,6 \\
\hline $29 / 9$ & 21,7 & 9,6 & 0,0 & 71,0 & 1,8 & 19,1 & 6,0 & 3 \\
\hline $30 / 9$ & 17,3 & 7,9 & 0,0 & 73,0 & 1,6 & 19,7 & 4,5 & 2,5 \\
\hline $1 / 10$ & 16,0 & 5,0 & 8,1 & 74,0 & 1,8 & 22,6 & 4,3 & 3 \\
\hline $2 / 10$ & 9,9 & 1,5 & 45,4 & 92,0 & 1,6 & 20,9 & 5,6 & 1, \\
\hline $3 / 10$ & 14,8 & 4,8 & 0,0 & 82,0 & 1,7 & 21,6 & 4,2 & 2 \\
\hline $4 / 10$ & 19,8 & 9,3 & 0,0 & 69,0 & 3,2 & 21,1 & 7,7 & 3, \\
\hline $5 / 10$ & 14,7 & 5,5 & 0,0 & 75,0 & 0,9 & 20,8 & 3,5 & 2 , \\
\hline $6 / 10$ & 17,3 & 8,6 & 0,7 & 69,0 & 2,1 & 22,7 & 6,4 & 3, \\
\hline $7 / 10$ & 7,5 & 0,1 & 5,4 & 86,0 & 2,8 & 19,9 & 3,4 & 1 \\
\hline $8 / 10$ & 4,7 & 0,2 & 12,3 & 93,0 & 2,4 & 17,6 & 1,8 & 0 \\
\hline $9 / 10$ & 13,6 & 5,0 & 0,0 & 78,0 & 3,4 & 18,9 & 4,9 & 2 , \\
\hline $10 / 10$ & 22,6 & 10,7 & 0,0 & 73,0 & 1,8 & 20,1 & 6,2 & 3, \\
\hline $11 / 10$ & 18,0 & 7,4 & 5,3 & 76,0 & 1,8 & 20,9 & 5,7 & 2 , \\
\hline $12 / 10$ & 8,4 & 1,5 & 21,4 & 93,0 & 1,4 & 21,3 & 5,6 & 1, \\
\hline $13 / 10$ & 14,9 & 5,8 & 0,0 & 77,0 & 1,8 & 23,1 & 5,4 & 2,7 \\
\hline
\end{tabular}


Tabela 1 - Valores de Radiação Solar Global ao nivel da superfície (RSG), insolação (INS), Precipitação pluviométrica (PP); Umidade Relativa do ar (UR); Evaporação do Tanque Classe (ECA) e Evapotranspiração potencial (ETo) estimada pelo método de Penman-Monteith, para o período de 01/06 a 14/12/1992 em Piracicaba, SP. (Continuação)

\begin{tabular}{|c|c|c|c|c|c|c|c|c|}
\hline DATA & $\begin{array}{c}\text { RSG } \\
\mathrm{MJ} \mathrm{m}^{-2} \mathrm{dia}^{-1}\end{array}$ & HORAS & PP & $\begin{array}{l}\text { UR } \\
\% \\
\end{array}$ & $\begin{array}{c}\mathrm{U} 2 \\
\mathrm{~m} \cdot \mathrm{s}^{-1} \\
\end{array}$ & ${ }^{\circ} \mathrm{C}$ & ECA & ETo \\
\hline $14 / 10$ & 19,3 & 9,6 & 0,0 & 71,0 & 1,4 & 22,8 & 4,3 & 3,0 \\
\hline $15 / 10$ & 17,2 & 8,3 & 0,0 & 72,0 & 2,1 & 23,9 & 5,5 & 3,1 \\
\hline $16 / 10$ & 14,6 & 5,4 & 9,3 & 79,0 & 2,4 & 24,8 & 5,0 & 3,0 \\
\hline $17 / 10$ & 11,3 & 2,1 & 0,0 & 83,0 & 1,4 & 22,0 & 3,1 & 2,3 \\
\hline $18 / 10$ & 13,6 & 2,9 & 0,0 & 82,0 & 1,8 & 23,2 & 4,3 & 2,9 \\
\hline $19 / 10$ & 15,7 & 8,7 & 0,0 & 76,0 & 1,9 & 24,2 & 5,5 & 2,6 \\
\hline $20 / 10$ & 20,9 & 9,1 & 0,0 & 68,0 & 1,9 & 23,9 & 6,7 & 3,7 \\
\hline $21 / 10$ & 15,2 & 5,1 & 0,0 & 76,0 & 3,0 & 22,6 & 6,6 & 3,1 \\
\hline $22 / 10$ & 24,9 & 11,3 & 0,0 & 69,0 & 2,0 & 20,3 & 6,9 & 3,7 \\
\hline $23 / 10$ & 23,7 & 11,1 & 0,0 & 72,0 & 1,8 & 19,7 & 6,2 & 3,4 \\
\hline $24 / 10$ & 21,7 & 10,4 & 0,0 & 67,0 & 1,5 & 23,4 & 6,8 & 3,5 \\
\hline $25 / 10$ & 19,9 & 9,5 & 0,0 & 66,0 & 1,7 & 23,2 & 6,7 & 3,4 \\
\hline $26 / 10$ & 18,2 & 8,2 & 4,9 & 71,0 & 1,8 & 24,5 & 6,0 & 3,3 \\
\hline $27 / 10$ & 13,4 & 6,6 & 43,2 & 87,0 & 2,1 & 25,2 & & 2,4 \\
\hline $28 / 10$ & 14,4 & 5,7 & 70,3 & 87,0 & 2,5 & 24,8 & & 2,7 \\
\hline $29 / 10$ & 13,6 & 4,6 & 15,8 & 85,0 & 2,2 & 23,8 & 3,8 & 2,7 \\
\hline $30 / 10$ & 11,6 & 2,5 & 0,0 & 84,0 & 1,9 & 22,6 & 4,0 & 2,4 \\
\hline $31 / 10$ & 17,0 & 7,6 & 0,0 & 80,0 & 2,7 & 22,4 & 6,2 & 2,9 \\
\hline $1 / 11$ & 16,8 & 6,0 & 0,3 & 84,0 & 1,4 & 23,1 & 3,9 & 2,9 \\
\hline $2 / 11$ & 19,5 & 8,0 & 0,0 & 79,0 & 1,3 & 24,8 & 6,2 & 3,4 \\
\hline $3 / 11$ & 19,8 & 9,6 & 74,4 & 80,0 & 2,2 & 25,7 & & 3,4 \\
\hline $4 / 11$ & 12,6 & 2,9 & 4,2 & 82,0 & 3,2 & 21,5 & 4,3 & 2,7 \\
\hline $5 / 11$ & 10,1 & 0,2 & 0,0 & 76,0 & 4,3 & 19,2 & 3,3 & 2,8 \\
\hline $6 / 11$ & 9,1 & 0,0 & 0,9 & 88,0 & 3,1 & 21,2 & 2,5 & 2,2 \\
\hline $7 / 11$ & 15,2 & 2,8 & 0,0 & 82,0 & 1,4 & 19,8 & 3,7 & 2,8 \\
\hline $8 / 11$ & 16,9 & 7,4 & 7,4 & 83,0 & 1,2 & 22,0 & 5,8 & 2,6 \\
\hline $9 / 11$ & 12,3 & 2,8 & 0,2 & 83,0 & 1,4 & 21,1 & 3,5 & 2,3 \\
\hline $10 / 11$ & 17,7 & 7,8 & 0,0 & 73,0 & 1,0 & 23,1 & 4,9 & 2,8 \\
\hline $11 / 11$ & 22,1 & 9,5 & 0,0 & 67,0 & 1,3 & 24,3 & 7,1 & 3,8 \\
\hline $12 / 11$ & 18,5 & 7,7 & 12,2 & 73,0 & 1,3 & 25,4 & 7,5 & 3,4 \\
\hline $13 / 11$ & 21,1 & 9,7 & 0,0 & 69,0 & 1,6 & 25,7 & 7,2 & 3,8 \\
\hline $14 / 11$ & 22,0 & 11,2 & 0,0 & 68,0 & 1,8 & 25,7 & 8,5 & 3,8 \\
\hline $15 / 11$ & 21,3 & 9,1 & 0,0 & 74,0 & 1,1 & 25,2 & 6,2 & 3,7 \\
\hline $16 / 11$ & 15,1 & 6,1 & 12,7 & 86,0 & 1,7 & 26,0 & 5,5 & 2,9 \\
\hline
\end{tabular}


Tabela 1 - Valores de Radiação Solar Global ao nivel da superfície (RSG), insolação (INS), Precipitação pluviométrica (PP); Umidade Relativa do ar (UR); Evaporação do Tanque Classe (ECA) e Evapotranspiração potencial (ETo) estimada pelo método de Penman-Monteith, para o período de 01/06 a 14/12/1992 em Piracicaba, SP. (Continuação)

\begin{tabular}{|c|c|c|c|c|c|c|c|c|}
\hline DATA & $\begin{array}{c}\text { RSG } \\
\mathrm{MJ} \mathrm{m}^{-2} \mathrm{dia}^{-1} \\
\end{array}$ & HORAS & PP & UR & $\begin{array}{c}\mathrm{U} 2 \\
\mathrm{~m} \cdot \mathrm{s}^{-1} \\
\end{array}$ & ${ }^{\circ} \mathrm{C}$ & ECA & ETo \\
\hline $17 / 11$ & 11,6 & 3,1 & 0,0 & 86,0 & 1,7 & 22,7 & 3,8 & 2,3 \\
\hline $18 / 11$ & 21,9 & 9,3 & 0 & 75,0 & 2,0 & 22,6 & 6,8 & 6 \\
\hline $19 / 11$ & 24,4 & 11,1 & 0,0 & 66,0 & 1,4 & 22,6 & 6,6 & 3,8 \\
\hline $20 / 11$ & 21,4 & 10,2 & 0,0 & 62,0 & 1,8 & 24,3 & 7 & 3,8 \\
\hline $21 / 11$ & 23,3 & 10,9 & 0,5 & 65,0 & 2,0 & 24,8 & 7,5 & 4,2 \\
\hline $22 / 11$ & 13,1 & 2,7 & 3,5 & 90,0 & 1,5 & 24,1 & 3,7 & 2,7 \\
\hline $23 / 11$ & 11,1 & 0,9 & 2,6 & 85,0 & 2,6 & 23,1 & 4,5 & 2,7 \\
\hline $24 / 11$ & 22,0 & 10,3 & 87,8 & 82,0 & 2,2 & 23,8 & & 3,5 \\
\hline $25 / 11$ & 7,4 & 0,0 & 17,1 & 92,0 & 1,2 & 21,2 & 0,8 & 1,7 \\
\hline $26 / 11$ & 7,0 & 0,0 & 2,5 & 88,0 & 2,9 & 20,6 & 2,3 & 1,7 \\
\hline $27 / 11$ & 14,2 & 0,9 & 0,0 & 75,0 & 4,5 & 20,6 & 5,6 & 3,6 \\
\hline $28 / 11$ & 18,4 & 6,0 & 0,0 & 72,0 & 3, & 21,6 & 6,8 & 3,7 \\
\hline $29 / 11$ & 22,1 & 10,6 & 0,0 & 70,0 & $2, \mathrm{C}$ & 22,7 & 6,7 & 3,6 \\
\hline $30 / 11$ & 23,1 & 8,6 & 6,0 & 1,0 & 2, & 23,0 & 6,0 & 4,2 \\
\hline $1 / 12$ & 5,3 & 0,1 & 32,4 & 97,0 & 2, & 20,3 &, 5 & 1. \\
\hline $2 / 12$ & 13,6 & 5,4 & 0,0 & 2,0 & 1, & 22,7 & 2 & 2,5 \\
\hline $3 / 12$ & 20,7 & 9,7 & 0,0 & 73,0 & 1, & 22,0 & 6,1 & 3,2 \\
\hline $4 / 12$ & 24,4 & 11,5 & 0,0 & 67,0 & 2,7 & 22,2 & 8,9 & 4,2 \\
\hline $5 / 12$ & 25,8 & 11,7 & 0,0 & 66,0 & 1,8 & 21,8 & 7,6 & 4,1 \\
\hline $6 / 12$ & 18,4 & 6,9 & 7,0 & 77,0 & 1,6 & 23,5 & 5,8 & 3,3 \\
\hline $7 / 12$ & 12,9 & 2,0 & 0,0 & 83,0 & 1,4 & 23,7 & 3,7 & 2,9 \\
\hline $8 / 12$ & 20,6 & 8,1 & 0,0 & 74,0 & 2,4 & 23,4 & 8,0 & 3,8 \\
\hline $9 / 12$ & 20,9 & 9,5 & 7,2 & 75,0 & 1,7 & 23,8 & 6,2 & 3,5 \\
\hline 10 & 14,8 & 5,6 & 66,2 & 88,0 & 1,5 & 24,7 & & 2,7 \\
\hline $11 / 12$ & 9,3 & 0,6 & 8,9 & 94,0 & 1,8 & 22,1 & 2,7 & 2,0 \\
\hline 12 & 16,7 & 6,6 & 0,0 & 81,0 & 3,2 & 22,7 & 6,4 & 3,1 \\
\hline 12 & 22,7 & 11,5 & 0,0 & 73,0 & 3,0 & 21,2 & 7,9 & 3,6 \\
\hline 14 & 22,4 & 9,4 & 0,0 & 75,0 & 1,5 & 21,2 & 5,7 & 3,5 \\
\hline
\end{tabular}


Tabela 2 - Valores da evaporação medida com o atmômetro com escala de leitura comercial (ATMEC), e com os atmômetros com escala de leitura ampliada (ATMEA-1; ATMEA-2, ATMEA-3, ATMEA média) durante o período de 01/06 a 14/12/1992 em Piracicaba, SP.

\begin{tabular}{|c|c|c|c|c|c|c|c|}
\hline \multicolumn{3}{|c|}{ DATA } & $\begin{array}{c}\text { ATMEC } \\
(\mathrm{mm})\end{array}$ & $\begin{array}{c}\text { ATMEA-1 } \\
(\mathrm{mm})\end{array}$ & $\begin{array}{c}\text { ATMEA-2 } \\
(\mathrm{mm})\end{array}$ & $\begin{array}{c}\text { ATMEA-3 } \\
(\mathrm{mm})\end{array}$ & $\begin{array}{c}\text { ATMEA } \\
\text { média } \\
(\mathrm{mm})\end{array}$ \\
\hline 1 & 1 & 6 & 1,9 & 2,0 & 1,9 & 2,5 & 1,91 \\
\hline 2 & 1 & 6 & 2,8 & 2,9 & 2,6 & 2,5 & 2,79 \\
\hline 3 & I & 6 & 2,3 & 2,5 & $\begin{array}{l}\text { POUSIOO DE } \\
\text { PÁSSAROS }\end{array}$ & $\begin{array}{l}\text { POUSIO DE } \\
\text { PÁSSAROS }\end{array}$ & 2,40 \\
\hline 4 & I & 6 & 2,2 & 2,2 & 2,2 & 3,0 & 2,17 \\
\hline 5 & I & 6 & 3,1 & 3,4 & 3,1 & 4,0 & 3,21 \\
\hline 6 & I & 6 & 3,3 & 3,1 & 3,3 & 3,0 & 3,21 \\
\hline 7 & 1 & 6 & 3,1 & 3,3 & 3,1 & 4,0 & 3,15 \\
\hline 8 & 1 & 6 & 3,3 & 3,3 & $\begin{array}{l}\text { POUSIODE } \\
\text { PÁSSAROS }\end{array}$ & 3,5 & 3,26 \\
\hline 9 & I & 6 & 2,5 & 2,5 & 2,3 & 2,5 & 2,43 \\
\hline 10 & I & 6 & 1,7 & 1,7 & 1,7 & 2,0 & 1,71 \\
\hline 11 & I & 6 & 2,2 & 2,2 & 2,1 & 2,0 & 2,15 \\
\hline 12 & I & 6 & 2,5 & 2,5 & 2,5 & 3,0 & 2,48 \\
\hline 13 & I & 6 & 2,5 & 2,6 & 2,3 & 3,0 & 2,48 \\
\hline 14 & I & 6 & 2,2 & 2,5 & 2,2 & 2,0 & 2,27 \\
\hline 15 & I & 6 & 2,6 & 2,8 & 2,9 & 3,5 & 2,79 \\
\hline 16 & 1 & 6 & 2,8 & 2,9 & 2,6 & 3,0 & 2,77 \\
\hline 17 & 1 & 6 & 2,5 & 2,5 & 2,3 & 2,5 & 2,43 \\
\hline 18 & 1 & 6 & 2,2 & 2,2 & 2,2 & 3,0 & 2,20 \\
\hline 19 & I & 6 & 2,5 & 2,6 & 2,5 & 2,5 & 2,51 \\
\hline 20 & 1 & 6 & 2,8 & 2,9 & 2,6 & 3,5 & 2,79 \\
\hline 21 & 1 & 6 & 2,8 & 2,9 & $\begin{array}{l}\text { POUSIO DE } \\
\text { PÁSSAROS }\end{array}$ & 3,5 & 2,87 \\
\hline 22 & I & 6 & 2,5 & 2,5 & 2,5 & 2,5 & 2,48 \\
\hline 23 & $I$ & 6 & 3,1 & 3,3 & 3,1 & 5,0 & 3,17 \\
\hline 24 & 1 & 6 & 2,9 & 3,1 & 3,0 & 3,0 & 3,03 \\
\hline 25 & $I$ & 6 & 2,8 & 2,8 & 2,8 & 2,0 & 2,79 \\
\hline 26 & 1 & 6 & 2,6 & 2,6 & 2,5 & 3,0 & 2,58 \\
\hline 27 & 1 & 6 & 3,4 & 3,4 & 3,3 & 4,0 & 3,36 \\
\hline 28 & 1 & 6 & 1,2 & 1,7 & 1,1 & 1,0 & 1,34 \\
\hline 29 & $I$ & 6 & 1,8 & 1,8 & 1,8 & 2,5 & 1,80 \\
\hline 30 & $I$ & 6 & 2,6 & 2,5 & 2,4 & 2,5 & 2,49 \\
\hline 1 & 1 & 7 & 3,3 & 3,6 & 3,3 & 4,0 & 3,36 \\
\hline 2 & 1 & 7 & 2,6 & 2,8 & 2,3 & 3,0 & 2,58 \\
\hline 3 & 1 & 7 & 2,6 & 2,8 & $\begin{array}{l}\text { POUSIO DE } \\
\text { PÁSSAROS }\end{array}$ & 3,0 & 2,72 \\
\hline
\end{tabular}


Tabela 2 - Valores da evaporação medida com o atmômetro com escala de leitura comercial (ATMEC), e com os atmômetros com escala de leitura ampliada (ATMEA-1; ATMEA-2, ATMEA-3, ATMEA média) durante o período de 01/06 a 14/12/1992 em Piracicaba, SP. (Continuação)

\begin{tabular}{|c|c|c|c|c|c|c|}
\hline \multicolumn{2}{|c|}{ DATA } & ATMEC & ATMEA-1 & ATMEA-2 & ATMEA-3 & $\begin{array}{l}\text { ATMEA } \\
\text { média }\end{array}$ \\
\hline 41 & 7 & 2,0 & 2,2 & 2,0 & 2,0 & 2,09 \\
\hline 51 & 7 & 3,0 & 3,1 & 2,9 & 4,0 & 3,00 \\
\hline 61 & 7 & 2,6 & 2,8 & 2,6 & 1,0 & 2,69 \\
\hline 71 & 7 & 0,6 & 0,5 & 0,3 & 0,0 & 0,49 \\
\hline 81 & 7 & 0,0 & 0,0 & 0,0 & $-1,0$ & 0,00 \\
\hline 91 & 7 & 2,3 & 2,6 & 2,6 & 3,0 & 2,51 \\
\hline $10 /$ & 7 & 2,3 & 2,0 & 2,2 & 1,0 & 2,18 \\
\hline $11 /$ & 7 & 2,5 & 2,6 & 2,3 & 2,0 & 2,48 \\
\hline $12 /$ & 7 & 2,6 & 2,5 & 2,5 & 4,0 & 2,53 \\
\hline $13 /$ & 7 & 2,6 & 2,8 & 2,6 & 3,0 & 2,69 \\
\hline $14 /$ & 7 & 3,3 & 3,3 & 3,1 & 4,0 & 3,21 \\
\hline $15 /$ & 7 & 3,1 & 3,3 & 3,3 & 3,0 & 3,21 \\
\hline $16 /$ & 7 & 2,3 & 2,3 & 2,2 & 4,0 & 2,27 \\
\hline $17 /$ & 7 & 1,6 & 1,6 & $\begin{array}{l}\text { POUSIO DE } \\
\text { PÁSSAROS }\end{array}$ & 2,0 & 1,55 \\
\hline $18 /$ & 7 & 3,1 & 3,1 & 3,1 & 3,0 & 3,10 \\
\hline $19 /$ & 7 & 2,6 & 2,6 & 2,5 & 3,0 & 2,58 \\
\hline 201 & 7 & 2,6 & 2,5 & 2,8 & 3,0 & 2,64 \\
\hline $21 /$ & 7 & 2,8 & 2,5 & 2,6 & 4,0 & 2,63 \\
\hline $22 I$ & 7 & 2,0 & 2,3 & $\begin{array}{l}\text { POUŚIO DE } \\
\text { PÁSSAROS }\end{array}$ & 1,0 & 2,29 \\
\hline $23 /$ & 7 & 1,6 & 1,4 & 1,6 & $-0,5$ & 1,50 \\
\hline $24 /$ & 7 & 1,5 & 1,6 & 1,4 & 1,0 & 1,49 \\
\hline $25 /$ & 7 & 2,6 & 2,5 & 2,8 & 3,5 & 2,64 \\
\hline $26 /$ & 7 & 2,6 & 2,8 & 2,6 & 4,0 & 2,64 \\
\hline $27 /$ & 7 & 2,5 & 2,5 & 2,5 & 1,0 & 2,48 \\
\hline 281 & 7 & 1,7 & 1,7 & 1,9 & 1,0 & 1,77 \\
\hline 291 & 7 & 3,1 & 3,1 & 3,3 & 5,0 & 3,15 \\
\hline 301 & 7 & 3,6 & 3,6 & 3,6 & 4,0 & 3,57 \\
\hline $31 /$ & 7 & 4,2 & 4,3 & 4,1 & 4,0 & 4,22 \\
\hline 11 & 8 & 3,9 & 4,0 & 3,9 & 5,0 & 3,93 \\
\hline 21 & 8 & 1,9 & 1,9 & 2,0 & 2,0 & 1,91 \\
\hline 31 & 8 & 1,7 & 1,7 & 1,6 & 2,0 & 1,65 \\
\hline 41 & 8 & 3,7 & 3,6 & 3,6 & 4,0 & 3,64 \\
\hline 51 & 8 & 3,6 & 3,6 & 3,6 & 4,0 & 3,58 \\
\hline
\end{tabular}


Tabela 2 - Valores da evaporação medida com o atmômetro com escala de leitura comercial (ATMEC), e com os atmômetros com escala de leitura ampliada (ATMEA-1; ATMEA-2, ATMEA-3, ATMEA média) durante o período de 01/06 a 14/12/1992 em Piracicaba, SP. (Continuação)

\begin{tabular}{|c|c|c|c|c|c|c|}
\hline \multicolumn{2}{|c|}{ DATA } & $\begin{array}{c}\text { ATMEC } \\
(\mathrm{mm})\end{array}$ & $\begin{array}{c}\text { ATMEA-1 } \\
(\mathrm{mm})\end{array}$ & $\begin{array}{c}\text { ATMEA-2 } \\
(\mathrm{mm})\end{array}$ & $\begin{array}{c}\text { ATMEA-3 } \\
(\mathrm{mm})\end{array}$ & $\begin{array}{c}\text { ATMEA } \\
\text { média } \\
(\mathrm{mm})\end{array}$ \\
\hline 61 & 8 & 3,6 & 3,6 & 3,2 & 3,5 & 3,46 \\
\hline $7 /$ & 8 & 3,4 & 3,4 & 3,7 & 4,5 & 3,52 \\
\hline $8 /$ & 8 & 2,9 & 3,1 & 2,9 & 2,5 & 2,97 \\
\hline $9 /$ & 8 & 3,0 & 2,8 & 2,8 & 2,5 & 2,87 \\
\hline $10 /$ & 8 & 2,5 & 2,8 & 2,5 & 3,0 & 2,59 \\
\hline $11 /$ & 8 & 3,3 & 3,4 & 3,3 & 3,0 & 3,33 \\
\hline $12 /$ & 8 & 2,6 & 2,8 & 2,8 & 2,0 & 2,74 \\
\hline $13 /$ & 8 & 2,0 & 2,0 & 2,2 & 3,5 & 2,07 \\
\hline $14 /$ & 8 & 3,3 & 3,1 & 3,1 & 3,5 & 3,15 \\
\hline $15 I$ & 8 & 3,4 & $\begin{array}{l}\text { POUSIODE } \\
\text { PÁSSAROS }\end{array}$ & 3,7 & 3,5 & 3,57 \\
\hline $16 /$ & 8 & 3,3 & 3,4 & 3,5 & 3,5 & 3,37 \\
\hline $17 /$ & 8 & 3,7 & 3,7 & 3,6 & 4,0 & 3,69 \\
\hline $18 I$ & 8 & 1,9 & 1,9 & 2,0 & 2,0 & 1,94 \\
\hline $19 /$ & 8 & 2,6 & 2,6 & 2,6 & 3,0 & 2,64 \\
\hline $20 /$ & 8 & 2,9 & 3,0 & 2,9 & 3,0 & 2,95 \\
\hline $21 /$ & 8 & 0,9 & 2,6 & 1,2 & 1,0 & 1,60 \\
\hline $22 /$ & 8 & 0,8 & 0,8 & 0,8 & 1,0 & 0,77 \\
\hline $23 /$ & 8 & 1,8 & 2,0 & 1,9 & 1,0 & 1,91 \\
\hline $24 I$ & 8 & 3,7 & 3,7 & 3,6 & 3,0 & 3,70 \\
\hline $25 I$ & 8 & 3,6 & 3,6 & 3,7 & 4,0 & 3,66 \\
\hline $26 I$ & 8 & 3,6 & 3,7 & 4,0 & 4,0 & 3,77 \\
\hline $27 /$ & 8 & 3,4 & 3,6 & 3,3 & 4,0 & 3,41 \\
\hline $28 I$ & 8 & 4,0 & 4,3 & 4,3 & 6,0 & 4,24 \\
\hline 291 & 8 & 3,9 & 4,2 & 3,9 & 5,0 & 3,98 \\
\hline $30 /$ & 8 & 3,7 & 4,0 & 3,9 & 3,0 & 3,88 \\
\hline $31 /$ & 8 & 1,6 & 1,5 & 1,4 & 1,0 & 1,49 \\
\hline $1 /$ & 9 & 0,9 & 0,5 & 0,8 & 2,0 & 0,72 \\
\hline 21 & 9 & 0,2 & $-0,5$ & 0,0 & $-3,0$ & $-0,10$ \\
\hline 31 & 9 & 1,6 & 1,7 & 1,7 & $\begin{array}{l}\text { POUSIO DE } \\
\text { PÁSSAROS }\end{array}$ & 1,65 \\
\hline $4 /$ & 9 & 2,5 & 2,3 & 2,3 & 4,0 & 2,38 \\
\hline $5 /$ & 9 & 0,3 & 0,0 & 0,3 & 0,0 & 0,21 \\
\hline $6 /$ & 9 & 0,5 & $-0,5$ & 0,3 & $-1,0$ & 0,10 \\
\hline 71 & 9 & 2,2 & 2,2 & 3,3 & 4,0 & 2,53 \\
\hline 81 & 9 & 3,6 & 3,7 & 3,7 & 3,0 & 3,68 \\
\hline
\end{tabular}


Tabela 2 - Valores da evaporação medida com o atmômetro com escala de leitura comercial (ATMEC), e com os atmômetros com escala de leitura ampliada (ATMEA-1; ATMEA-2, ATMEA-3, ATMEA média) durante o período de 01/06 a 14/12/1992 em Piracicaba, SP. (Continuação)

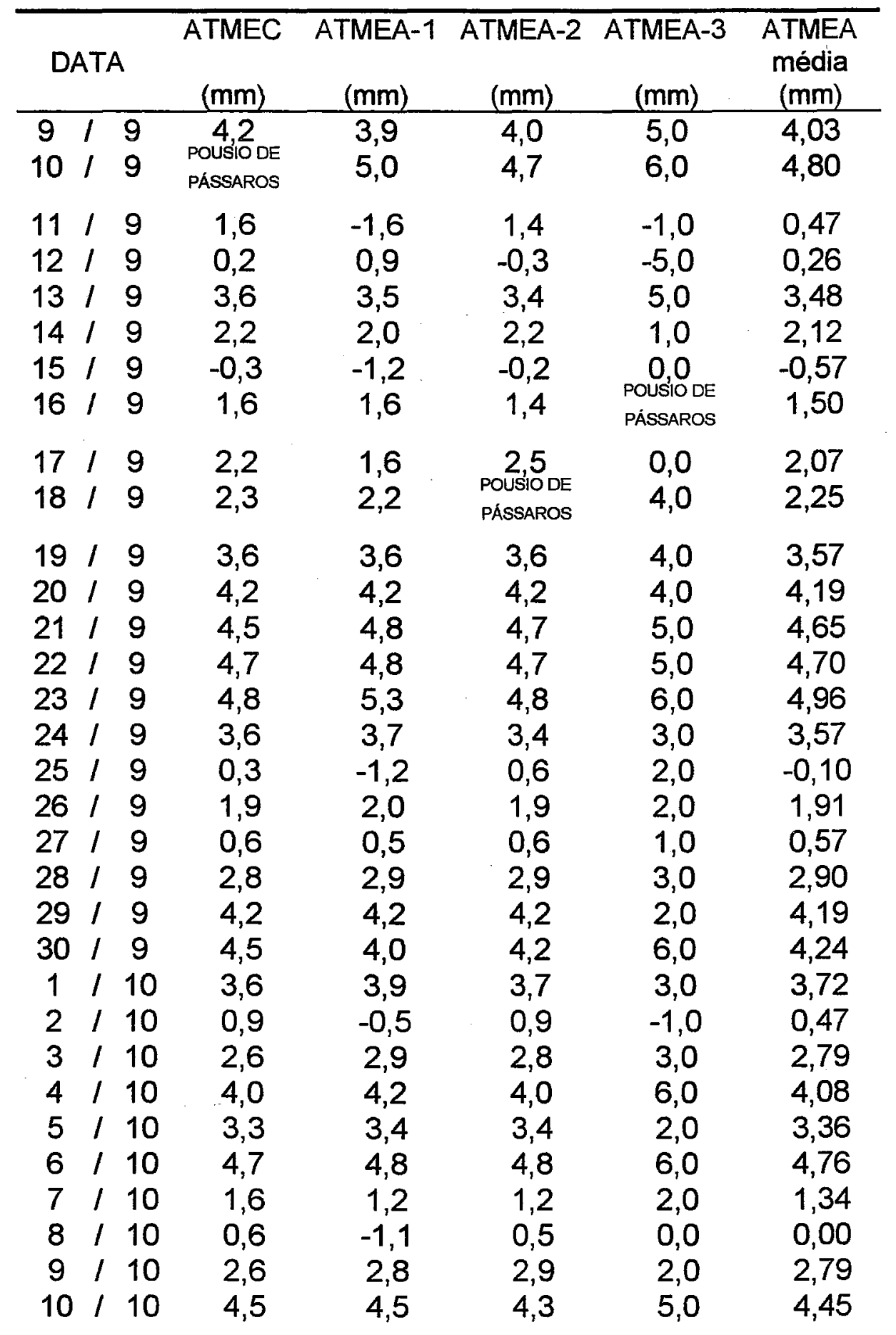


Tabela 2 - Valores da evaporação medida com o atmômetro com escala de leitura comercial (ATMEC), e com os atmômetros com escala de leitura ampliada (ATMEA-1; ATMEA-2, ATMEA-3, ATMEA média) durante o período de 01/06 a 14/12/1992 em Piracicaba, SP. (Continuação)

\begin{tabular}{|c|c|c|c|c|c|}
\hline DATA & ATMEC & ATMEA-1 & ATMEA-2 & ATMEA-3 & $\begin{array}{c}\text { ATMEA } \\
\text { média }\end{array}$ \\
\hline $11 / 10$ & 3,7 & $\begin{array}{l}\text { POUUSTOLE } \\
\text { PÁSSAROS }\end{array}$ & 4,0 & 4,0 & 4,02 \\
\hline $12 / 10$ & 1,1 & 0,0 & 0,9 & 1,0 & 0,67 \\
\hline $13 / 10$ & 3,9 & 3,9 & 3,9 & 4,0 & 3,88 \\
\hline $14 / 10$ & 4,7 & 4,7 & 4,7 & 5,0 & 4,65 \\
\hline $15 / 10$ & 4,3 & 4,3 & 4,3 & 4,0 & 4,29 \\
\hline $16 / 10$ & 4,3 & 4,3 & 4,3 & 5,0 & 4,34 \\
\hline $17 / 10$ & 4,0 & 3,6 & 2,9 & 1,0 & 3,52 \\
\hline $18 / 10$ & 3,4 & 3,4 & 3,4 & 4,0 & 3,41 \\
\hline $19 / 10$ & 4,0 & 4,2 & 4,0 & 5,0 & 4,08 \\
\hline $20 / 10$ & 5,0 & 5,4 & 5,0 & 5,0 & 5,12 \\
\hline $21 / 10$ & 3,1 & 2,9 & 3,1 & 4,0 & 3,05 \\
\hline $22 / 10$ & 4,7 & 4,8 & 4,7 & 4,0 & 4,70 \\
\hline $23 / 10$ & 4,8 & 4,8 & 5,0 & 6,0 & 4,86 \\
\hline $24 / 10$ & 5,4 & 5,7 & 5,9 & 7,0 & 5,69 \\
\hline $25 / 10$ & 5,1 & 5,0 & 4,7 & 5,0 & 4,91 \\
\hline $26 / 10$ & $-44,8$ & $-43,1$ & $-43,3$ & 5,0 & $-43,74$ \\
\hline $27 / 10$ & 0,0 & 3,4 & 0,0 & 2,0 & 1,14 \\
\hline $28 / 10$ & 0,0 & 0,0 & 0,0 & 3,0 & 0,00 \\
\hline $29 / 10$ & 0,0 & 0,0 & 0,0 & 2,0 & 0,00 \\
\hline $30 / 10$ & 3,3 & 3,3 & 3,3 & 3,0 & 3,28 \\
\hline $31 / 10$ & 3,6 & 3,9 & 3,9 & 5,0 & 3,77 \\
\hline $1 / 11$ & 3,4 & 3,7 & $\begin{array}{l}\text { POUSIO DE } \\
\text { PÁSSAROS }\end{array}$ & 4,0 & 3,60 \\
\hline $2 / 11$ & 4,8 & 4,8 & 4,8 & 4,0 & 4,81 \\
\hline $3 / 11$ & 3,9 & 1,4 & 0,0 & 4,0 & 1,76 \\
\hline $4 / 11$ & 2,5 & 1,9 & 0,0 & 2,0 & 1,45 \\
\hline $5 / 11$ & 2,3 & 2,5 & 2,3 & 2,0 & 2,38 \\
\hline $6 / 11$ & 1,2 & 1,1 & 0,0 & 0,0 & 0,78 \\
\hline $7 / 11$ & 3,3 & 3,3 & 3,3 & 3,0 & 3,26 \\
\hline $8 / 11$ & 3,7 & 2,9 & 0,0 & 6,0 & 2,22 \\
\hline $9 / 11$ & 2,3 & 2,3 & 0,0 & 3,0 & 1,55 \\
\hline $10 / 11$ & 4,3 & 4,7 & 4,3 & 6,0 & 4,45 \\
\hline $11 / 11$ & 5,1 & 5,0 & 5,0 & 4,0 & 5,00 \\
\hline $12 / 11$ & 3,4 & 4,0 & 0,8 & 4,0 & 2,74 \\
\hline
\end{tabular}


Tabela 2 - Valores da evaporação medida com o atmômetro com escala de leitura comercial (ATMEC), e com os atmômetros com escala de leitura ampliada (ATMEA-1; ATMEA-2, ATMEA-3, ATMEA média) durante o período de 01/06 a 14/12/1992 em Piracicaba, SP. (Continuação)

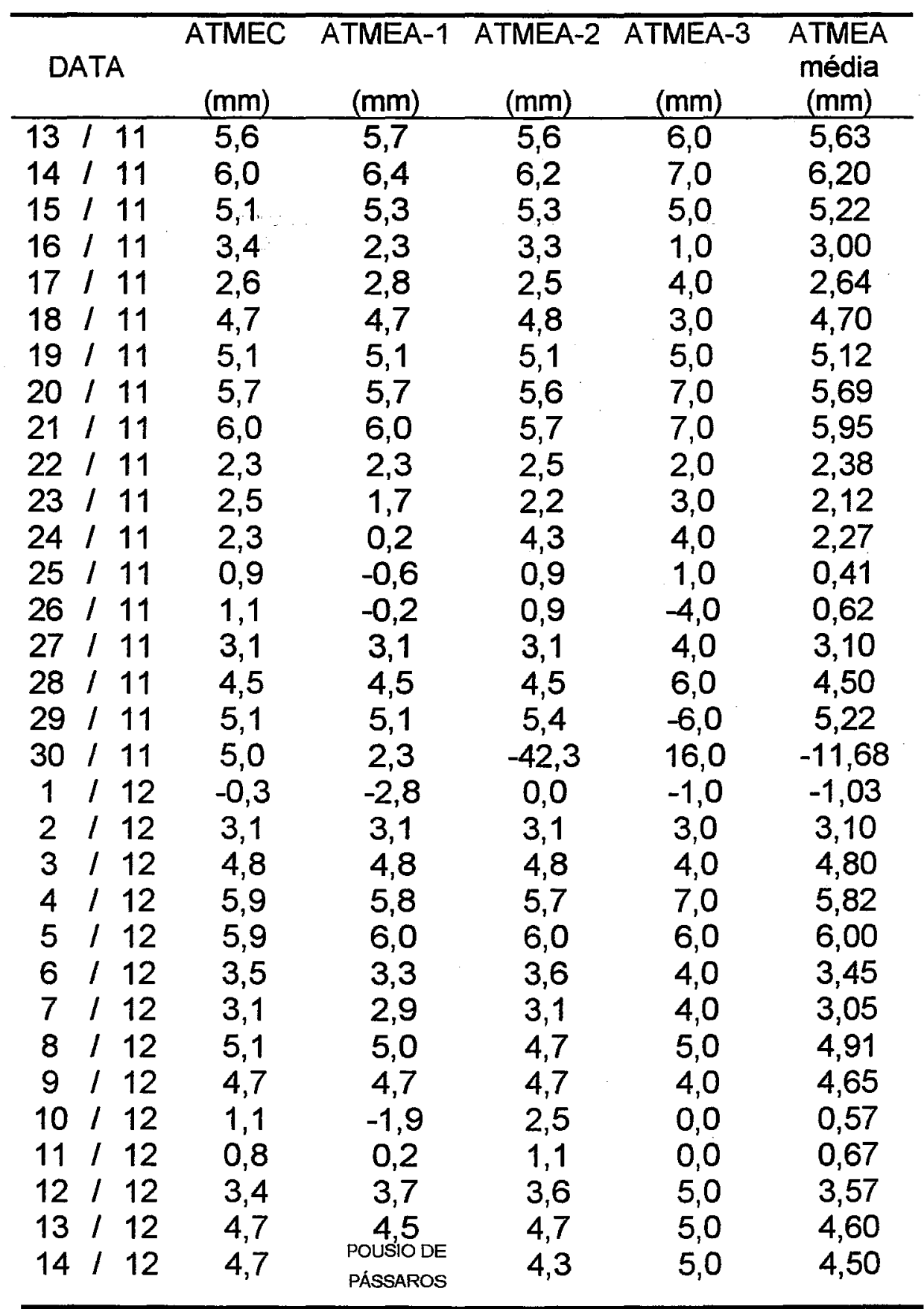

OBS: Os valores negativos apresentados na Tabela 2 são referentes a dias com ocorrência de chuvas. 
Tabela 3 - Valores de evaporação do Atmômetro modificado com escala de leitura ampliada (ATMEA), do atmômetro modificado com escala de leitura comercial (ATMEC), do tanque classe "A" (mm) e evapotranspiração potencial estimada pelo método de PenmanMonteith, para o período de um dia, utilizados nos ajustes dos modelos de regressão.

\begin{tabular}{|c|c|c|c|}
\hline $\begin{array}{l}\text { ATMEA } \\
(\mathrm{mm})\end{array}$ & $\begin{array}{l}\text { ATMEC } \\
(\mathrm{mm})\end{array}$ & $\begin{array}{l}\mathrm{ECA} \\
(\mathrm{mm})\end{array}$ & $\begin{array}{l}\text { ETo } \\
\text { (mm) }\end{array}$ \\
\hline 2,17 & 3,00 & 2,32 & 1,00 \\
\hline 2,43 & 2,50 & 2,62 & 1,77 \\
\hline 2,48 & 3,00 & 3,09 & 1,19 \\
\hline 2,43 & 2,50 & 2,89 & 1,11 \\
\hline 2,48 & 2,50 & 3,42 & 1,36 \\
\hline 3,36 & 4,00 & 3,65 & 1,43 \\
\hline 3,36 & 4,00 & 4,31 & 1,77 \\
\hline 2,51 & 3,00 & 2,08 & 1,15 \\
\hline 2,69 & 3,00 & 3,71 & 1,40 \\
\hline 3,10 & 3,00 & 5,24 & 2,22 \\
\hline 2,64 & 3,50 & 4,35 & 1,93 \\
\hline 3,15 & 5,00 & 3,86 & 1,57 \\
\hline 1,91 & 2,00 & 4,09 & 1,77 \\
\hline 3,46 & 3,50 & 4,36 & 1,83 \\
\hline 2,59 & 3,00 & 3,04 & 2,00 \\
\hline 3,15 & 3,50 & 4,12 & 1,99 \\
\hline 2,95 & 3,00 & 5,11 & 2,08 \\
\hline 3,77 & 4,00 & 2,95 & 1,78 \\
\hline 3,88 & 3,00 & 4,72 & 2,19 \\
\hline 3,48 & 5,00 & 4,76 & 2,59 \\
\hline 4,65 & 5,00 & 6,02 & 3,11 \\
\hline 2,90 & 3,00 & 4,78 & 2,56 \\
\hline 2,79 & 3,00 & 4,17 & 2,58 \\
\hline 2,79 & 2,00 & 4,86 & 2,44 \\
\hline 4,34 & 5,00 & 4,96 & 3,02 \\
\hline 4,70 & 4,00 & 6,92 & 3,71 \\
\hline 3,28 & 3,00 & 3,95 & 2,45 \\
\hline 2,38 & 2,00 & 3,31 & 2,77 \\
\hline 4,45 & 6,00 & 4,90 & 2,83 \\
\hline 5,22 & 5,00 & 6,16 & 3,68 \\
\hline 5,12 & 5,00 & 6,60 & 3,84 \\
\hline 4,80 & 4,00 & 6,08 & 3,24 \\
\hline 4,91 & 5,00 & 8,00 & 3,81 \\
\hline
\end{tabular}


Tabela 4 - Valores de evaporação do Atmômetro modificado com escala de leitura ampliada (ATMEA), do atmômetro modificado com escala de leitura comercial (ATMEC), do tanque classe " $A$ " (mm) e evapotranspiração potencial estimada pelo método de PenmanMonteith, para o período de um dia, utilizados na verificação dos modelos de regressão.

\begin{tabular}{|c|c|c|c|}
\hline $\begin{array}{l}\text { ATMEA } \\
(\mathrm{mm})\end{array}$ & $\begin{array}{c}\text { ATMEC } \\
(\mathrm{mm})\end{array}$ & $\begin{array}{l}\text { ECA } \\
(\mathrm{mm})\end{array}$ & $\begin{array}{l}\text { ETo } \\
\text { (mm) }\end{array}$ \\
\hline 1,91 & 2,50 & 2,56 & 1,60 \\
\hline 3,21 & 3,00 & 2,74 & 1,72 \\
\hline 2,15 & 2,00 & 2,98 & 1,26 \\
\hline 2,79 & 3,50 & 2,86 & 1,37 \\
\hline 2,51 & 2,50 & 3,01 & 1,17 \\
\hline 2,79 & 2,00 & 3,42 & 1,37 \\
\hline 1,80 & 2,50 & 2,05 & 1,41 \\
\hline 2,09 & 2,00 & 2,80 & 1,59 \\
\hline 2,48 & 2,00 & 3,04 & 1,12 \\
\hline 3,21 & 3,00 & 4,46 & 1,83 \\
\hline 2,63 & 4,00 & 3,07 & 1,78 \\
\hline 2,48 & 1,00 & 3,39 & 1,96 \\
\hline 4,22 & 4,00 & 4,78 & 2,23 \\
\hline 3,64 & 4,00 & 4,40 & 2,05 \\
\hline 2,97 & 2,50 & 3,75 & 2,62 \\
\hline 2,74 & 2,00 & 3,48 & 1,54 \\
\hline 3,37 & 3,50 & 4,44 & 1,75 \\
\hline 3,70 & 3,00 & 5,40 & 2,41 \\
\hline 4,24 & 6,00 & 6,06 & 2,41 \\
\hline 3,68 & 3,00 & 5,80 & 2,82 \\
\hline 3,57 & 4,00 & 5,04 & 2,62 \\
\hline 4,96 & 6,00 & 5,91 & 3,23 \\
\hline 4,24 & 6,00 & 4,49 & 2,53 \\
\hline 3,36 & 2,00 & 3,45 & 2,28 \\
\hline 4,65 & 5,00 & 4,32 & 2,97 \\
\hline 4,08 & 5,00 & 5,55 & 2,58 \\
\hline 5,69 & 7,00 & 6,84 & 3,48 \\
\hline 4,81 & 4,00 & 6,19 & 3,40 \\
\hline 3,26 & 3,00 & 3,74 & 2,76 \\
\hline 5,63 & 6,00 & 7,16 & 3,79 \\
\hline 2,64 & 4,00 & 3,82 & 2,30 \\
\hline 3,10 & 4,00 & 5,62 & 3,58 \\
\hline 6,00 & 6,00 & 7,58 & 4,11 \\
\hline 4,60 & 5,00 & 7,86 & 3,60 \\
\hline
\end{tabular}


Tabela 5 - Valores de evaporação do Atmômetro modificado com escala de leitura ampliada (ATMEA), do atmômetro modificado com escala de leitura comercial (ATMEC), do tanque classe "A" (mm) e evapotranspiração potencial estimada pelo método de PenmanMonteith, para o periodo médio de dois dias, utilizados no ajuste dos modelos de regressão.

\begin{tabular}{cccc}
\hline $\begin{array}{c}\text { ATMEA } \\
(\mathrm{mm})\end{array}$ & $\begin{array}{c}\text { ATMEC } \\
(\mathrm{mm})\end{array}$ & $\begin{array}{c}\text { ECA } \\
(\mathrm{mm})\end{array}$ & $\begin{array}{c}\text { ETo } \\
(\mathrm{mm})\end{array}$ \\
\hline 2,69 & 3,50 & 3,54 & 1,49 \\
2,48 & 3,00 & 3,31 & 1,13 \\
2,35 & 2,75 & 2,75 & 1,26 \\
2,69 & 2,50 & 3,37 & 1,56 \\
2,34 & 2,00 & 2,45 & 1,18 \\
2,74 & 3,50 & 3,50 & 1,57 \\
1,50 & 0,25 & 3,41 & 1,62 \\
3,36 & 4,50 & 4,03 & 1,68 \\
3,61 & 4,00 & 4,56 & 2,14 \\
2,96 & 3,00 & 3,69 & 2,28 \\
3,68 & 3,50 & 5,51 & 2,37 \\
3,11 & 3,50 & 5,18 & 2,70 \\
4,83 & 5,50 & 6,07 & 3,17 \\
3,44 & 4,50 & 5,92 & 3,04 \\
4,27 & 4,50 & 4,86 & 2,86 \\
4,60 & 5,00 & 6,13 & 3,15 \\
3,53 & 4,00 & 5,09 & 2,68 \\
5,92 & 6,50 & 7,82 & 3,80 \\
3,80 & 5,00 & 6,23 & 3,62 \\
3,98 & 4,50 & 5,86 & 3,35 \\
5,92 & 6,50 & 7,82 & 3,80 \\
\hline
\end{tabular}


Tabela 6 - Valores de evaporação do Atmômetro modificado com escala de leitura ampliada (ATMEA), do atmômetro modificado com escala de leitura comercial (ATMEC), do tanque classe "A" (mm) e evapotranspiração potencial estimada pelo método de PenmanMonteith, para o período médio de dois dias, utilizados na verificação dos modelos de regressão.

\begin{tabular}{cccc}
\hline $\begin{array}{c}\text { ATMEA } \\
(\mathrm{mm})\end{array}$ & $\begin{array}{c}\text { ATMEC } \\
(\mathrm{mm})\end{array}$ & $\begin{array}{c}\text { ECA } \\
(\mathrm{mm})\end{array}$ & $\begin{array}{c}\text { ETo } \\
(\mathrm{mm})\end{array}$ \\
\hline 2,35 & 2,50 & 2,22 & 1,30 \\
2,07 & 2,25 & 2,19 & 1,65 \\
2,78 & 3,25 & 3,08 & 1,37 \\
2,83 & 3,75 & 3,44 & 1,39 \\
2,15 & 2,50 & 2,35 & 1,48 \\
2,61 & 3,50 & 3,40 & 1,34 \\
2,84 & 3,00 & 4,53 & 1,80 \\
2,56 & 2,50 & 3,64 & 1,75 \\
2,92 & 3,50 & 5,12 & 1,92 \\
3,24 & 3,50 & 4,16 & 2,46 \\
2,61 & 3,50 & 3,80 & 1,85 \\
3,83 & 5,00 & 5,08 & 2,25 \\
3,88 & 4,00 & 5,33 & 2,59 \\
3,54 & 2,50 & 5,38 & 2,85 \\
3,62 & 3,50 & 5,54 & 2,83 \\
3,46 & 2,50 & 3,71 & 2,60 \\
4,78 & 5,00 & 6,56 & 3,54 \\
4,72 & 5,00 & 5,99 & 3,29 \\
3,67 & 3,50 & 5,31 & 2,97 \\
5,31 & 5,50 & 7,48 & 3,70 \\
4,08 & 5,00 & 7,13 & 3,34 \\
\hline
\end{tabular}


Tabela 7 - Valores de evaporação do Atmômetro modificado com escala de leitura ampliada (ATMEA), do atmômetro modificado com escala de leitura comercial (ATMEC), do tanque classe "A" (mm) e evapotranspiração potencial estimada pelo método de PenmanMonteith, para o período médio de três dias, utilizados no ajuste dos modelos de regressão.

\begin{tabular}{cccc}
\hline $\begin{array}{c}\text { ATMEA } \\
(\mathrm{mm})\end{array}$ & $\begin{array}{c}\text { ATMEC } \\
(\mathrm{mm})\end{array}$ & $\begin{array}{c}\text { ECA } \\
(\mathrm{mm})\end{array}$ & $\begin{array}{c}\text { ETo } \\
(\mathrm{mm})\end{array}$ \\
\hline 2,86 & 3,33 & 3,27 & 1,57 \\
2,61 & 2,83 & 3,07 & 1,33 \\
2,55 & 3,00 & 3,00 & 1,58 \\
2,90 & 3,67 & 4,04 & 1,71 \\
2,25 & 2,83 & 4,00 & 1,68 \\
2,96 & 3,33 & 3,81 & 1,98 \\
3,71 & 3,67 & 4,66 & 2,18 \\
4,14 & 4,33 & 5,56 & 2,76 \\
3,41 & 3,67 & 5,09 & 2,79 \\
4,20 & 4,67 & 5,52 & 3,06 \\
5,69 & 6,00 & 7,27 & 3,76 \\
4,57 & 4,67 & 6,39 & 3,30 \\
\hline
\end{tabular}


Tabela 8 - Valores de evaporação do Atmômetro modificado com escala de leitura ampliada (ATMEA), do atmômetro modificado com escala de leitura comercial (ATMEC), do tanque classe "A" (mm) e evapotranspiração potencial estimada pelo método de PenmanMonteith, para o período médio de três dias, utilizados na verificação dos modelos de regressão.

\begin{tabular}{cccc}
\hline $\begin{array}{c}\text { ATMEA } \\
(\mathrm{mm})\end{array}$ & $\begin{array}{c}\text { ATMEC } \\
(\mathrm{mm})\end{array}$ & $\begin{array}{c}\text { ECA } \\
(\mathrm{mm})\end{array}$ & $\begin{array}{c}\text { ETo } \\
(\mathrm{mm})\end{array}$ \\
\hline 2,93 & 3,50 & 3,65 & 1,63 \\
2,56 & 3,00 & 3,18 & 1,56 \\
2,38 & 2,37 & 3,26 & 1,68 \\
2,94 & 2,75 & 3,77 & 2,34 \\
3,64 & 3,75 & 4,52 & 2,16 \\
4,28 & 4,50 & 5,73 & 2,85 \\
4,03 & 3,75 & 4,92 & 2,87 \\
4,93 & 5,00 & 6,69 & 3,50 \\
\hline
\end{tabular}


Tabela 9 - Valores de evaporação do Atmômetro modificado com escala de leitura ampliada (ATMEA), do atmômetro modificado com escala de leitura comercial (ATMEC), do tanque classe "A" (mm) e evapotranspiração potencial estimada pelo método de PenmanMonteith, para o periodo médio de quatro dias, utilizados no ajuste dos modelos de regressão.

\begin{tabular}{cccc}
\hline $\begin{array}{c}\text { ATMEA } \\
(\mathrm{mm})\end{array}$ & $\begin{array}{c}\text { ATMEC } \\
(\mathrm{mm})\end{array}$ & $\begin{array}{c}\text { ECA } \\
(\mathrm{mm})\end{array}$ & $\begin{array}{c}\text { ETo } \\
(\mathrm{mm})\end{array}$ \\
\hline 2,93 & 3,50 & 3,65 & 1,63 \\
2,56 & 3,00 & 3,18 & 1,56 \\
2,38 & 2,37 & 3,26 & 1,68 \\
2,94 & 2,75 & 3,77 & 2,34 \\
3,64 & 3,75 & 4,52 & 2,16 \\
4,28 & 4,50 & 5,73 & 2,85 \\
4,03 & 3,75 & 4,92 & 2,87 \\
4,93 & 5,00 & 6,69 & 3,50 \\
2,35 & 2,50 & 3,16 & 1,19 \\
\hline
\end{tabular}


Tabela 10 - Valores de evaporação do Atmômetro modificado com escala de leitura ampliada (ATMEA), do atmômetro modificado com escala de leitura comercial (ATMEC), do tanque classe " $A$ " (mm) e evapotranspiração potencial estimada pelo método de PenmanMonteith, para o período médio de quatro dias, utilizados na verificação dos modelos de regressão.

\begin{tabular}{cccc}
\hline $\begin{array}{c}\text { ATMEA } \\
(\mathrm{mm})\end{array}$ & $\begin{array}{c}\text { ATMEC } \\
(\mathrm{mm})\end{array}$ & $\begin{array}{c}\text { ECA } \\
(\mathrm{mm})\end{array}$ & $\begin{array}{c}\text { ETo } \\
(\mathrm{mm})\end{array}$ \\
\hline 2,87 & 3,13 & 3,41 & 1,38 \\
2,43 & 2,50 & 2,76 & 1,19 \\
2,74 & 3,25 & 3,62 & 1,53 \\
2,79 & 3,25 & 4,24 & 1,89 \\
4,54 & 4,75 & 6,16 & 3,41 \\
\hline
\end{tabular}

